University of Rhode Island

DigitalCommons@URI

Open Access Master's Theses

1991

\title{
A GUIDELINE FOR THE DEVELOPMENT OF COMMUNITY BIKE PATHS
}

Curt T. Bellavance

University of Rhode Island

Follow this and additional works at: https://digitalcommons.uri.edu/theses

\section{Recommended Citation}

Bellavance, Curt T., "A GUIDELINE FOR THE DEVELOPMENT OF COMMUNITY BIKE PATHS" (1991). Open Access Master's Theses. Paper 477.

https://digitalcommons.uri.edu/theses/477

This Thesis is brought to you for free and open access by DigitalCommons@URI. It has been accepted for inclusion in Open Access Master's Theses by an authorized administrator of DigitalCommons@URI. For more information, please contact digitalcommons-group@uri.edu. 
A GUIDELINE FOR THE DEVELOPMENT

OF COMAUNITY BIRE PATHB

\author{
BY \\ CURT T. BELLAVANCE
}

\begin{abstract}
A REBEARCH PROJECT SUBMITTED IN
PARTIAL FULFILLMENT OF THE REQUIREMENTS

FOR THE DEGREE AND MABTER OF

COMAYUNITY PLANNING
\end{abstract}

UNIVERBITY OF RHODE IBLAND

1991 
MASTER OF COMMUNITY PLANNING

RESEARCH PROJECT

OF

CURT T. BELLAVANCE

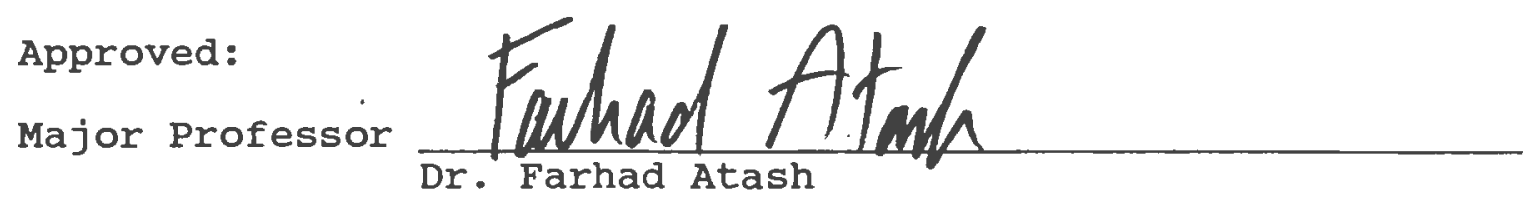

Acknowledged:

Director

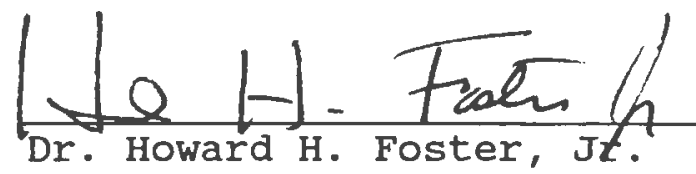




\section{ACRNOWLEDGEMENTS}

I would like to thank several people for the assistance they provided me in researching this study. I would like to thank Jane Weidman for the valuable information she provided, as well as Connie Daniels from the Rhode Island Department of Transportation. I would also like to thank Kevin O'Malley, Regional Director, Colt State Park and Lucy Icobucci from the Division of Contracts at the Rhode Island Department of Transportation.

I would also like to thank some of my fellow Community Planning students who provided me with some information that they had collected: Amy Bell, Daniel Clement, and Micheal Fawcett.

I want to acknowledge my appreciation to Michael and Susan Horan for allowing me to log many hours on their computer for writing and editing this study.

I would like to thank my parents for their support. And I would especially like to thank Nancy Horan for assistance with editing and typing, as well as her physical and emotional support over the past four semesters. 
I. CHAPTER ONE

Introduction

1.1 Subject statement

1.2 Relevant Literature

1.3 Significance of the study

1.4 Objectives of the study

1.5 Methods

1

2

3

4

6

7

II. CHAPTER TWO

History and Development

2.1 Community Development Patterns 9

2.2 Role of Recreation 11

2.3 National Bicycle Movement 12

2.4 Case Studies 16

2.5 Conclusion 17

$\begin{array}{ll}\text { Endnotes } & 19\end{array}$

III. CHAPTER THREE 21

Economic Benefits for Developing Bike Paths 21

3.2 Impact on Property Values 21

3.3 Impact on Commercial Activities and Businesses 23

3.4 Impacts on Tourism 25

3.5 Corporate Relocation 29

3.6 Conclusion 31

Endnotes $\quad 32$

IV. CHAPTER FOUR 33

Roles and Guidelines

4.1 Introduction 34

4.2 Local Roles and Guidelines 35

4.3 State Roles and Guidelines 42

4.4 Federal Roles and Guidelines 47

4.5 Federal Funding Sources 49

4.6 Other Funding Sources 51

Endnotes $\quad 53$

V. CHAPTER FIVE 56

Construction and Maintenance

5.1 Introduction $\quad 55$

5.2 Bicycle Tolerant 55

5.3 Independent Bike Paths and cost Comparisons 59

5.4 Pre-construction steps 62

5.5 Maintenance $\quad 64$

$\begin{array}{ll}\text { Endnotes } & 68\end{array}$ 
VI. CHAPTER SIX

Community Involvement

6.1 Community Participation $\quad 70$

6.2 Arguments for Bike Paths 71

6.3 Arguments Against Bike Paths 74

6.4 Promotional Planning 77

6.5 Strategic Planning 79

Endnotes $\quad 83$

$\begin{array}{ll}\text { VII. CHAPTER SEVEN } & 84\end{array}$

Conclusion

VIII. APPENDICES

Appendix A Manual for Uniform Traffic Control A-1 Devices Appendix B American Association of State and
Highway Transportation officials

B-1 Design Manual

Appendix C Rhode Island Bicycle Policy Document C-1

Appendix D National Park Service Land \& Water

$\mathrm{D}-1$

Conservation Fund and Grant Assistance Program Fact sheet

IX. BIBLIOGRAPHY

vi 


\section{LI8T OF FIGUREB}

Figure 1: Bicycle Classifications 
CHAPTER ONE

INTRODUCTION 


\subsection{BUBJECT BTATEMENT}

Since the earliest foundations of community planning and development, man has generally agreed that open space is important. Several "new town" designs have included open space as a necessary part of developing a new community. Unfortunately, larger cities did not have any room for great amounts of open space and the urbanization of many cities continued.

During the 1960's an increased awareness of the environment brought many changes, the most important being the way we think. This attitude has given an entire generation a new perspective. Open space and its environmental significance has played a key role in the development of linear parks and bike paths. And although many of the first bike paths developed in the United States were built in rural areas, the idea to rehabilitate abandon rails into trails gives new hope for urban areas.

The national awareness of developing abandon rails into trails is increasing. Unfortunately many towns are unaware of the process in which they must follow. The methods and approaches in which communities need to follow differ among communities. Key variables that will discussed in my study are: federal, state, and local government roles; costs; land use; population and demographics; site development; and design guidelines. The population variable will refer to the size of the community, while demographics refer to the character (age, 
race, sex, and religion) of the community.

Bicycle paths are the latest design for linear parks. The need for communities to develop these types of parks depends on the community. The objective of this study is to examine how to go about getting a bicycle path for your community, and the benefits that go along with developing a bike path.

\subsection{RELEVANT IITERATURE}

There has been many types of literature released on this matter, including government documents, newsletters, and public and private organizational promotions. Each type offers several viewpoints.

The first type includes government documentations. Several reports and studies have been done that mostly discuss governmental rules and regulations, guidelines, and assessments of bicycle paths. Two specific reports outline the Department of Transportation's role and funding process which need to be followed by local governments. other governmental documents outline bicycle design guidelines and Rhode Island bicycle rules and regulations. Several short informational documents have been produced by governmental agencies which are mainly used as promotional guidelines for rules and regulations created through specific legislation.

The second type includes articles published in various magazines. The latest surge of bicycle path awareness has 
been created through the large number of published articles on that subject. The articles are good to the extent that they cover certain sites, and the specific problems those sites faced. The articles also list the benefits each particular site has to offer the community in which it is located. A benefit which is also noticeable in the articles is that bicyclists write the articles, and their expertise in that sport produce specific, straight forward and useful information.

The third type includes promotional information created by bicycle groups such as the Rails-to-Trails conservancy and the Narragansett wheelmen. The information provided by private non- profit organizations is mostly promotional information. The information is unfortunately bias and must be carefully reviewed. The Rails-to-Trails Conservancy has a newsletter called Trailblazer. This newsletter offers a wide range of information.

\subsection{BIGNIFICANCE OF THE BTODY}

The increase in passive recreation over the past decade has created a demand for communities to develop more recreational sites. Unfortunately the cost of developing and maintaining a new recreational site is beyond most communities' budget. But the examination of recreational statistics illustrates that passive recreation is increasing the most, and the two activities that are most popular are 
walking and bicycling.

These two activities have been enjoyed by many people for many years, and the popularity is still increasing. This study will focus on the activity of bicycling, although many bicycle trails are also used by walkers.

The increase in passive recreational activities has created a demand for more linear parks and open spaces. While most communities do not want to spend anymore money for recreation, the development of bike paths can be inexpensive. This study will examine both costs and benefits of bike paths for a community. Future considerations include the potential of a $12^{\prime}$ wide path stretching from 2 to $20 \mathrm{miles,}$ and becoming a successful national project that link the corridors of America by trails. Several cities across America have already developed bike paths for their communities, and all of them are successful. The East Bay Bike Path in Rhode Island has been in place for approximately one year and most of the complaints are that too many people are using the trail.

Bike paths are not only being used for recreational activities, but also as transportation modes. The Burke-Gilman Trail in Seattle, washington is used mainly as a commuting trail. The $12.1 \mathrm{mile}$ path leads from the suburbs of Seattle into the heart of the business district. The path has been so successful that many realtors include it as a selling point. Several other communities use the bike trails as a corridor to connect rural towns. The use of abandon rails has 
been a key factor in the development of these bike paths.

\subsection{OBJECTIVES OF THE 8TUDY}

This study will examine the process which a community can follow to create a bike path. The increase in recreational activities such as walking and biking are one example of the use for a bike path. others include a new mode of transportation, creation of linear parks, and developing a national corridor.

The techniques used in developing a bike path in Rhode Island will always be the same if funding is received through the Rhode Island Department of Transportation (RIDOT). The RIDOT has guidelines for developing a bike path. This study will examine the steps a community should follow to develop a bike path funded by the RIDOT. Several projects currently underway in Rhode Island include the East Bay Bike Path, Blackstone Bike Path, and the North Kingston to Narragansett Bike Path. Each project is in a different phase. Chapter Four will provide a review of the different project phases, while examining the roles at each governmental level will provide the necessary research to examine guidelines for communities interested in developing a bike path. Chapter Four of the study will also review the funding sources available for communities developing bicycle facilities.

chapter six of the study will provide information pertaining to community involvement. Chapter six will review 
the citizen arguments for and against bicycle paths. Chapter Three has been added to illustrate the economic benefits of a community bike path, benefits which include higher property values, increases in tourism, corporate relocation, and the increase in general business activity.

\subsection{METHODS}

This study will be a descriptive analysis of several cases involving the development of a bike path. In recent years the growth of bike path development has produced generous amounts of information which will support this study . The great deal of literature available will be reviewed and the relevant information which supports the study objectives will be used to develop the necessary components of the study. Each component of the study will be a concise and descriptive analysis of case studies and government publications which contain information most relevant to each subject.

This study will also involve interviewing citizens and municipal officials. This technique is used to gain actual perspectives and thought pertaining to bike path development. As a study devoted to the development of guidelines, it is important to examine all variables involved in the decision making process. 
CHAPTER TTO

HI8TORY AND DEVELOPMENT 


\subsection{COYMUNITY DEVELOPMENT PATTERNB}

Since the earliest of times man has strived to create the perfect community. Many types of designs have been created; from the earliest of Egyptian towns built in the third millennium B.C. to that of Reston, Virginia, constructed during the 1960 's. Throughout this period of time, one common denominator remains clear, open space. The oldest communities in the world have plazas and parks created for aesthetics, recreational purposes and community gatherings. Today we view open space as an environmental necessity: trees produce oxygen, vegetation controls run-off and protects wildlife, while grassy swails purify our drinking water. The benefits of open space are limitless

Fortunately not only parks and plazas are considered valuable open space, but so are the farmlands, lakes and trails that connect these open spaces. This property is considered to be some of the most important open space in our country. In recent years the amount of open space in the United states has grown substantially. In Rhode Island alone, thousands of acres of open space have been preserved over the past decade. Today, the greenways between the open space are considered a valuable asset. The idea has been developed from greenways found throughout Europe, particularly in England and Germany, where royal highways and avenues are common, as are linear parks for recreational purposes.

The greenway concept that is used to connect open spaces 
takes in a variety of forms ranging from the 155 mile Hudson River Greenway, to the 12.1 mile Burke-Gilman trail in Seattle, Washington. "Today, over 250 greenways are either complete, or in the works." 1 This movement towards trails has spawned an incredible growth in passive recreational activities.

The two most affected activities are walking and bicycling. Increases in these two sports has been identified in 1991 preliminary Rhode Island state Comprehensive Outdoor Recreation Plan (SCORP) results. During three recreation workshops held by the R.I. Department of Envirommental Management, a questionnaire was handed out to the attendants. When asked if more walking trails and bike trails are needed, 37 to 5 answered "yes" to more walking trails and 45 to 2 said "yes" to more bike trails. The R.I. Department of Administration, Division of Planning is currently developing a project called "Greenspace 2000". This project is being developed to examine the amount of greenways in RI, to develop management and planning techniques to protect greenways, and also to design a format to help gain more open space greenways in the future.

The awareness for a need of open space has come a long way, but it is obvious that much more must be accomplished. The first step is to identify the goal; the need for trails as greenways. The next step is to design guidelines on how to reach that goal. This study will examine what cities and 
towns need to know when they design a bicycle trail in their community.

Increases in greenway activities has spurred national attention towards trails as a greenway alternative. Locally, the recognition and support received for the creation of the East Bay Bike Path, has developed and increased a constituency devoted to developing more bike paths across the state. The development of bike paths is supported by three groups: bicycle groups, environmentalists and general recreational groups. And although many common goals exist between these groups, the common denominator of greenways is evident.

The interest in bike trails as a greenway is two-fold. Besides the fact that bike paths act as links between open spaces, they serve two important needs. The first is recreational. Bike paths support off road paths for bikers young and old, as well as people who enjoy walking. It is more difficult to adjust bikes to a walking trail than it is for walkers to a bike trail. The second need is purely economical. Bike paths can be used by commuters. As indicated in section 2.3 of this chapter, commuting by bicycle is growing, and the economic benefits (Chapter 3) are excellent.

\subsection{ROLE OF RECREATION}

Bicycles have been around since 1790. The "walk-along" was pushed along by the riders feet, like a child's car. The 
improved model appeared about 1816, designed by Karl Drais. The first bicycle patent (approximately 1880) was the "safety bicycle" design. This bike had tires the same size, ball bearings, rubber tires, adjustable handle bars and a cushioned seat for comfort.

Some believe that in the last decade of the 19th century, the bicycle hit its highest popularity. "Four million people regularly rode a bike".2 Bicycle riding increased though during world War II because of the lack of automobiles, tires and gasoline. Since WW II, the bicycle has been replaced by the automobile. In other countries, such as Denmark, two out of every three persons is a bicycle rider. In other areas such as China, North Africa and India the bicycle is the only non-public transportation for millions of people.

\subsection{MATIONAL BICYCLE MOVEMENT}

Currently in the United States, "one in sixty Americans commute by bike, and one in five would commute by bike if bike facilities were improved." 3 According to Bicycling Magazine, America would embrace bicycling as a practical transportation option, as has much of Europe and Japan, if government and employers provided safe bike lanes, convenient bike parking and other supporting facilities.

According to a Louis Harris Poll conducted in 1990, nearly three million adults say they sometimes commute by bicycle. The poll also states that this number could rise to 
thirty-five million, more than one in five; if bike-friendly transportation systems existed. A special report by BICYCLING Magazine shows that in cities such as seattle the use of bicycle paths is greater because bike parking and storage facilities do exists. Successful case studies such as this have prompted government agencies (local, state and federal) to explore bike lane options and hire bike coordinators.

The key findings from BICYCLING Magazine's Harris Poll include:

- 2.8 million adults said they sometimes used a bicycle for commuting to work during the month preceding the survey (October). This accounts for 78 of all adults who rode a bike that month.

- 208 of adults, or 32.9 million people, said they would sometimes commute to work by bicycle if there were safe bike lanes on roads and highways.

- 18 of adults, or 29.7 million people, said they would sometimes commute to work by bicycle if employers offered financial incentive (as in traffic-clogged Los Angeles, where such incentives are mandatory).

- If 1 in 4 people rode just five miles a week that they normally would drive, our annual national gasoline bill would drop by $\$ 1.2$ billion. And each year, the air would be spared 6.7 million tons of carbon dioxide. 
- If gas rose to $\$ 2.00$ per gallon, more than 608 of all adult cyclists said they would sometimes use their bicycle for trips they now make by car.

- Among those households with annual income below $\$ 15,000$, nearly $3 \%$ bike commute, while only $1.6 \%$ of those with incomes above $\$ 35,000$ cycle to work.

- Of those adults who sometimes commute by bike, $36 \%$ do so between one and five days per month.

"These poll results are a ringing testimony to how extensive bike commuting can be with very little investment," says James E. MCCullagh, editor and publisher of BICYCLING Magazine. He adds, "But right now most people consider roads unsafe for practical riding... and they're right. In october 1991, Congress will consider the surface Transportation Assistance Act, and we're calling for a provision that at least 3\% of all highway dollars be spent on bicycle and pedestrian projects. We believe this could save billions in imported oil and help clean up the environment." 4

The other findings of the Harris Poll include:

- Half of all car trips in the United states are 5 miles or less.

- Around the world, especially in Europe and Japan, the bicycle is a meaningful transportation option. In Tokyo, $25 \%$ of all daily passenger trips are by bicycle. In Denmark, 338 
of all people cycle to work.

- More states and municipalities are hiring full-time bike programs coordinators. The Department of Transportation is hiring two bicycle program managers, the first such federal appointments.

- A group of congressmen is backing the "3t solution," which would commit that percentage of federal highway money to bike and pedestrian projects.

- In seattle you can pedal 25 miles from the suburbs to downtown and almost never ride with cars. Police patrol downtown areas on mountain bikes. A freeway tunnel appropriation included $\$ 11$ million for bike and pedestrian levels.

- Some employers are promoting bicycle commuting. For example, Xerox, in Palo Alto, California, provides bike lockers. In Pasadena, city employees who ride to work get their bike maintenance paid by the city.

This poll shows that attitudes are changing. On the whole, Americans are still very much in love with cars. But now we know that millions of people ride a bike to work, and tens of millions would, if not for a few impediments. The growth in bicycling to work is on the move and the creation of more bike paths is necessary. 


\subsection{CABE 8TUDIEB}

According to BICYCLING Magazine one in five Americans would bike to work if the facilities were better. As part of this study, examination of some of the United States' best bike trails will illustrate that these paths will be used. One example is the Burke-Gilman Trail in the northeast, in seattle, washington. This trail, according to peter Lagerway who manages the trail, has become a prized asset for an entire region, serving over 750,000 users a year. In fact, some people who opposed the trail are now its greatest supporters.

The trail, like many trails in America, follows the route of an abandoned rail corridor. The land was acquired by the city after lobbying efforts by local citizens and city planners. Today the Burke-Gilman trail is the most heavily used bike trail in the seattle area. The bike path has so much support that it is the basis for a bond issue which will support the creation of new trails throughout seattle and Washington state.

The Mohawk-Hudson bike trail travels 41 miles from the Erie Canal to Albany, New York. As of the late 1960's, both the Mohawk and Hudson Rivers were polluted. Once major lifelines for industry, commerce and expansion to the western states, the two rivers were little more than open sewers. Two major factors played an important role in the development of the bike trail. The first was the 1965 passage of the \$1 
billion State Pure Waters Bond Act, which brought renewed hope for the future of the neglected rivers. In 1967, Schenectady County's Planning Department unveiled a plan to create a greenway and recreational trail paralleling the Mohawk River. The plan seemed very feasible because much of the area was undeveloped. The Planning Department began feasibility studies.

The second turning point came in 1973 when General Electric, the area's largest employer, donated 38 acres of the old Erie Canal towpath to the Town of Rotterdam for public recreational use. At this point, the county began to design plans for the first miles of trails. Unfortunately when plans for the trail were revealed, the cost estimate of $\$ 390,000$ drove the county Board to vote against funding. Two weeks later at the next county Board meeting, there was an outpouring of citizen support. The Nature Conservancy, Boy Scouts, civic groups, hiking groups, school groups, and other organizations all came to speak on behalf of the proposed trail. This support, along with a $25 \%$ reduction in costs resulted in a complete turn-around unanimous vote in support of the bike trail. The donation of time and money to help fund the parks, picnic areas, and boat launches along the bikeway was due to heavy involvement by civic groups.

\subsection{CONCLU8ION}

The trend in biking across America is growing and the 
support of bike trails is equally successful, as the federal government continues to support this effort. Today, bicycling and walking have become even more popular than in the past. The federal-aid highway program provides support and funding for improving facilities to enhance these two methods of transportation. Funds may be used to build bicycle facilities as part of regular highway projects, in other words the tax we spend on gasoline will eventually be used to support biking facilities. The option of spending money on bike facilities is left to the state's discretion, which will be discussed in Chapter 4 - Roles in Bikeway Development. 


\section{ENDNOTES}

1. Didato, Barry. "The Path Less Traveled", Planning Magazine. January 1990, Volume 56, Number 1, APA Chicago, p.7.

2. Pena, Nelson. "Power in Numbers", Bicycling Magazine. April 1991, p.40

3. Ibid p.40

4. McCullagh, James E.. "Harris Poll on Bicycling Commuting", Bicycling Magazine Press Release, Rodale Press Publication, Frank Cioffi, March 1991. p.3 
CHAPTER THREE

ECONOMIC BENEFITB FOR DEVELOPING BIKE PATHB 


\subsection{INTRODUCTION}

Rivers, trails and greenways corridors are traditionally recognized for their environmental protection, recreational values and aesthetic appearance. These corridors also have the potential to create jobs, enhance property values, expand local businesses, attract new businesses, increase local tax revenues, decrease local government expenditures and promote tourism for a local community. One example which illustrates the range of possible economic benefits is the Delaware and Raritan Multi-Use Trail, built along an abandoned railroad and canal in central New Jersey. According to James Amon, Executive Director of the Delaware Trail, property values adjacent to the trail have increased. Amon also adds that it is now common to see concessionaires and rental establishments catering to the many users of the trail and canal. These two amenities seem to be the most important concerns and are usually key issues raised by home owners an business owners in the trail areas. This chapter will examine the economic benefits of trails for communities.

\subsection{IMPACT ON PROPERTY VALUES}

As mentioned earlier, greenway corridors provide a variety of amenities, such as attractive views, open space preservation and convenient recreational opportunities. Residents of communities value these amenities, and this can be reflected in increased property values and an increase in 
marketability for property located near open space.

Several studies have been conducted, and the most recent study was a survey of the residents and real estate agents located near the Burke-Gilman Trail. This method was used because it was found to be the most effective in perceiving landowners views and increases in property values. These surveys can be less time consuming, less expensive and generally require less specialized expertise than professional detailed statistical analysis, which is why most smaller communities choose to use the survey technique. The following findings are based upon surveys of property owners and real estate professionals.

According to the May 1987 survey, property near but not immediately adjacent to the trail is easier to sell. The property sells for an average of six percent more then comparable homes in the area because they are located near the trail. The property located on the trail is only slightly easier to sell. That property ranges from zero to one-half percent higher. The residents who bought their homes after the trail had opened are more likely to view the trail as a positive amenity. The residents who owned their homes before the trail was opened are generally less likely to view the trail as an economic benefit. Housing advertisements from local Seattle, washington magazines and newspapers mention the location of the property to the Burke-Gilman Trail. The entire survey and its results can be acquired through the 
Seattle Engineering Department, office for Planning.

\subsection{IMPACT ON COMMERCIAL ACTIVITIEB AND BU8INE8BEB}

In addition to higher property values, greenways and trails can also provide business opportunities, locations, and resources for commercial activities. These activities may include "on-site concessions, permittee's, partnerships between the managing agency and other groups, special events and even commercial filming activities. Compatible business ventures can provide a wide range of visitor services and facility improvements." 1

The documentation and estimation of economic impacts of the commercial uses associated with rivers, trails and greenways can be useful in promoting community bicycle path projects. Demonstrating these impacts might also help to expand a project or provide information to assist greenways and trails into other communities.

According to the Park Service manual concessionaires, permittee's and partnerships are recruited and usually bid for the right to provide a wide range of on-site visitor services. Examples of commercial activities include food services, recreation equipment rentals and sales. On larger trails such as the Elroy-Sparta Trail of wisconsin, lodging is provided along the trail. The most effective increase in commercial activities includes special events. Special events not only generate revenues to sponsors and the community, but 
promote the greenway itself to residents and visitors. According to the Economic Impacts of Protecting Rivers, Trails, and Greenway Corridors, prepared by the National Park Service in 1990, three examples of successful promotions are:

- Eppie's Great Race consists of a 6 mile run, 12.5 mile bike ride, and 6.35 paddle down the American River in California. The Sacramento County Department of Parks, Recreation and open space sponsors this annual event, held along the American River Parkway. All proceeds are donated to Adaptive Leisure Services (AIS). The 1989 Great Race raised $\$ 40,000$ and race donations to date total over $\$ 260,000$. These proceeds have allowed ALs to expand programs to meet the leisure interests and needs of persons with disabilities (County of Sacramento, 1989).

- The 12th annual "Great Race" in Pittsburgh attracted 12,807 runners to the city. Those runners living outside Pittsburgh, but within Allegheny County, spent an average of $\$ 14.40$ on race-related items, with 54 percent spent within city limits. Pennsylvania runners travelling to the race from beyond Allegheny county spent an average of $\$ 28.29$ within Allegheny County, 75 percent of which was spent within Pittsburgh. Not only did the event attract runners to the City of Pittsburgh, but it is estimated that over 40 percent of all travelling parties brought at least one nonrunner to the event. In fact, one estimate showed that those runners living outside city limits brought over 4,000 spectators to the event.

Overall, the 1987 Great Race generated an estimated direct economic impact of $\$ 220,000$ within Allegheny county. Adding registration fees paid by race participants, this total exceeds $\$ 330,000$. This total does not include spectator expenditures except for those spectators brought by runners. Thus the overall total expenditures associated with the event would likely be much higher (Gitelson, 1987).

- "Take a Walk on the wild side Ice Age Trail Hike-AThon" in wisconsin, drew over 1,200 hikers and raised $\$ 30,000$, against $\$ 15,000$ in expenses. The Ice Age Trail Council and Ice Age Park and Trail Foundation sponsored the event to raise money to support the development and maintenance of the trail, raise public awareness and strengthen organizations by providing a rallying point. Marketing techniques included distribution of several thousand posters featuring a "hiking mammoth," advertisements and feature article in wisconsin silent 
Sports, and a steady stream of articles in state and local newspapers (Pathways Across America, Fall 1988).

It can be seen that special events can also be used to raise money and promote the trail for community benefits. The events can serve as a catalyst to gain support, strengthen volunteer organizations and raise public awareness for the bicycle path. Approaches to developing these techniques can be found in the "Economic Impacts of Protecting Rivers, Trails, and Greenway Corridors Manual", provided by the National Park Service.

\subsection{IMPACTB ON TOURI8M}

Greenways, rivers and trails which attract visitors from outside the locality can stimulate the local economy. This section begins with examples stressing the importance of natural and cultural areas for attracting visitors, followed by examples showing how trails and greenways can contribute to the travel and tourism sectors. The last part of this section will demonstrate how corridor projects can increase marketing potential for the local community.

A bike trail, which provides local opportunities and enhances tourist draw, can be an important asset to a community. "Recent trend analysis show that weekend trips to nearby areas are on the increase, while the traditional two week summer vacation is on the decline for today's travelers."2 According to the National Park Service, trends 
such as these are due to the job complications of two-income families, limited time, interest in more specialized recreation experiences, increased mixing of personal and business travel and some year round schools.

Outdoor recreation, natural, historical and cultural resources are increasingly more important attractions for travellers. The significance of these attractions may be relevant in deciding the bike path design. several communities have built bicycle paths on abandoned rail rightof-ways or along river corridors. These properties tend to have a great deal of historical and cultural significance. Bike trails often link together cultural and natural resources. Environmental travel or ecotourism, in which the attraction is nature and conservation, emerged during the 1980 's and is expected to increase during the 1990 's. Travellers are also increasingly attracted to educational oriented experiences provided by cultural and historic sites. One of the fastest growing areas of tourism includes cultural and historic community fairs and festivals, which usually contribute to local community-based tourism. The Azalea Trail in Mobile, Alabama, serves as a city beautification project and attracts tourists as well as stimulates preservation and rehabilitation to historic areas.

"In 1988, 75 percent of all travel was for pleasure. outdoor recreation and entertainment are growing in importance and accounted for 41 percent of pleasure travel, while 34 
percent was attributed to visiting family and friends. Business travel accounted for 17 percent of all travel in 1988, with the remaining 8 percent attributed to personal and other reasons."3

"In 1988, users of the Elroy-Sparta Trail in Wisconsin averaged expenditures of $\$ 25.14$ per day for trip-related expenses. The total 1988 trail users' expenditures were over $\$ 1.2$ million. Approximately 50 percent of the users were from out-of-state, and the typical user travelled 228 miles to get to the trail." 4

More than 6000,000 Americans took a bicycle vacation in 1985. Touring cyclists, when travelling in a group, spent $\$ 17$ per day (camping), and $\$ 50$ per day (staying in motels). Cyclists travelling alone spent an average of $\$ 22$ per day (camping) and $\$ 60$ per day (motels)."5

Trails and greenways provide unique resources which nearby travel and tourist-serving establishments, chambers of commerce and local visitors bureaus can capitalize on and feature in their advertising. Because bicycle trails and greenways are a desired and profitable amenity for these businesses, they may also be willing to contribute to the funding and development of the project. According to the National Park Service, as a condition for development, the Campbell Inn (Campbell, California) was required to provide an easement for the Los Gatos Trail. Upon realizing the marketing potential of the trail, developers constructed part 
of the trail, an additional spur, and now provide rental bicycles for hotel guests. They also promote the trail in their brochure: "For fitness and fun, The Campbell Inn offers a jogging/biking trail connecting to a full series par course which...runs along a scenic trail, passing through forests and alongside a stream and two beautiful lakes." Room rates at the Campbell Inn range from $\$ 80$ to $\$ 275$ per night.

Relying on private advertising is one method of providing promotion for a community's trail system. The National Park Service has developed a method for promoting greenways to the public. First, develop a plan for marketing a greenway, but be careful the designated name of the project and any related brochures or information accurately reflect the nature of the project. The second step is to combine efforts with tourism boards, chamber of commerce, hotels, event planners, travel agents, tour guides and visitor bureaus. The last step involves assisting in the distribution of this information to visitor centers, conference centers, hotels and other traveller information locations.

Locally, according to the Manager of East Providence Cycle, business is increasing due to the East Bay Bike Path. Located several miles from the path entry point, East Providence cycle enjoys the benefits that this successful trail has created. Also, the popularity of the Newport Cliff Walk has always played a role in the charm which help attracts many of the tourists to Newport each year, and is an excellent 
example of promoting a trail as a reason to visit Newport.

\subsection{CORPORATE RELOCATION}

Another success of greenway and bicycle trails has been the interest of corporate relocation. As most larger organizations leave the congested metropolitan areas, the opportunity for relocating in a quiet, attractive community is increasing. Many communities want to attract new, expanding or relocating businesses to their area in order to increase their employment and tax bases. This section of the study discusses the importance of the quality of life factor in attracting new and relocating businesses. Bicycle trails contribute to the quality of life and their use is a benefit to corporate employees for exercise and relaxation.

The importance of quality of life in an area is increasingly cited as a major factor in corporate location decisions. Although several factors may be included in quality of life, one of the aspects is location with convenient access to natural settings, recreational and cultural opportunities and open space. In a recent report, the governors of New England states officially recognized open space as a "key element in the quality of life in their region"6, and continue to add "that it is a characteristic responsible for bringing rapid economic growth to the region, as well as providing the foundation of a multi-billion dollar tourism industry".7 
The American River Bike Trail in Sacramento, California, is included as an important outdoor recreation amenity in the Chamber of Commerce's publication titled "All About Business in sacramento". It is described as a 30 mile oasis in the heart of the City. The President of the Sacramento Metropolitan Chamber of Commerce, Roy Brewer, considers the trail to be evidence of the high quality of life in Sacramento, as well as one of Sacramento's treasures. "At many locations along the bicycle trail you can wade into the river, cast a line, and not see a single sign of civilization. The river trails provide abundant salmon fishing and natural areas for hiking, horseback riding, or biking - a chance to get away from it all without having to leave the City." 8

In the always increasing strive for better health and welfare, America is realizing that exercise is important. Companies are also realizing the benefits of healthy employees, both in increased efficiency and decreased health insurance claims. Bike trails help promote fitness by providing convenient opportunities for exercise, such as biking, walking and jogging. An analysis of the 1980 census data by the Northeastern Illinois Planning Commission (NIPC) showed 7,000 commuters in the Chicago region use bicycle to get back and forth to work every day, weather permitting. During the peak summer months, this figure climbed to 14,000 commuters. NIPC found most of the commuters using bicycles to travel to work live near on of the five linear trails found in 
the Chicago region. In census zones where these trails exist, an average of 15.6 percent of the commuter trips are by bicycle. When the region is taken as a whole, however, only one percent of the working population commutes by bicycle. These trails, therefore, seem to offer an alternative to using congested roadways to get to work (Eubanks, 1986).

\subsection{CONCLUBION}

The economic benefits of developing a bike trail are obvious. With national increases in bicycling, bicycling commuting, recreational vacation activities, and environmental conscious citizens, the time is now to act on strengthening any community's marketability. Currently in the Northeast, recession is obvious and attempts to set communities apart depend on planning and developing new strategies to rejuvenate an economy. Bicycle trails can be a low cost attempt to provide natural and recreational amenities for a community. Chapters 4 and 5 will discuss the approaches which need to be addressed for developing guidelines for creating a community bike path. 


\section{ENDNOTES}

1. "Economic Impacts of Protecting Rivers, Trails, and Greenway Corridors", National Park Service. Washington, D.C.. 1990, p.3-3

2. Schweck, Tim and Sprehn, Dave. A Look at Visitors on Wisconsin's Elroy-Sparta Trail. Madison, WI 1989, p. 5-5

3. "Economic Impacts of Protecting Rivers, Trails, and Greenway Corridors", National Park Service. Washington, D.C.. 1990, p.3-3

4. Ibid, p.5-6

5. Ibid, p.6-3

6. Governor's Committee on the Environment-Report, 1988 , P. 17

7. Ibid, p.17

8. "Economic Impacts of Protecting Rivers, Trails, and Greenway Corridors", National Park Service.

Washington, D.C..1990, p.6-6 
CHAPTER FOUR

ROLEB AND GUIDELINEB

33 


\subsection{INTRODUCTION}

This Chapter will explain how local governments can work with federal and state agencies in developing bicycle facilities. The objective is to discuss the role of state and local cooperation in developing a network of state and local bicycle facilities which will enable safe and efficient bicycle travel between and within local communities. This chapter also outlines a specific set of procedures for local governments to follow that will best enable municipalities to develop bicycle paths. The state policies and federal procedures will also be discussed because of the important role they play within the development of bicycle paths. Federal funding plays a major role in the development of most bicycle paths. The power of funding is used to control the development of bicycle facilities, and is administered through the Federal Highway Administration (FHWA). Most of the guidelines reviewed for this study examine Federal and state policies.

Many states have specific policies regarding bicycle paths and facilities (parking and storage areas). These policies play an important role in design, construction, and development of bike paths. In the state of Rhode Island, the Department of Transportation is the ruling body for bicycle facilities. The Department also allocates most funds for their development. Larger states, such as California, Colorado, and washington have their own bicycle departments 
which work with the Department of Transportation on specific projects.

\subsection{LOCAL ROLES AND GUIDELINES}

The Rhode Island Department of Transportation recommends that each municipality develop a plan for a local system of bicycle facilities. This should be a comprehensive plan covering the construction of new bikeways, storage facilities, maintenance and safety education programs and other bicycle related issues. In establishing a municipal bicycle facilities program, it is advisable to seek input from local residents and bicycle enthusiasts.

Safety and education programs, conducted in the schools or through civic organizations, are a natural component of a local bicycle facilities program. Such programs also increase the public awareness of bicycling as a transportation mode. Federal funding is available through the RIDOT for nonconstruction projects which include activities such as safety and education programs and the development of route maps for transportation purposes.

According to the RIDOT Manual for Local Government Participation in Developing Bicycle Facilities, May 1985, in developing a local system of bicycle facilities, the following steps are suggested:

1. Identification of major attractions and residential areas that need to be served 
and connected by the system.

2. Identification of potential routes on existing highways.

3. Comparison of the identified routes against state plans to determine the extent to which they overlap.

4. Identification of the segments of the local systems that are not included in current state plans.

5. Identification of potential routes for independent bike paths which can provide important links in the local system or between the local system and the state system.

It should be the responsibility of local communities to initiate projects on all of these segments. Local communities may seek funding through the RIDOT for transportation related facilities that are on state highways, on local federal highways, for those that are eligible independent bike paths, and for storage facilities. Also according to the Manual, Federal funding opportunities under the section of construction projects include:

1. Improvement of roadways through shoulder widening.

2. Construction of transportation related independent bicycle paths.

3. Replacement of non-compatible drainage grates.

4. Signing of roadways to guide, regulate, and warn bicycle (and motorist) traffic.

5. Development and installation of bicycle parking facilities such as bicycle racks.

During the process of developing a local plan, potential 
routes and segments of the local system that are not included in state plans should be identified. A survey of local streets, including arterial, collector, and neighborhood roads would also be needed to provide information about the conditions of the surface, width of pavement, traffic volumes and speed, and barriers to bicycling. Hazardous conditions such as drainage grates, narrow pavement, high traffic volumes and speeds, and dangerous intersections should be identified. These types of conditions that are not corrected will be barriers to bicycling and will prohibit the development of linking the local system to a larger network. Alternative routes should be considered if the results of the survey indicate that the problems are too severe.

When the local community is assessing the results of the survey, and prioritizing the needs of the community, three criteria, in particular, need consideration: the safety and protection of the bicyclist, the demand for access to particular destinations, and the linkage of the system. These criteria should be examined in light of local opportunities, problems, and constraints for developing bicycle facilities.

The safety and protection of the bicyclist is a primary reason for providing bicycle accommodations. Safety criteria should play a prime role in planning bicycle protected roadways and independent bicycle paths. Particular attention should be given to improving streets with the highest bicycle use, dangerous intersections, and the streets with high 
traffic volumes and speeds. Although the reporting of bicycle accidents is often limited, accident statistics can be helpful in identifying problem areas.

Any assessment studies of demand completed by the community should consider destinations with high bicycling commuting potential, such as schools, civic centers, employment sites, commercial and shopping areas and recreation centers. The access to these locations is best provided by routes that are direct and expeditious. Bicycle storage facilities at end-of-route destinations should encourage bicycling as a transportation mode. In communities where high bicycle usage is experienced, the need for provisions for bicycle parking facilities may arise. Zoning code adaptations for inclusion of bicycle parking facilities have been adopted in Portland, oregon. This example illustrates how one city responded to the space demands of this vehicle type by designating minimum bicycle parking requirements in commercial, industrial and high density residential areas according to a formula similar to that for automobile parking. By use of the zoning technique, the City of Portland indicates its desire to promote bicycling as an equal to that of the automobile.

Linked with safety and demand issues are those of the systems connectivity or linkage. The safety of the bicyclist is enhanced where bikeways are continuous and the rider is not exposed to dangerous conditions. The linkage of destination 
points to state and local systems will also influence bicycle usage.

The more information collected about bicycle usage, road compatibility and linkage, the better the opportunity will be for the community to assess current local needs. It will also provide valuable information to the state in the review of proposed state road construction projects and to the state transportation planning process. In the state of Rhode Island, in consultation with the Rhode Island office of state Planning and the Rhode Island Department of Transportation, communities can identify bicycle transportation projects for inclusion in the state's Transportation Improvement Program (TIP). The projects listed on the TIP are eligible for federal funding. Unfortunately many Rhode Island municipalities are unaware of this funding source.

The local municipality should not have to develop detailed design criteria for the construction phase of these bicycle projects. The Department of Transportation has standardized guidelines for the construction of independent bicycle paths and the improvement of shoulders for bicycle friendly roads. Also, the Manual for Uniform Traffic Control Devices (MUTCD) will be used as the standard by the DOT for signing trails, shoulders, and intersections. Part IX of the manual, Traffic controls for Bicycle Facilities is included in Appendix A. Use of this manual as a guideline for the state assures consistency and will avoid confusion for bicyclists 
and motorists. Design criteria for bicycle facilities in Rhode Island are controlled by the American Association of State and Highway Transportation officials, (AASHTO). Portions of their published guidelines are included in Appendix B.

When local communities plan, design, and finance bicycle path projects independently of state and federal funding, the RIDOT recommends that the communities follow the AASHTO and MUTCD standards to ensure statewide compatibility. All of the Rhode Island federally funded bicycle projects follow the guidelines and standards included in these two documents.

The process guidelines created by the DOT for local governments to follow in planning, designing, constructing, and maintaining bicycle facilities were designed as requirements for federal funding. Local governments are free to undertake these steps independently for projects they intend to fund and operate such as recreational bicycle facilities or bike paths which serve local internal needs.

The Rhode Island Department of Transportation has also designed guidelines for local governments to follow if they wish to independently develop a bicycle system. The nine stages are:

1. Identify a project. This consists primarily of looking for routes from all the potential routes and segments identified in the local system plan, where need can be established for bicycle paths and where opportunities exist for using appropriate land and/or rights-of-way. 
2. Establish need using the suggested procedures detailed:

a. Importance of demand estimation

b. Bicycle facility service area

c. Historical data

d. Population demand indicators

e. Density demand indicators

f. Climate

g. Bicycle ownership demand indicator

h. Trip generation factors

The level of detail for this step will depend upon the size and type of project. It is important to note that the creation of a new bicycle facility, route or path, may result in new users. Simple extrapolation of past trends in bicycle ridership may understate future ridership, given a new facility.

3. Conduct a study to assess project merit as a transportation facility. The assessment should incorporate information gathered in steps 1 and 2 about need and opportunities with an overview of major constraints or problems. This will vary depending on the type of project proposed.

4. Contact the DOT to verify project merit and assess Federal/state funding availability. It is at this step in the process that the local community should provide the DOT with a map and description of the project and the results of the project assessment. Documentation of local support for the project signed by the local council president or chief elected official is required. Federal funding requests should be made through the state's Transportation Improvement program (TIP) and/or the RIDOT's Six-Year Program processes.

5. For high cost independent bicycle projects not incidental to other highway construction, which show merit, work with the Department to conduct a feasibility study. If a proposed facility has merit and is eligible for federal funds, the Department will fund a formal feasibility study subject to the availability of federal funds. A specific route, crossings, structural improvements, and landscape and design features should be specified in the feasibility analysis. Problems and solutions for land 
acquisition, traffic control, signing, and maintenance should be included, as should preliminary design, engineering, and cost analysis for required features. This study should also include specific elements such as bicycle racks or lockers that are felt to be important in the overall facility.

6. Sign agreement of conceptual approval to the final design of bicycle facility. This step follows the standardized procedures that include the review of preliminary design and engineering studies and public hearings for the project and is subject to FHWA approval.

7. Negotiate and sign an agreement with the Department that specifies the responsibilities for maintenance and law enforcement.

8. Take necessary steps to enforce maintenance and law enforcement agreements signed with the Department. This step would be taken when the Department has completed the project. It may be necessary for a local government to designate a bicycle law enforcement officer in the local police department, send her/him for special training, acquire special maintenance equipment such as a small sweeper, or institute an increased maintenance schedule for improved bicycle tolerant roads. other additional actions may include establishing sites for bicycle storage facilities or procedures for renting or assigning bicycle lockers to individuals.

9. The last step in the process is the dissemination of information about new bicycle facilities in conjunction with ongoing safety and education programs.

\subsection{BTATB ROLEB AND GUIDELINES}

Much of the design and development phases of bicycle paths begin with Federal Highway Administration funds, and end with local municipalities supplying the land and responsibility. But the planning and administering of rules, 
regulations, and funds is carried out by the state's Department of Transportation. In carrying out its program the department, through its planning division and design section, proposes to undertake several activities in accordance with specific policies designed at the state level. The development of bicycles as an alternate mode of transportation has been considered a goal of the Federal Highway Administration (FHWA), and concern is that the bicycle mode is a very viable but under-utilized transportation mode. For this reason a set of policies have been developed and adopted by the FHWA and the Department of Transportation for bicycle facilities planning at the state level. Appendix $\mathrm{c}$ includes a summary of the Rhode Island Bicycle Facilities Policy Document of 1985 .

According to the 1985 Policy Document, the Department must first provide local communities with information that will enable them to know where state highway construction and reconstruction will take place. The Rhode Island Department of Transportation has a six year plan for highway improvements. This document identifies which projects are already scheduled and budgeted. Examples of Rhode Island projects show that the Jamestown Bridge project is first on the list. Local communities can use this information to determine if any local projects have the potential for bicycle related activity. The RIDOT is currently designing a proposal for a future statewide bicycle system. In the plan both 
scheduled projects and proposed facilities will be identified.

After the state provides information about highway projects, the state planning office must aid in the identification of additional projects beyond those to be included in a statewide bicycle system plan. These projects include independent bicycle paths, signing, and storage and parking facilities. The state plan focuses primarily on completing a system of inter-city and town facilities, and insuring bicycle access to key regional facilities and activities. The RIDOT plans to identify and evaluate the bicycle facilities needed to accomplish this goal as well as working with the local communities to identify additional facilities not incorporated in the state plan. Under state policy though, the local communities should initiate this process.

When proposed projects illustrate merit, and are eligible for federal funds, the Department will assist in the feasibility analysis of the selected project. The local governments will be responsible for following all the proper guidelines and procedures outlined in accordance to Rhode Island policies, with help from the state. If all the specific guidelines have been followed, then the state is responsible for assisting the community.

The crucial phase of a bicycle facilities project is the feasibility study. A formal study will be funded through the RIDOT subject to the availability of federal funds and the 
FHWA approval. The feasibility study, according to a Design Policy Memo released through RIDOT Division of Public Works, must examine the following areas:

1. Farmland impacts

2. Relocation impacts and right-of-way acquisition

3. Considerations relating to pedestrians and bicyclists

4. Air quality impacts

5. Noise impacts

6. Hater quality impacts

7. Wetlands

8. Floodplain impacts

9. Coastal impacts

10. Threatened or endangered species/wildife

11. Historic and archaeological preservation

12. Hazardous waste sites

13. Construction impacts

14. Visual impacts

15. Public facilities

Further information about these variables is provided through the RIDOT. other information required may include trip estimates, master plan consistency, design elements, maintenance, cost, and other characteristics unique to the project. The study must be developed in accordance with the required guidelines administered through the FHWA. At this stage, the RIDOT and state Planning will assist with proper staff and materials if possible. A proposed Providence to the Connecticut border rails-to-trails project recently was discarded because of the fact that the trail crossed an abandoned hazardous waste site in Cranston. The site would have been too expensive to clean up and liability for the site was also too high. The data collection phase of the feasibility study revealed enough information to cancel the 
project.

Upon successful completion of the feasibility study, hearings, public workshops, and then community and FHWA approvals, the project will proceed to final design and engineering phases. The proposed Kingston to Narragansett Pier Bike Path is currently holding workshops for the community to voice any objections or praises it may have for the project. A large scale map of the site was available for citizens to review. It is important at this stage of the project that the RIDOT meet with the citizens and discuss the projects variables. This process affords the citizens to play a role in the development of the project. Final design and engineering should be provided by the state or by contract through the local community. At this juncture, the state will be responsible for negotiating an agreement. The agreement should cover such items as responsibilities for facility maintenance, law enforcement, and safety.

The final phase in the process is the commitment by the RIDOT to construct the facility, which upon completion will be opened for use and maintained according to the agreements signed by the Department, local governments, and other state agencies. Larger areas, such as Xing's county in Washington State, have their own Bicycle Divisions as part of the Parks and Recreation Department. In Rhode Island, the Department of Environmental Management is responsible for maintenance and upkeep of the East Bay Bike Path. The state will 
continue to disseminate safety, education, and informational materials on a statewide basis. The state also encourages the promotion of education, civic and bicycle organizations at the local level.

\subsection{FEDERAL ROLES AND GUIDELINES}

The Federal role is an important step when developing a bicycle path. The FHWA reviews, then approves or denies any bicycle project that is using Federal monies. Depending on the size and budget of the bicycle path, this could be very important.

The FHWA, which is the ruling body in transportation, has been holding workshops and hearings for the past several years to discuss bicycle paths as an alternative to the automobile. As discussed earlier, commuting by bicycle has been successful in several countries around the world, and while each country is different, information reveals that commuting by bicycle could be viable in the United States. Thomas D. Larson, Federal Highway Administrator, "bikes about 14 miles every Sunday, and has been for many years. Larson states... I am pro-bike. Flat out, pro-bike."1

The first approval for an independent bicycle facility, is sought after preliminary discussions regarding a specific route design has been designated by the state or state and a local community. This is the first phase, which starts a conceptual approval of a project. The FHWA must be provided 
with a map and description of the proposed route. At this stage, the project must include a detailed description of how the facility is to be utilized primarily as a transportation mode. This summary is very important, because if the state or community can not prove that the facility will be utilized specifically as a transportation facility rather then a recreation facility the project will not be approved. When the project has been reviewed and approved by the FHWA, the state should begin to develop a work program.

The work program should specify and define the needs that must be addressed in the feasibility study and preliminary design study conducted for the project. The work program should include clarified objectives of the project. The documentation of the project as a transportation facility, the identification of trip generators, and the linkage of the facility are elements of the work program. After the state completes the work program, it must be approved by the FHWA. Upon approval of the work program, the feasibility/preliminary design study should be conducted by either the Department of Transportation or a consultant. Additionally, the Department/consultant must specify the variables to be examined in the feasibility study.

Following the public workshops, and acceptance of the feasibility study, a final design is reviewed by the FHWA. The FHWA comments on the final plans and specifications, and estimates costs for the final product. The project then goes 
out. to bid. The final phase gives the FHWA the authority to proceed with the construction of the project. During the construction phase, the FHWA can inspect and review the work at the project site. The last payments of the project are released only after a final inspection and acceptance of the site is completed.

\subsection{FEDERAL FUNDING SOURCES}

There are three related programs for funding class II \& Class III roadway and bikeway improvements through the FHWA. These are administered through local transportation departments. The three programs have been established and funded by the federal government. They are based on a uniform road classification system used throughout the United states, which categorizes roadways by their function in the system and their location in either an urban or a rural area. The three federal funding programs available are:

\section{Consolidated Primary \\ 2. Urban Systems \\ 3. Rural Secondary}

There is no separate pool of funds for creating bicycle tolerance in roadway construction or reconstruction projects. The costs of constructing additional width for the shoulder, signs for the route, and/or converting to bicycle compatible drainage grates are built in to the overall project costs. At present, the urban systems, consolidated primary, and rural secondary projects are funded $75 \%$ by federal money, and $25 \%$ by 
state money. The state share of the funding formula can be paid in full or in part by the local government. More progressive states use bonds and other techniques for funding bicycle projects. In seattle, "the people voted in favor of a \$117 million open-space bond issue, with nearly \$33 million earmarked for trails."2

Class I-Independent bicycle path projects are $100 \%$ federally funded. Independent bicycle projects may include construction of bicycle lanes, paths, shelters, bicycle parking facilities, and other roadway and bridge work necessary to accommodate bicyclists. Non-construction bicycle projects, also eligible for 1008 federal funding, must be related to the safe use of bicycles for transportation. These projects can include the development of educational materials and maps. Independent bicycle facilities, however, are constrained by a federally established limit of $\$ 4.5$ million per year per state.

If the community chooses not to apply for FHWA funds, then other alternatives are available. The National Park Service has funds that are available through the "Iand and Water Conservation Fund Grant Assistance Program" (L\&WCF). "The L\&WCF program was enacted in 1964 to encourage nationwide creation and expansion of high quality, outdoor recreation opportunities."3 An L\&WCF fact sheet is included in Appendix D. 


\subsection{OTHER FUNDING 8OURCEB}

There are several ways of obtaining funds for most bike path projects. All avenues should be explored when trying to fund such a project. The local government can directly fund or facilitate funding for bicycle facilities. These are activities undertaken without federal transportation funds. Several alternatives are possible:

1. Directly appropriate funds for facilities from local tax and fee revenues. Such actions frequently occur when public facilities are built, such as town libraries, which include bicycle racks, or recreation complexes that have bicycle lockers. Cities and towns can also appropriate local funds for more costly bike facilities, such as paved pathways through parks and along town roads.

2. Direct locally received state and federal grant money toward the creation of bicycle facilities (i.e. UDAG, CDAG, and $(D B G)$. The bicycle facilities must be included in a larger project. Some of these grants are currently difficult to be obtained because of the fiscal crisis at federal and state levels. "Small Cities" and "Economic Development Program" funds can all be used to include bicycle tolerant support facilities in larger projects, such as housing projects, sewer, landscaping and streetscaping, and building or adaptive reuse of structures for industry and business. These funds can also be combined with state transportation funds to construct bicycle paths. 
3. Establish a local transportation improvement funds program. This could consist of contributions from developers (i.e. impact fees), transportation fees (i.e. parking), or voluntary contributions (i.e. from local businesses or groups).

4. Private project requirements is another form for bicycle facilities funding. Communities can require developers to include facilities as part of zoning and subdivision regulations. The cities and towns can simply require bicycle compatible roadway design, bicycle storage compatibility, and other facilities where a development intersects an existing network of bike paths. Bicycle facilities can also be part of sidewalk requirements. Planning departments and zoning boards can determine which program(s) within the locally funded projects would be the best for their specific community.

When receiving funds through federal grants or programs, communities must follow a specific set of guidelines that may be too stringent. Each federal program contains different regulations and should be examined fully to determine which is best for the community. The several local funding opportunities available also contain several options that should be fully reviewed. 


\section{ENDNOTEB}

1. Larson, Thomas D.. Transportation Strategies for the 21st Century. 1990. p.3

2. Mills, Judy. "Clearing the path for all of us where trains once ran", Smithsonian, April 1990, p.139

3. United States Department of the Interior, Division of the National Park Service. Land \& Water Conservation Fund Grant Assistance Program, Fact Sheet 1987 


\section{CHAPTER FIVE \\ CONSTRUCTION AND MAINTENANCE}




\subsection{INTRODDCTION}

When considering the construction of a bicycle path, a community must first consider what type of facility it should build. There are several types of bicycle paths, each given a specific classification (descriptions of the bicycle classifications are listed in Figure 5.1).

Depending on the type of facility a community wants to provide, the classifications provide three alternatives that are widely accepted throughout the United States. Each bicycle classification is suited for specific needs of the bicycle path site. Some bicycle paths may be independent, while others must use part of the roadway. Because parts of the abandoned right-of-way are occupied with buildings, the Kingston to Narragansett Bike Path was forced to alternate between Class I and class II types. The State of Rhode Island considers two types of bikeways, independent bike paths (i.e. East Bay Bike Path, Class I) and bicycle tolerant bikeways "(i.e. all other roads and highways, where feasible, shall accommodate bicycle transportation, class II \& III)".I This chapter will address the two types of bikeways and conditions that surround the implementation of both networks. It will also address maintenance and security, signing, and the approaches to preconstruction procedures.

\subsection{BICYCLE TOLERANT ROADWAY8}

The philosophy of the bicycle tolerant roadway is based 


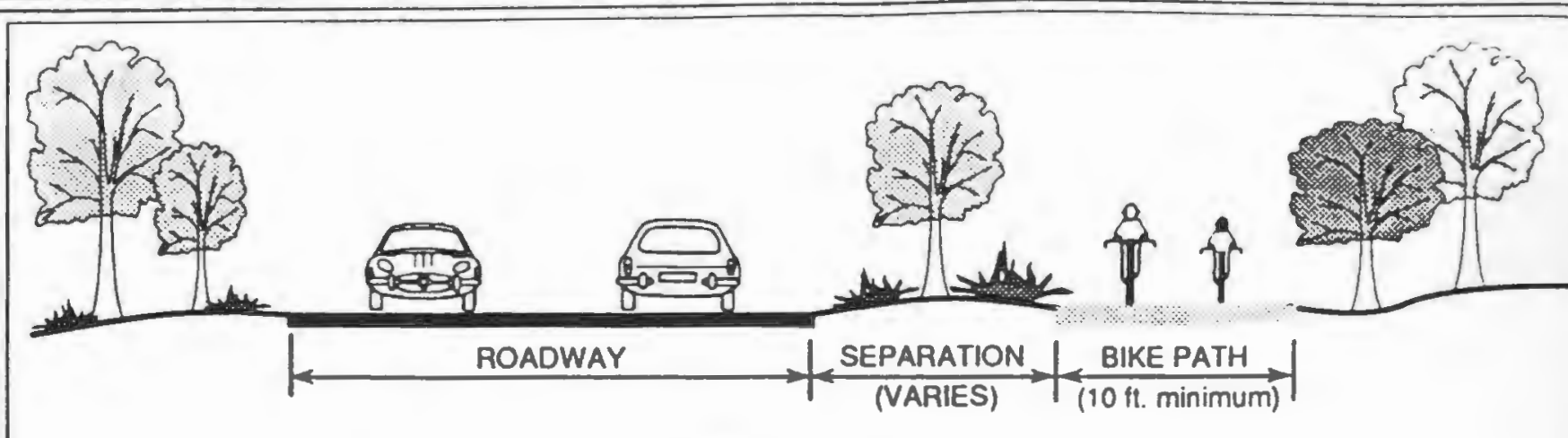

CLASS I BIKEWAY

A path for the exclusive use of bicyclists, physically separated from motorized vehicular tralfic either within an exisling right-of-way or a completely new location.

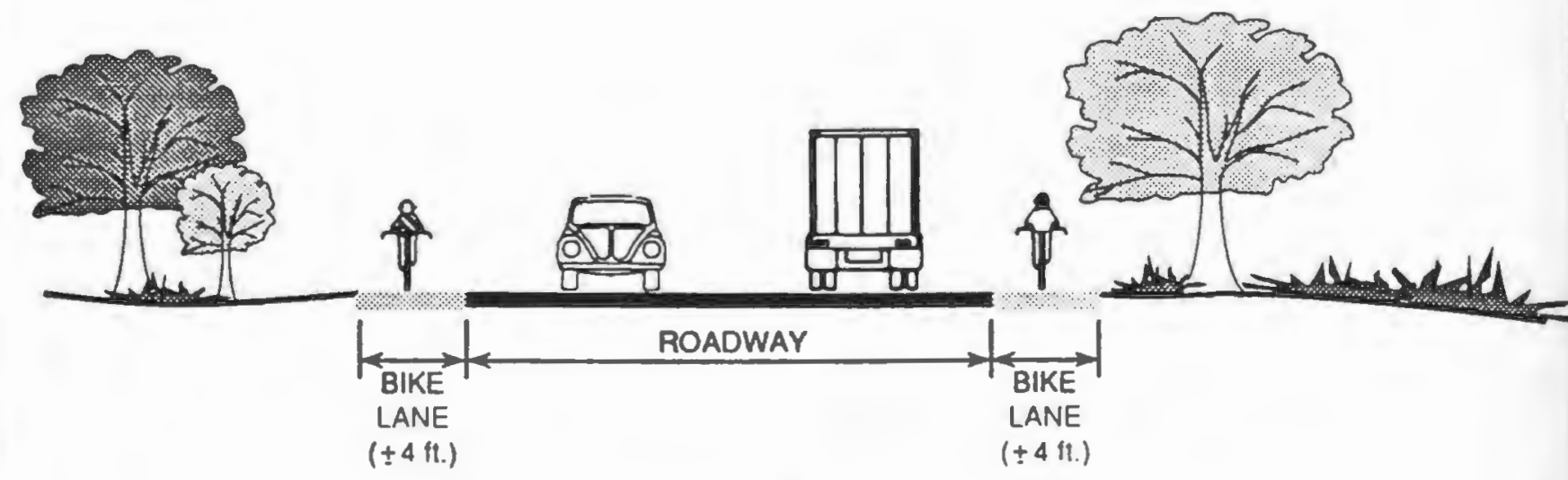

CLASS /I BIKEWAY

A portion of a roadway which has been designated by striping, signing. and pavement markings for the preferential or exclusive use of bicyclists.

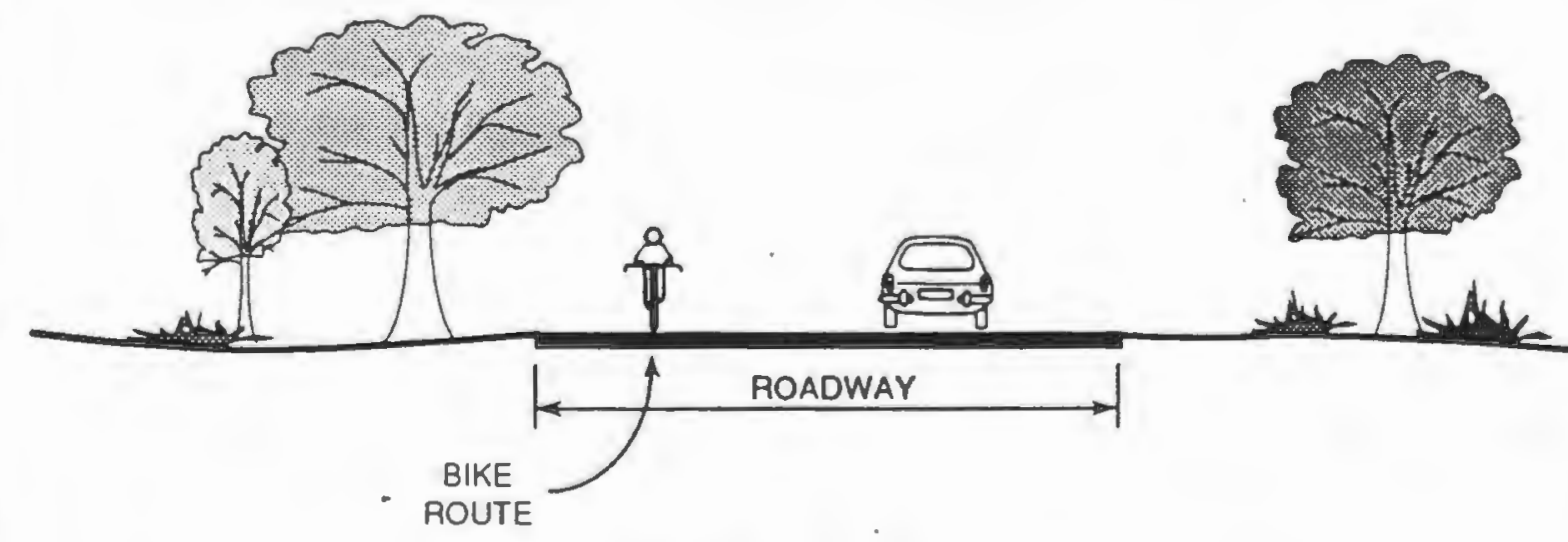

\section{CLASS III BIKEWAY}

A shared right-ol-way identilied only by signing. Bike routes are proposed along low speed, low volume roadways where there is insufficient width to provide bicycle lanes.

Docos

PLavenc orvsion
Narraganscu / South Kingstown Bicycle Facility Feasibility / Design Study Rcpon

\section{Bikeway Facility Classifications}


on the premise that existing roadways, where bicycles are not prohibited, should be appropriate and safe for bicycle transportation. In the state of Rhode Island a bicycle tolerant system of roads is a goal of the RIDOT for expanding transportation opportunities for all modes of travel.

The bicycle tolerant system is considered to be cost effective, compatible with the environment, and a safe way for bicyclists to travel. The accommodation of bicycle traffic will increase roadway construction costs, but the price is substantially less than the construction costs of independent bike paths. Reconstruction of existing roads is also considered less expensive than independent bike paths, and is believed to be more easily funded through federal programs.

A recent survey by the Rhode Island coalition identified problems perceived by bicyclists. "The most serious problems included litter and debris, traffic conditions, potholes and rough roads. A lack of signed routes, unsafe drainage grates, and a lack of safe storage facilities were also cited as serious problems for the bicyclists." 2 The bicycle tolerant facilities should address these problems. The RIDOT Manual for Local Government Participation in Developing Bicycle Facilities in Rhode Island sets forth the procedural and design requirements that consider these problems.

The riding surface is obviously one of the most important features of a bikeway. Smooth surfaces, free of debris assures safety. Whether the bikeway is an exclusive bike path 
or a shared roadway, the proper maintenance of the surface is critical.

Traffic conditions are another very serious problem identified by bicyclists. This is because the bicyclists must share the road with motor vehicles, often under conditions of high traffic volumes accompanied by high speeds (average bicycle speed of 7-15 mph versus average motor vehicle speed of 30-40 mph). When bicycle facilities are incorporated into the highway, they are designed to ensure safe bicycling under the existing and projected traffic conditions. For example, bicycles can safely share the roadway with motor vehicles on some rural roads with light traffic, low speeds, and good sight distances; however, it is necessary that they be separated from traffic on highways with high traffic volumes and speeds. A bicycle compatible shoulder would permit this separation and allow safer alternatives to bicyclists. Traffic control devices are also important in protecting the bicyclists. The control devices include road signs, signals, and markings. Other frequent problems on shared roadways are obstructions in the bicycle lane or shoulder, specifically drainage grates. The RIDOT Division of Public Works specifically requires that bicycle safe drainage grates must be installed where bicycles may pass over them. The standards for such grates are:

1. Waffle-type grates

2. High capacity "cascades"

3. Modified parallel bar 
Where there are hazardous obstructions in or close to the bikeway, markings, advanced warning signals, and/or roadway striping must be used.

On a bicycle tolerant highway, railroad crossings are preferably perpendicular in design and marked well in advance. The perpendicular widening of the roadway is desirable to allow bicycles to swing out to the right, make the crossing, and avoid entrapment in the spaces beside the rails. The design was first incorporated during the construction of the East Bay Bike Path, and has been incorporated in other independent trails as well as other bicycle tolerant paths.

The design of a complete independent bikeway or bicycle tolerant path is unlikely. Many independent trails cross over roadways and bridges, railroad tracks, and run alongside many roadway shoulders (i.e. North Kingston - Narragansett Bike Path). The Jamestown Bridge will have a class II bike path, but will have a class I or III bike path leading to the bridge (if successfully completed).

\subsection{IMDEPENDENT BIKE PATHS AND COBT COMPARIBONB}

The independent bicycle path serves and supports the bicycle tolerant road system, it also encompasses many of the same issues. But the independent bike path provides an alternative, in both densely developed urban areas and rural areas, where traffic (volume and/or speed) is a barrier to bicycle use and the right-of-way for wider lanes, bicycle 
lanes, or shoulders is unavailable. The independent bike path can extend transportation opportunities where it serves as a conduit between bicycle tolerant systems.

In general, the cost of constructing an independent bicycle path exceeds, on a per mile basis, that of providing for bicycle accommodation on existing roads. Justification for independent paths will be based on variables such as: areas with a demonstrated need; the availability of right-ofways; and a linkage system to other state and local projects. Independent bicycle paths can be initiated by local or state governmental agencies through their own department of transportation.

The independent bike path also provides the opportunity for recreational bicyclists. While many of the bicycle tolerant roadways will serve commuters, the "sunday afternoon" bicyclists can use the independent bike path. Unfortunately the FHWA will only fund those projects which consider bike paths mainly as a commuting facility.

The most important issue for developing an independent bicycle path is that of availability of right-of-ways. If a community is able to provide enough land for the development of an independent bike path then a bicycle tolerant roadway will not be considered. The non-profit group Rails-to-Trails Conservancy is a leading trails advocate which offers seminars, books, brochures, and many other information mediums that help communities develop bike paths from abandoned 
railroad right-of-ways. The costs are lower when converting the abandoned rails into trails because one of the most expensive facets in developing a bikeway is the supporting bed. The abandoned rail line beds are easily converted and updated into supportive structures for today's bikeways.

The American Association of State and Highway Transportation officials Manual is considered the best tool for developing cost projections for both independent and bicycle tolerant roads. Some states also have their own restrictions for developing bike paths, and costs may vary. Many factors are considered when developing a bicycle path. The East Bay Bike Path is an example of an expensive bicycle network. It cost approximately $\$ 6$ million dollars to build the first three sections of the East Bay Bike Path. The cost of rebuilding three bridges was one reason why the total costs were so high. The trail used the best surface materials.

The community must consider the property that will be acquired in the development of the bike path. The straight, flat trails in the midwest do not cost as much to develop as curving trails that abut water bodies. As discussed earlier, a proposed Providence to the Connecticut bicycle facility was abandoned because a hazardous waste site was discovered along the trail. Although all the land was being donated (usually a substantial cost), the cost to clean up the site was astronomical. The costs that are involved in developing a bicycle facility are consistent with other roadway projects 
and facilities. Breakdown of costs relative to the development of an independent bike path are listed below:

1. Land

2. Design consultant

3. Environmental assessment and impact study

4. Soft costs

5. Hard costs

6. Maintenance

The costs do not have to be limited to that of the community. Several communities have worked with local utility companies to use the trail to house gas, electric, phone, water and sewer lines. The community charges either a small monthly rent, gets assistance from the company when building the facility, or both. Creative ways for increasing revenues for developing or maintaining the trail are discussed in Chapter six.

\subsection{PRE-CONBTRUCTION BTEPB}

While the costs of developing a bicycle facility may vary, the steps to developing the facility do not. According to Lucy Icobucci of the RIDOT, Division of Contracts, there are several steps that must be followed when planning to develop a bicycle facility. When a community decides that it wants to build a bike path, and FHWA funds are wanted, the following agenda must be incorporated. The community must contact their local or state Department of Transportation, which will begin to process the application for approval of FHWA funds. An outline of the steps are listed below:

1. SCOPE OF WORK - The scope of work is a job description 
of the proposed bicycle facility. It includes dimensions of the project site, what is to be expected of the project, and deadines. The scope of work is then advertised in several local and regional newspapers.

2. IETTER OF INTEREST - The perspective design firms must then write a letter of interest to the state Department of Administration. The letter will include the design firms method of approach, architects and engineers at their firm, and general resume of other projects they designed. The DOA and DOT both review the letter, and a short list is made of at least three potential design firms.

3. SHORT LIST - The list of potential design firms is considered the short list. After the accepted design firms are contacted, they must purchase a "specs" book. The book contains a listing of all mechanical, architectural, and engineering work that must be accomplished on the job. The "specs" book provides all the necessary technical jargon that is needed for the design firm to develop the bike path.

4. TECHNICAL PROPOSAL - The technical proposal is an actual design of the bike path created by the design firm. The technical proposal is then reviewed by the RIDOT contracts and Planning Department. The committee of RIDOT architects and engineers then reviews the project proposal. Final consideration includes financial, mechanical, and architectural design. The committee then decides which firm will received the contract. 
5. FEE PROPOSAL - The Planning Division of the Department of Transportation and the design firm will then work together to develop the final design cost and final specifications of the bike path project.

6. BUDGET - When the decision is made on the cost of the design, the State's Budget office and Purchasing Department are notified. A contract is then drawn up for both the state and the design firm. The project is then ready to be put out for bid.

Construction firms are then notified by listings in the newspaper. The interested construction companies buy a "specs" book, which includes the bike path design, develop a proposed plan and budget, and submit the budget to the RIDOT Division of contracts. The budget is sealed, and is not opened until a specified meeting date has been set for all construction companies to attend. At the meeting the budget proposals are revealed and company with the lowest bid will win the contract to construct the bicycle path. The final step involves the design firm and construction company working together to develop the bicycle path. A DOT "resident engineer" is assigned to oversee the project until its completion.

\subsection{MINTENANCE}

Bicycle facility maintenance is a subject of serious concern for bicycling safety. This includes maintenance of 
physical facilities and of operations related to security. "Federal funding for the construction of bicycle facilities will not be granted without an agreement for maintenance and policing from an authorized legal entity."3

Maintenance of bikeways on the shoulders of state highways should be incorporated into normal procedures with attention paid to small potholes, sand, gravel, and litter on the trail surface. However, since bicycles are more sensitive to road conditions than automobiles, the frequency of inspection and maintenance activities should be increased during the bicycle season. Particularity at the end of winter, gravel should be removed from road shoulders. In the repair of potholes the molding of materials into the hole should be designed for bicyclists and not for motorized vehicles. Responsibility for the maintenance of shoulders should rely on owner of the road (federal, state, or local government).

The maintenance of independent bicycle trails will require a series of negotiated agreements dependent upon the site specific issues. The negotiated agreement for maintenance and patrolling of independent bike paths will specify the responsibilities and procedures. Independent bike paths should not be sanded in the winter because of lack of use. This will prevent further maintenance in the spring. However, regular inspection is encouraged. Frequent litter pickup, trash removal and security patrols are necessary for 
bike paths. Debris removal is the most important maintenance job. Glass, branches and litter may be hazardous to the bicyclists. Maintenance of grass and shrub areas along bike paths is very important, particularly at intersections where shrubs should be cut to provide required sight distances. Maintenance also includes sustaining structural and functional characteristics on a long term basis. For example, part of the East Bay Bike Path was washed out from a series of storms, repair to a damaged bed was necessary. The frequency of maintenance is listed for both peak and of seasons:4

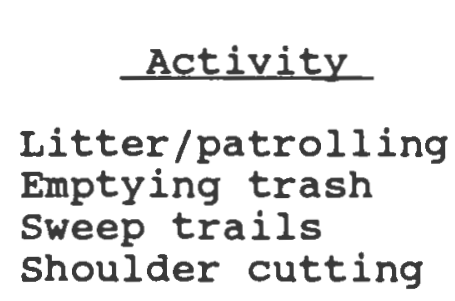

Peak Season
May to Sept
twice a day
twice a week
twice a month
once a week

\begin{tabular}{c} 
Off Season \\
oct to April \\
\hline twice a week \\
once a week \\
once a month \\
as needed
\end{tabular}

Responsibility for maintenance of bike paths will probably depend upon the relative significance of the bike path to the state and to the local community. Bike paths will typically be the responsibility of the initiating authority. If a bike path is important to the local community, they may want to consider assisting in the costs of maintaining the path. For example, the East Bay Bike Path crosses several communities and state parks. Kevin O'Malley of the Department of Environmental Management is responsible for maintaining the facility.

The maintenance and security of bicycle storage facilities will depend on the agreement signed by all parties 
involved. The community in which the facilities are usually located often help maintain the facilities. When corporate offices have facilities located on their property, they assume the responsibility. 


\section{ENDNOTES}

1. Rhode Island Department of Transportation Division of Planning. Rhode Island Bicycle Facilities Policy

Document. May 1985, p.8

2. Rhode Island Bicycle Coalition News. October 18 , 1982 . P. 2

3. United States Department of Transportation, Division of the Federal Highway Administration. Bicycling and Pedestrian Facilities in the Federal-Aid Highway Program. Publication Number FHWA-ED-90-020. September 1990.

4. O'Malley, David, Regional Director Colt State Park. Interview April 1991. 
CHAPTER BIX

COMMUNITY INVOLVEMENT

69 


\subsection{CONONITY PARTICIPATION}

The development of a bike path is going to affect many of the community's citizens. The bike path is a community project that will most likely pass through citizens backyards. Chapter six will discuss important development and community Issues that concern worried citizens, elected officials, and bicycling advocates. The encouragement of heavy community participation will ensure that projects will be successfully implemented in accordance to community feedback.

When anything new is introduced to government officials, they are usually hesitant in making any changes. When state and/or federal representatives seek to get laws passed or funding created for their constituents, the representatives are often persuaded by large groups of citizens that have band together. currently, a group called the "Chain Gang" has formed in washington D.C.. This group is a collection of congressional aides, federal agency staff personnel, activists, and journalists. There are also other groups in America that are advocates of bicycle trails. The Rails-toTrails Conservancy is a large organization that holds seminars across the country each year to help develop trails. The Federated Wheelmen of America, which is located in Baltimore, is probably the largest bicycle advocate in America.

It is suggested that when developing a bike path, the community should form a committee or organization. According to Connie Daniels at the Rhode Island Department of 
Transportation, it is vital to get the community involved during all phases of a bicycle project. This approach is used by the RIDOT to help prevent any unnecessary problems further along in the project.

The creation of a Project Advisory Committee (PAC) is an advisable concern when developing a bicycle path coalition mostly because of the land acquisitions involved in the project. The PAC also considers what routes would be best, add expertise to the issues addressed, and make recommendations concerning most aspects of bicycle path development. It is advised to create the PAC when an interest in the bicycle path first develops.

When a community is developing its own network of bikeways (without federal or state funding), the process of developing a community advisory committee has usually been considered. This type of group is usually led by citizens already interested in bike trails.

\subsection{NRGUMENTE TOR BIKB PATHB}

There are several arguments for and against bicycle paths, some of which were discussed in Chapter Two. It is important that all aspects of developing a bicycle path be addressed. One of the most important reasons for developing a citizen committee is to make sure that residents are involved in every step.

The following list will address the positive aspects for 
developing a bike path.

1. COMMUTING - The idea of commuting by bicycle has been very popular in countries across the world. Unfortunately the concept of bicycle commuting in the United states did not develop until the 1970's oll shortage. Twenty years later, the increase is growing. Last year, according to BICYCLE Magazine, 1 in 60 people bike to work, and 1 in 5 would bike to work if facilities were better. The Federal Highway Administration is also involved in developing funding opportunities for bicycle paths used for commuting. According to the FHWA, "bicycling and walking are two overlooked options in our national transportation mix. The FHWA is committed to working with the states to encourage their use and make them safe."1 The FHWA views bicycle paths as a commuting possibility which will lessen the burden on Federal roads and highways, decrease car trips and pollution as well as traffic congestion.

2. ECONOMIC BENEFITS - The economic benefits of a bicycle facility are many. Chapter Three lists 4 specific areas that could be affected if a bicycle facility was implemented. Those include higher property values, commercial businesses, corporate relocation, and tourism. The economic benefits is a secondary feature in creating a bicycle facility. Many bike paths that have been developed were not built for the reason 
of economic development but rather environmental, recreation, and commuting purposes. The positive affects which came after the development of a bicycle path were areas studied after the paths were in place.

3. RECREATION - The 1986 Rhode Island State Comprehensive Outdoor Recreation Plan (SCORP) had a survey which asked a selected group of Rhode Island Citizens what recreation activities they participated in during their leisure time. Recreation involving bicycling and walking trails were in the top ten. The 1991 SCORP is currently being completed, and while the survey methods were different, the reaction to biking and walking has been overwhelming. Passive recreation has been on the rise over the past decade. Walking and biking combined have been the most popular activities.

4. GREENWAYS/SPACES - During the past decade, millions of dollars were budgeted across the country in an effort to preserve open space. Much of that money was allocated for the development of bicycle trails. The development of bike trails for open space is not new. The Appalachian Mountain club has been preserving thousands or acres of open space specially for use as trails. Since the development of mountain bikes in the 1970's, the trails can now be used by bicyclists. But the trails not only provide recreation for the nature enthusiast, but also provide greenways and links for wildlife habitat. 
The network of linear parks in urban areas provides shelter for many animals, while allowing access to suburban and commercial areas for day trippers. The design of open spaces as linear parks provides the opportunity for everyone to use the trails as nodes for linking rural and urban areas. The most beneficial reason to develop bike paths as open space and linear parks is to promote green spaces in all types of land use patterns. The Burke-Gilman Trail in seattle passes through several residential neighborhoods, two industrial parks, a college campus, and the central business district of seattle. The only other element linking these sites is the Seattle Freeway.

\subsection{ARGUHENTS AGAINBT BIRE PATHB}

The interest and support for bicycle paths has been increasing over the past two decades, and without much opposition. Most of the opposition comes from the neighbors and residents that are directly related to new bike paths. The major concern in developing a bicycle trail is NIMBYism (Not In My Back Yard). Most of the citizens do not complain about the trail as a whole, but rather that they do not want it to border their property. The major complaints that property owners have are:

1. REDUCED PROPERTY VALUE - This complaint is the highest concern of citizens who would be located near or on the trail. 
This controversy has been an issue that has attracted a lot of attention. Several studies have been done. One of the most comprehensive studies was the "Evaluation of the Burke-Gilman Trail's Effect on Property Values and Crime" completed by the Seattle Engineering Department and office for Planning in May 1987. The study found that the property near but not adjacent to the trail was easier to sell, and the value increased $6 \%$ more than comparable property in the area. The homes located on the trail were slightly easier to sell, and property values only increased 0 to $1 / 2 \%$. There were no signs of any property decreasing in value because the trail was located adjacent to someone's home. Some real estate agencies promote the fact that a house is on the trail.

Residents who feel the increased property values will bring higher taxes should realize that the increases are not high enough to make much of a difference.

2. CRIME - The second major concern after decreased property values is the crime rate. Many citizens feel that the path will give access to criminals who will vandalize or commit burglaries in their neighborhood. The Burke-Gilman study also examines the amount of crimes that have occurred since the trail was opened. The study found that no increases in criminal activities were due to the trail. Police in that area felt that the lack of automobiles was the reason that crimes were low. The other fear that property owners had was 
unwanted intruders on their property. Many of the citizens felt that their quiet neighborhood would be infected by hundreds of bicyclists, some of which would stop and rest on their property. Only a few incidents were ever reported involving bicyclists and property owners. Not one single resident felt that they trail should be closed, and almost two-thirds felt that the trail increased their quality of life.

3. LIABILITY - In 1965, "Suggested State Legislation" by the Council of State Governments created a model for recreational use statute. The statute was designed to encourage private property owners to open their lands for public recreation by limiting the landowner liability. Research regarding private landowners and their willingness to provide recreation indicates that liability is a major concern and barrier to developing trails. Currently under the recreational use statutes, there is no property owner liability for recreational injuries from ordinary negligence (i.e. carelessness). To recover damages, the injured person who entered the property must prove "willful and wanton misconduct on the part of the landowner. Unlike ordinary negligence, such misconduct is much more outrageous behavior demonstrating an utter disregard for the physical well-being of others."2 


\subsection{PROMOTIONAL PLANNING}

The first step in community participation and developing support for a bicycle facility is promotional planning. The decision to develop a bike path in a specific community will depend on several key variables, many of which were discussed in previous chapters. Important factors such as crime and lower property values are two strong opinions that motivate citizens against bicycle paths. If a group or organization wants to successfully develop a bicycle facility, they must first achieve strong support, which will depend highly on the strategy design.

successful types of strategies should include the following necessary components:

1. Educate the local politicians - In Michigan, members who supported the Paint creek Trail project distributed documents called "Responses to Questions About the Paint Trail creek" to all the local officials. This helped to raise support as well as help the politicians respond accurately to questions from constituents.

2. Develop bicycling activities involving prominent people - Holding events with leading local figures, including politicians, can greatly improve a trail's visibility and acceptance. It is also suggested that an invitation to the media will be beneficial.

3. Develop a broad based coalition - When building a trail support group, try to assemble as broad a base of 
support as possible. The coalition should also include none bicycling activities who may share the trail, such as walking groups, cross-country skiers, and joggers. It is also important to involve civic and youth groups (Boy scouts), as well as handicapped and senior citizens.

These three techniques are basic for all types of trails. Other suggestions for designing a strategy include:

1. Solicit utility company involvement - As mentioned in Chapter Five, many successful trails have higher values than most people think. Fiber optic cables, gas and electric lines, water and sewer mains are all being successfully laid under bicycle trails. Working cooperatively with utilities companies can often save time and money.

2. Institutionalize trails into existing plans - It is recommended that instead of focusing exclusively on developing guidelines or plans for bicycle paths, public officials should consider including bicycle requirements in other official reports and documents. The trails concept should be used in several other city documents, policy statements, capitol improvement projects, and environmental impact statements.

Final suggestions for developing a successful strategy involve quality work, leadership, and public relations. A solid strategy needs successful candidates to operate terrific slide show presentations, develop creative slogans, and provide knowledge of funding techniques and sources. 


\subsection{BTRATBgic pLANNING}

When a successful organization is created, and promotional techniques are implemented, specific strategies and guidelines should be considered. One specific strategy was created by The Open space Imperative (OSI), an organization created to develop more open space, trails, and greenways. The group publishes informational letters, fact sheets, and other planning guides to help create an educated public. The design strategy that they have developed has been used in several open space projects throughout the Northeast and across America. Although the plan is currently designed for open space programs, the OSI supports it as a useful planning tool for regional bikeway systems.

According to The Open space Imperative, there are three elements needed to begin work towards a regional network of greenways and trails. The three common elements are:

1. Set of Guiding Principles

2. Regional Plan

3. Good Implementation Techniques

1. A set of guiding principles will help in defining essential goals of open space and greenway development. When developing a bicycle facility, setting principles will promote common planning techniques, design standards, and preservation of natural systems. Protecting land is one of the best ways to preserve water and air quality. The development of natural systems goals will also promote both environmental awareness and recreation opportunities. 
Creating a bicycle path to be used as open space serves many purposes, protecting the environment, supplying recreation facilities to communities, and providing commuting alternatives. The OSI strongly supports bicycle paths as an excellent method for environmental protection.

The strategic guidelines should also include area location principles. The development of bike paths should not be limited to any particular communities. As many paths are located within urban limits as they are in rural locations. The network should be accessible to all types of people. The greenways idea is designed to establish bike paths within urban areas to connect the rural open spaces already in place.

The last principle that the OSI supports is landscape requirements. The design of parks and paths should be created around areas that provide a "sense of place". Examples are farmlands, neighborhood districts, historic districts, and aging industrial remnants. The protection of these features can make outdoor activities more interesting and enjoyable.

2. The design of a regional plan, if there is not one in place, will act as a way to meet all greenway needs. The plan should provide positive ways to address open space protection in a region. The identification of sensitive areas can provide opportunities for promoting bicycle facilities to protect open space linkages. Several possible open space 
linkages include designs around sensitive areas such as river and stream corridors, coastlines, wetlands, and ridges, most of which are regional components. Sensitive man-made corridors that can act as open space linkages include abandoned right-of-ways, vacant lots, and city streets and parkways.

3. According to the OSI, the implementation strategy should be the most important, because without solid implementation techniques, plans and principles do not build bike paths. Included in the OSI's strategies were some of the promotional techniques mentioned in this chapter.

The first step for creating a solid implementation strategy involves contacting state officials. This serves two purposes. The first is to find who is responsible for state bike path development, what plans are being implemented, and what the state's policy is regarding bike paths. The second is to inform the individual responsible that an organization/committee is begin created to examine the laws and provisions regarding state bicycle facilities policy.

The second step is the examination of state policies. The main element of a successful implementation strategy is the package of laws and programs that will help establish bikeway networks. The better the policies are, the easier it will be for states and municipalities to pursue bicycle facilities projects. Some policy elements may be insufficient 
for current needs and legislative action may be necessary. At this point it would be necessary to involve specialists, including lobbyists and national bicycle clubs. 


\section{ENDNOTES}

1. United States Department of Transportation, Division of Federal Highway Administration. Bicycle and pedestrian Facilities in the Federal-Aid Highway Program. Publication Number FHWA-ED-90-020. September 1990.

2. Kozlowski, Dr. James C.. The Supply of Recreational Lands \& Landowner Liability: Recreational Use Statutes Revisited. University Press. 1988. p.VI D1 
CHAPTER BEVEN

CONCLUSION 
Bicycle paths provide several benefits to a community, with little negative impacts. Bicycle paths go far beyond that of a recreational trail for the weekend bicyclists. The development of bicycle facilities supply necessary environmental and transportation components. The identification of bikeways as potential greenways and as an alternative to super highways has been accepted. The challenge now lies with the state and local governments to support the development of bike paths. The research in the previous chapters illustrates the needs for developing bicycle paths, as well as the benefits communities will receive. Funding sources for bicycle paths are also identified. The procurement of federal funds for such a project may serve to stimulate economic activity. Leasing options can also be considered as a funding alternative for developing a trail and increasing local revenue.

As mentioned earlier, the two primary factors for developing a bicycle trail are transportation and recreation. The support of a bicycle facility as a transportation mode acts to serve as an alternative to automobile transportation. Less automobiles serve many other benefits, which include less gasoline consumption, less congestion and traffic jams, better air and water quality.

The support of a bicycle facility for recreation also has several benefits. The bicycle facility provides access to local stores, municipal buildings, and parks for citizens at 
several locations. The trail also has many uses. It can be used by people who walk, jog, roller skate, and bike.

Both the transportation and recreational components also promote environmental benefits. The development of parks and trails create linkages that combine with other trails form a network of open spaces. These open spaces are often referred to as greenways. Greenways serve as wildlife corridors through urban and rural areas. Greenways also serve to protect natural corridors such as rivers, streams, beaches, and farmland. In urban areas, greenways provide protected areas of open space often used for bicycle paths and other recreational purposes.

The two primary factors for developing bicycle paths are often considered to be essential for environmental protection. Bicycle activists also like to promote the environmental benefits that bike paths provide. As mentioned in chapter six, when building a constituency it is important to get an established organization involved in the effort. The diversified benefits which bike paths provide should draw several groups into the effort (i.e. Sierra club, Appalachian Mountain Club, and the Audobon).

The development of a bicycle facility is not for every community, and should be considered carefully before investing time and money. This study serves to address several issues, as well as guide the community through the development process. If a community is interested in developing a bicycle 
facility, then this study should be helpful. 
APPENDICEB 


\title{
Part IX. TRAFFIC CONTROLS FOR BICYCLE FACILITIES
}

\author{
A. GENERAL
}

\section{A-1 Requirements for Bicyclist Traffic Control Devices}

Traffic control devices, whether they are intended for motorists or bicyclists, must adhere to five basic requirements to be able to perform their intended function. They must:

1. Fulfill a need.

2. Command attention.

3. Convey a clear, simple meaning.

4. Command respect of road users.

5. Give adequate time for proper response.

The design, placement, operation, maintenance, and uniformity of traffic control devices must be considered to meet the above requirements. Design is a critical feature to permit the device to fulfill a need and to command respect of road users. The placement-lateral, vertical, and longitudinal-plays an important part in making the device effective and in giving adequate time for proper response. The operation of. traffic in response to the device is, of course, the critical test of the device's effectiveness and a check on all five of the basic requirements.

Uniformity, achieved by following the recommendations and standards of this Manual, greatly enhances the ability of a device to convey a clear, simple meaning to the user.

Whenever devices are installed, they should be warranted and based on a prior engineering study. Where the guidance provided by this part of the Manual does not fully define where particular devices should be used, qualified traffic engineers should determine the application of devices on any bicycle facility before installation is made. It is intended that this Manual define the standards for traffic control devices, but shall not be a legal requirement for their installation.

\section{A-2 Scope}

This Part covers bicycle-use related signs, pavement markings and signals which may be used on highways or bikeways. 


\section{A-3 Definitions Relating to Bicycles}

The following terms are used throughout Part IX:

1. Bikeway - Any road, street, path, or way which in some manner is specifically designated as being open to bicycle travel, regardless of whether such facilities are designated for the exclusive use of bicycles or are to be shared with other transportation modes.

2. Bicycle Trail-A separate trail or path from which motor vehicles are prohibited and which is for the exclusive use of bicycles or the shared use of bicycles and pedestrians. Where such trail or path forms a part of a highway, it is separated from the roadways for motor vehicle traffic by an open space or barrier.

3. Designated Bicycle Lane-A portion of a roadway or shoulder which has been designated for use by bicyclists. It is distinguished from the portion of the roadway for motor vehicle traffic by a paint stripe, curb, or other similar device.

4. Shared Roadway - A roadway which is officially designated and marked as a bicycle route, but which is open to motor vehicle travel and upon which no bicycle lane is designated.

5. Bicycle Route-A system of bikeways designated by appropriate route markers, and by the jurisdiction having authority.

\section{A-4 Standardization of Devices}

Standards for basic design elements and devices using these standards are given in this Manual. These standard devices generally will serve most applications. Where particular conditions require the use of a device that is not included in this Manual, the general principles in this Manual as to color, size, and shape should be followed wherever practical. Such devices should also follow the design, installation and application concepts contained in the Manual.

\section{A-5 Maintenance}

Bicycle signs and markings should be properly maintained to command respect from both the motorist and the bicyclist. When installing signs and markings on bicycle facilities, care should be taken to have an agency designated to maintain these devices.

9A-6 Legal Authority - See: Section 1A-3.1 


\section{A- 7 Meanings of "Shall," "Should," and "May"}

In this Part as in other parts of the Manual, the words "shall," "should," and "may" are used to describe specific conditions concerning traffic control devices. To clarify the meanings intended by use of these words, the following definitions are provided:

1. SHALL-A mandatory condition. Where certain requirements in the design or application of the device are described with the "shall" stipulation, it is mandatory that these requirements be met.

2. SHOULD-An advisory condition. Where the word "should" is used, it is considered to be advisable usage, recommended but not mandatory.

3. MAY - A pemuissive condition. No requirement for application is intended. If a particular device is used under a "may" condition, however, its design shall follow the prescribed format.

\section{A-8 Relation to Other Documents}

The Uniform Vehicle Code and Model Traffic Ordinance published by the National Committee on Uniform Traffic Laws and Ordinances, have provisions for bicycles and are used as the legal basis for the control devices included herein. Under the Uniform Vehicle Code, bicycles are generally considered to be vehicles, so the bicyclists have the same privileges and obligations as other drivers.

Informational documents used during the development of the signing and markings recommendations in this part of the Manual include the following:

1. Guide for Bicycles, American Association of State Highway and Transportation Officials, 1974.

2. Bikeways, State of the Art, Federal Highway Administration, 1974.

3. Bicycle Facility Location Criteria, Federal Highway Administration, 1976.

4. Bicycle Facility Design Criteria, Federal Highway Administration, 1976

5. State and municipal design guides.

Other documents which relate to the application of traffic control devices in general, are listed in section 1A-7 of this Manual.

\section{A-9 Colors}

The use of colors for bicycle facility traffic control devices should conform to the color code specified in section $1 \mathrm{~A}-8$ for signs and markings. This in part is as follows:

YELLOW-General warning

RED-Stop or prohibition

BLUE-Service guidance 
GREEN - Indicated movements permitted, direction guidance BROWN-Public recreation and scenic guidance

ORANGE-Construction and maintenance warning BLACK-Regulation

WHITE-Regulation 


\section{B. SIGNS}

\section{B-1 Application of Signs}

Bicycle-use related signs on highways and bikeways serve three basic purposes: regulating bicycle usage, directing bicyclists along preestablished routes, and warning of unexpected conditions. Care should be taken not to install too many signs. A conservative use of regulatory and warning signs is recommended as these signs, if used to excess, tend to lose their effectiveness. The frequent display of guide signs, however, aids in keeping the bicyclist on the designated route and does not lessen their value. Some signs for the bicyclist can also serve the motorist and the pedestrian.

\section{B-2 Location and Position}

Where signs are to serve both bicyclists and motorists, mounting heights and lateral placement shall be as specified in Part II, Signs. Figure 9-1 illustrates typical signing placement for bicycle trails. Overhead sign clearance on bicycle trails shall be a minimum of 8 feet. The clearance provided should also be adequate for the typical maintenance vehicles used on the bikeway. Where signs are for the exclusive use of bicyclists, care should be taken that they are located so that motorists are not confused by them.

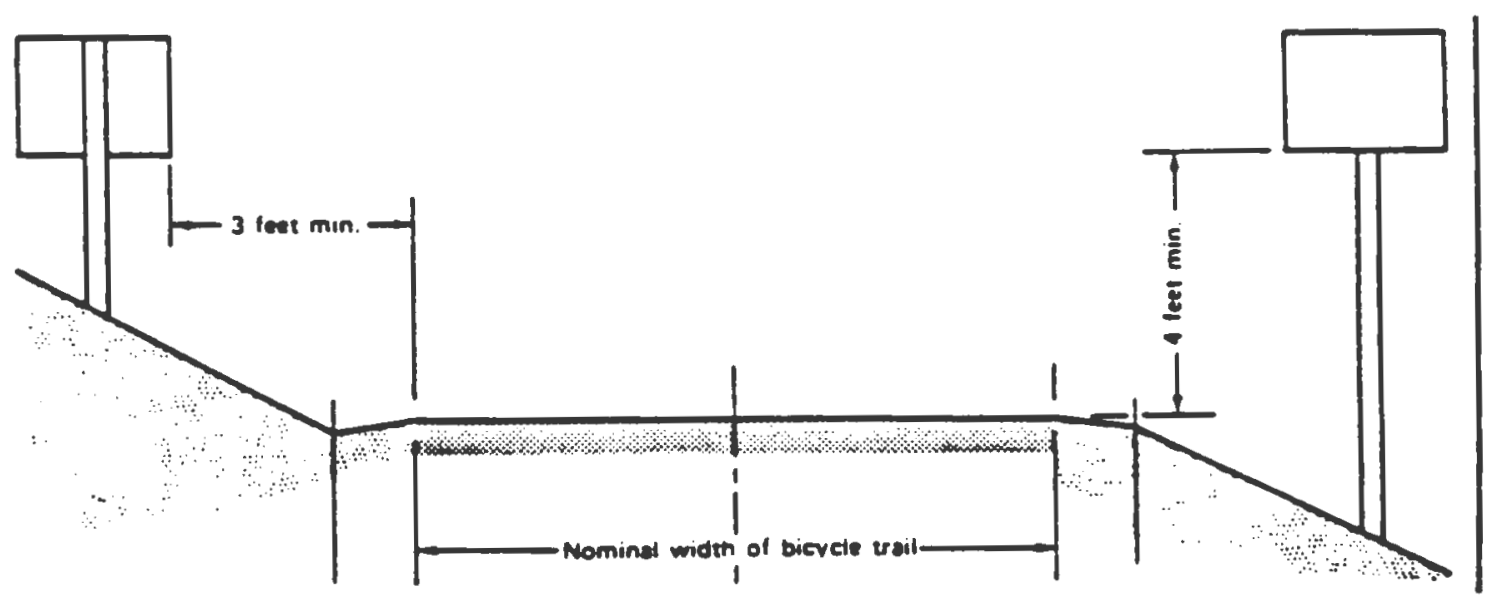

Figure 9-1. Bicycte sign placement on a trail.

\section{B-3 Design}

The design of signs for bicycle facilities should, whenever possible, be identical to that specified in this Manual for motor vehicle travel. Uni- 
formity in design includes shape, color, symbols, wording, lettering, and illumination or reflectorization. Detailed drawings of the standard signs illustrated in this Manual are available to State and local highway and traffic authorities, sign manufacturers, and similar interested agencies.* Standardization of these signs does not preclude further improvement by minor changes in the proportion of symbols, stroke width, and height of letters, or width of borders. However, all shapes and colors shall be as indicated, all symbols shall be unmistakably similar to those shown and (where a word message is applicable) the wording shall be as provided herein.

The sign dimensions shown in this part of the Manual shall be considered standard for application on all types of bicycle facilities. Where signs shown in other parts of this Manual are intended for exclusive bicycle use, smaller sign sizes from that specified may be used. Incremental increases in special bicycle facility signs are also desirable to make the sizes compatible with signs for motor vehicles, where both motorists and bicyclists benefit by a particular sign.

The sign lettering shall be in upper-case letters of the type shown in the Standard Alphabets for Highway Signs and Pavement Markings*

All signs should be reflectorized for bicycle trails as well as for shared roadway and designated bicycle lane facilities.

\section{B-4 Regulatory Signs}

Regulatory signs are to inform bicyclists, pedestrians and motorists of traffic laws or regulations and indicate the applicability of legal requirements that would not otherwise be apparent.

Regulatory signs normally shall be erected at the point where the regulations apply. The sign message shall clearly indicate the requirements imposed by the regulations and shall be easily visible and legible to bicyclists and where appropriate, motorists and pedestrians.

\section{B-5 Bicycle Prohibition Sign (R5-6)}

This sign is intended for use at the entrance to facilities, such as freeways, where bicycling is prohibited. Where pedestrians and motor-driven cycles are also prohibited from using these facilities, it may be more desirable to use the R5-10a word message sign (sec. 2B-28).

In reduced size ( $18 \times 18$ inches), this sign may be used on sidewalks where bicycle riding is prohibited.

\section{B-6 Motor Vehicle Prohibition Sign (R5-3)}

This sign is intended for use at the entrance to a bicycle trail.

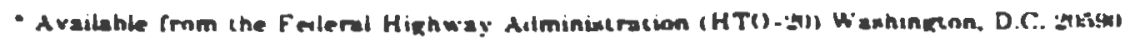




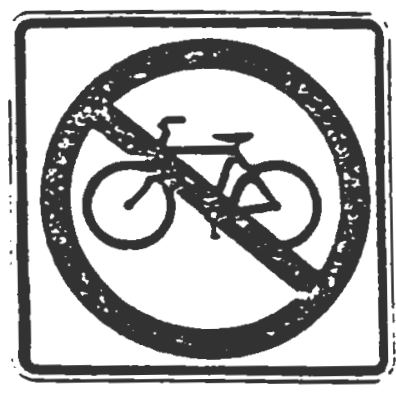

R5-6

$24^{\prime \prime} \times 24^{\prime \prime}$

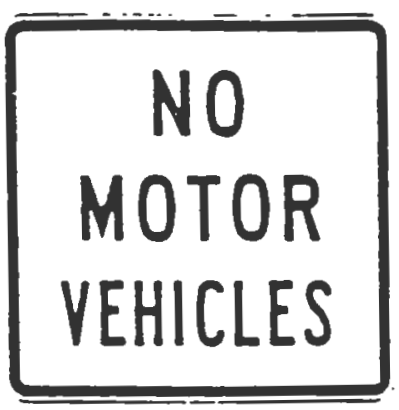

RS-3

$24^{\prime \prime} \times 24^{\prime \prime}$

\section{B-7 Bicycle Restriction Signs (R9-5 \& 6)}

This series of signs is intended for use where pedestrian facilities are being used for bicycle travel. They should be erected off the edge of the sidewalk, near the crossing location, where bicyclists are expected to dismount and walk with pedestrians while crossing the street.

The R9-5 sign may be used where bicycles can cross the street only on the pedestrian walk signal indication.

The R9-6 sign may be used where bicycles are required to cross or share a facility used by pedestrians and are required to yield to the pedestrians.

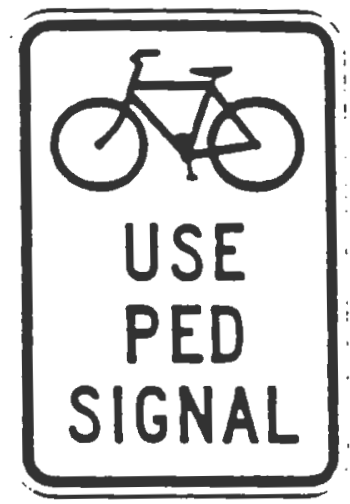

R9-5 $12^{\prime \prime} \times 18^{\prime \prime}$

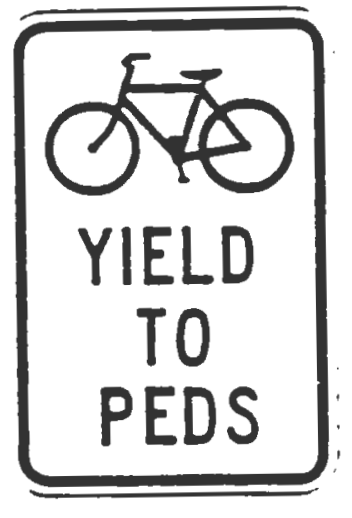

R9-6 $12^{\circ} \times 18^{\prime \prime}$ 
9B-S Designated Lane Signs (R,3-10 \& 11)

The R3-16 sign should be used in advance of the beginning of a marked designated bicycle lane to call attention to the lane and to the possible presence of bicyclists. The R3-16 and R:3-M signs should be used only in conjunction with the Preferential Lane Symbol pavement marking and erected at periodic intervals along the ciesignated bicycle lane and in the vicinity of locations where the preferential lane symbol is used (sec. 9(-t).

Where appropriate. the message ENDS may be substituted for $A H E A D$ on the R3-16 sign and LEFT or CLRB can be substituted for RIGHT on the R3-17 sign.

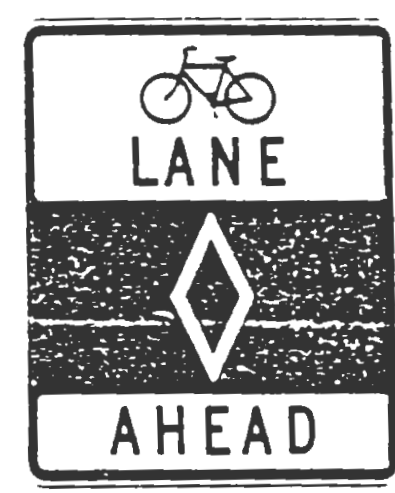

R3-16

$24^{\prime \prime} \times 30^{\prime \prime}$

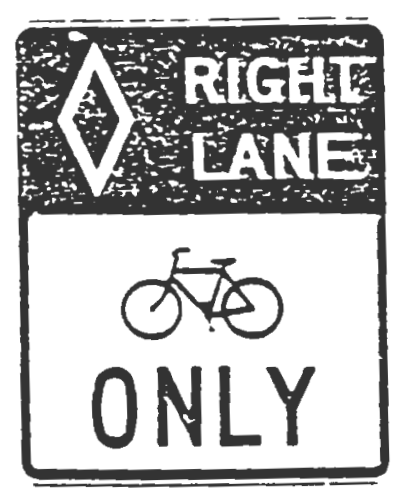

R3- 17

$24^{\prime \prime} \times 30^{\prime \prime}$

\section{B-9 Travelpath Restriction Signs (R9-i)}

The R9- 7 sign is intended for use on facilities which are to be shared by pedestrians and bicycles and on which a designated area is provided for each (sec. 9C-3). Two of these signs may be erected back-to-back with the symbols reversed for the opposite direction.

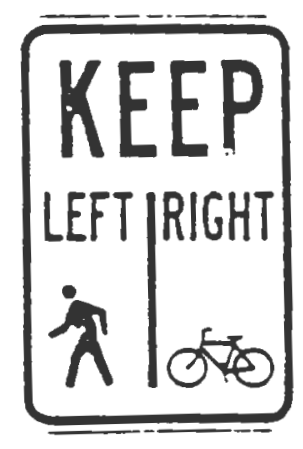

R9-7

$12^{\prime \prime} \times 18^{\prime \prime}$ 
STOP signs are intended for use on bicycle facilities where bicyclists are required to stop. Where conditions require bicyclists and not motorists to stop, care should be taken to place the sign so it is not readily visible to the motorist.

YIELD signs are intended for use where the bicyclist can see approaching traffic and where bicyclist must yield the right of way to that traffic. The visibility of approaching traffic must be adequate to permit the bicyclist to stop or to take other measures to avoid that traffic.

For added emphasis STOP and YIELD signs in regular $30 \times 30$-inch and $36 \times 36 \times 36$-inch sizes may be used.

The smaller signs shown below are intended for use on bicycle trails where hicyclists are required to stop or yield the right of way. If the sign applies to motorists and bicyclists, then the size should be as shown in Part II-B.
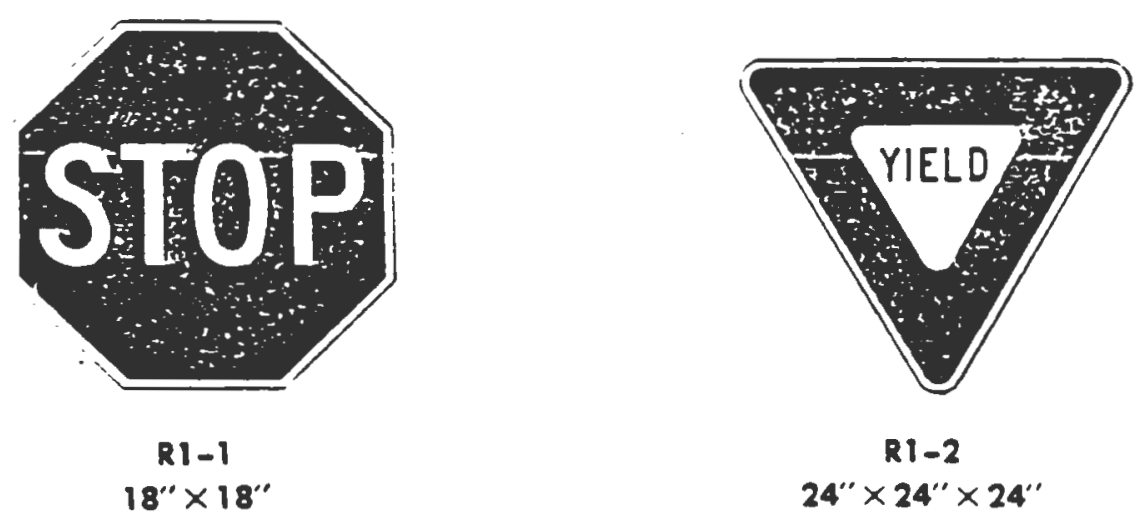

\section{B-11 No Parking Signs (R7-9, \& 9a)}

Where it is necessary to restrict parking, standing, or stopping in a designated bicycle lane, appropriate signs as described in sections $2 B-31$ through $2 B-33$ may be used, or signs $R 7-9$ or $R 7-92$ shall be used.

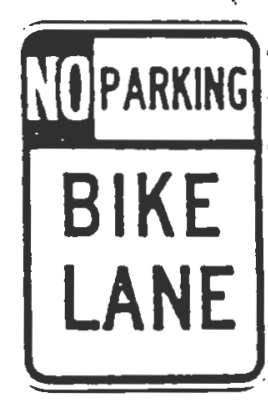

RT-9 $12^{\circ} \times 18^{\prime \prime}$

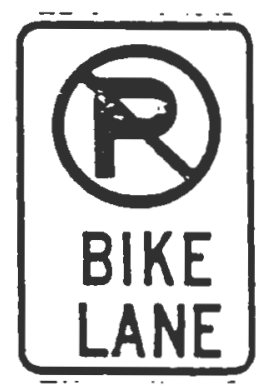

$R T-90$ $12^{\prime} \times 18^{\prime \prime}$ 
9B-12 Lane-Use Control Signs ( R3-7, Rt- 4 )

Where right turning motor venicles must merge with bicycle traffic on designated bike lanes. the RS-T and $R+-4$ signs may be used. The R4-4 sign is intended to inform both the motorist and the bicyclist of this merging maneuver. Where a designated bicycle lane is provided near the stnp line. an R3-T sign may be used to prevent motorists from crossing back over the bike lane.

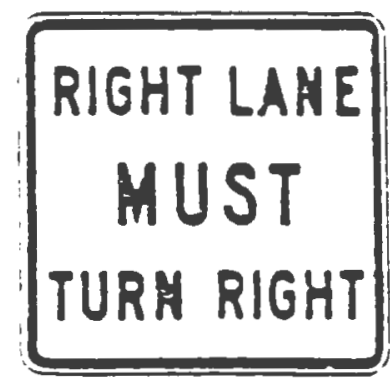

R3-7 $30^{\prime \prime} \times 30^{\prime \prime}$

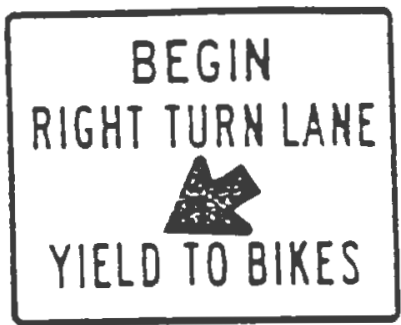

R4-4

$36^{\prime \prime} \times 30^{\prime \prime}$

\section{B-13 Warning Signs}

Warning signs are used when it is deemed necessary to warn bicyclists or motorists of existing or potentially hazardous conditions on or adjacent to a highway or trail. The use of warning signs should be kept to a minimum because the unnecessary use of them to warn of conditions which are apparent tends to breed disrespect for all signs.

Warning signs specified herein cover most conditions that are likely to be met. If other warnings are needed, the signs shall be of standard shape and color for warning signs, and the legends shall be brief and easily understood.

\section{B-14 Bicycle Crossing Sign (W11-1)}

The Bicycle Crossing sign is intended for use on highways in advance of a point where a bikeway crosses the roadway. It should be erected about $\tau 50$ feet in advance of the crossing location in rural areas where speeds are high, and at a distance of about 250 feet in urban residential or business areas, where speeds are low.

If the approach to an intersection is controlled by a traffic control signal, stop sign or yield sign, the W11-1 sign may not be needed.

\section{B-15 Hazardous Condition Sign (W8-10)}

The Hazardous Condition sign is intended for use where roadway or bicycle trail conditions are likely to cause a bicyclist to lose control of his bicycle. These conditions could include slippery pavement, slick bridge 


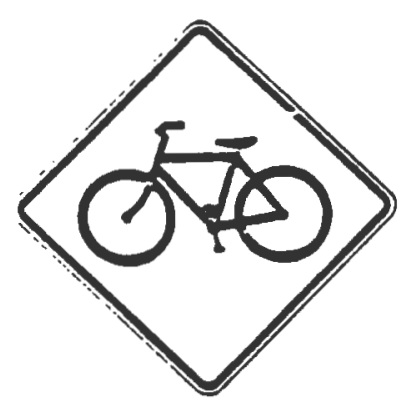

w11-1

$30^{\circ} \times 30^{\prime \prime}$

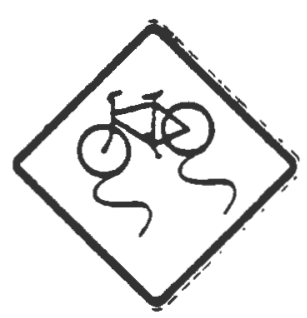

SLIPPERY

WHEN WET

W8-10

Roadway Signs

$30^{\prime \prime} \times 30^{\prime \prime}$

$24^{\prime \prime} \times 18^{\prime \prime}$
Bicycie Trail Signe

$18^{\prime \prime} \times 18^{\prime \prime}$

$12^{\prime \prime} \times 9^{\prime \prime}$

decking, rough or grooved pavement, or water or ice on the roadway. The W8-10 sign may be used with a supplemental plaque describing the particular roadway or bicycle trail feature which might be of danger to the bicyclist such as SLIPPERY WHEN WET, STEEL DECK, ROUGH PAVEMENT, BRIDGE JOINT, or FORD.

\section{B-16 Turn and Curve Signs (W 1-1, 2, 4, 5, 6, $)$}

On bicycle trails where it is necessary to warn bicyclists of unexpected changes in path direction, appropriate turn or curve signs should be used. They should normally be installed no less than 50 feet in advance of the beginning of the change of alignment.

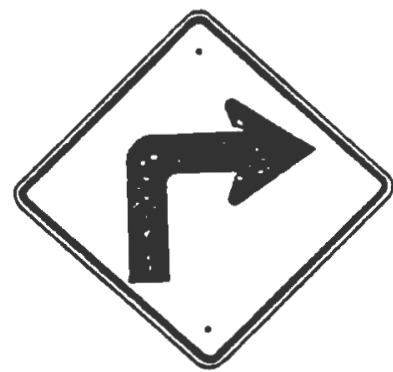

$W 1-1$

$18^{\prime \prime} \times 18^{\prime \prime}$

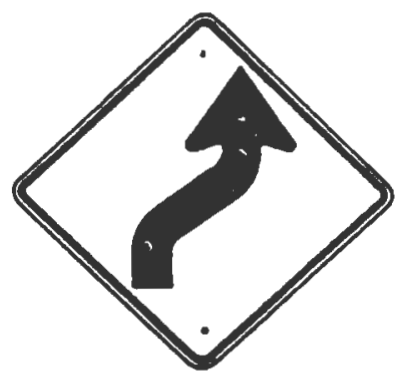

W1-4

$18^{\prime \prime} \times 18^{\prime \prime}$

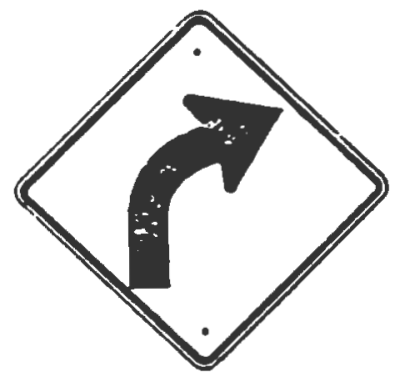

Wi-2

$18^{\prime \prime} \times 18^{\prime \prime}$

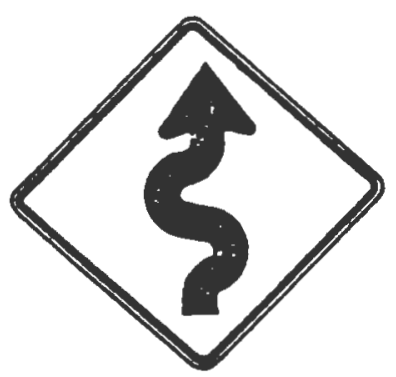

w1-5

$18^{\circ} \times 18^{\prime \prime}$ 


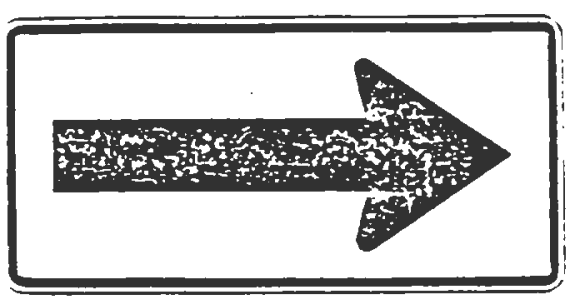

W1-6

$24^{\prime \prime} \times 12^{\prime \prime}$

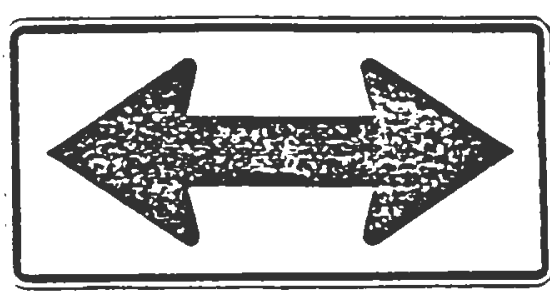

W1-7

$24^{\prime \prime} \times 12^{\prime \prime}$

\section{B-17 Intersection Signs (W2-1, 2, 3, 4, 5)}

Intersection signs are intended for use as appropriate to fit the prevailing geometric pattern on bike trails where connecting routes join and where no STOP or YIELD signs are required. They should be used wherever sight distance at the intersection is severely limited. and may be used for supplemental warning at intersections where STOP and YIELD signs are erected.

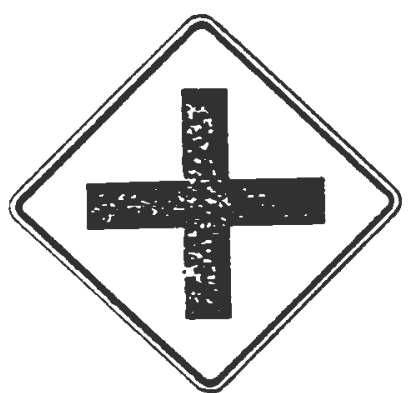

W2-1

$18^{\prime \prime} \times 18^{\prime \prime}$

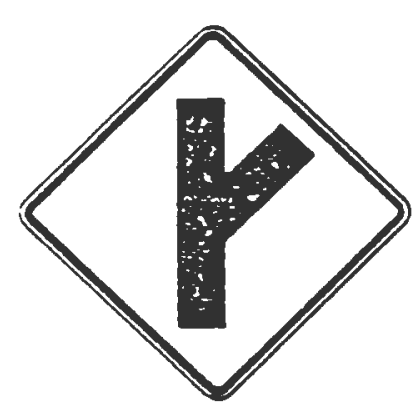

W2-3

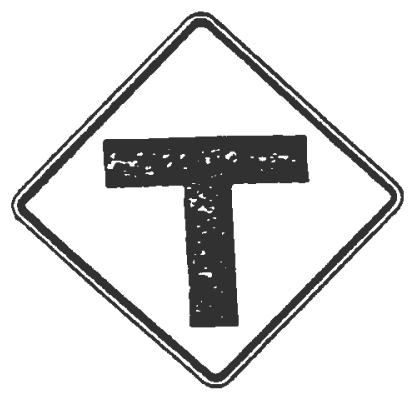

W2-4

$18^{\prime \prime} \times 18^{\prime \prime}$

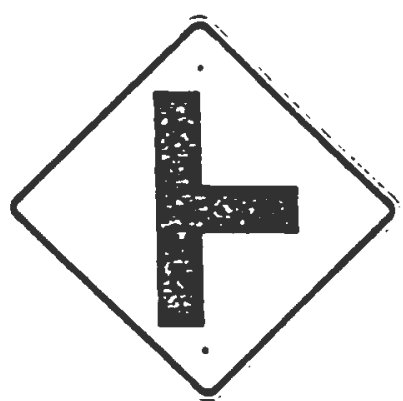

W2-2 $18^{\prime \prime} \times 18^{\prime \prime}$

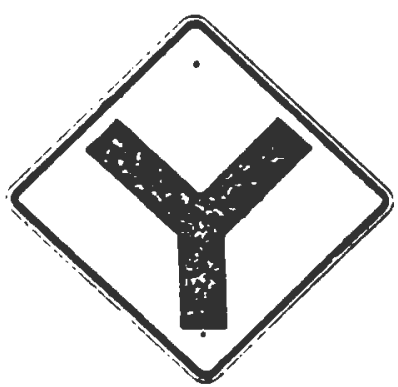

W2-5 $18^{\prime \prime} \times 18^{\prime \prime}$ 


\section{B-18 Other Warning Signs}

Other warning signs may be required on bicycle facilities to warn riders of unexpected conditions. The intended use of these signs generally is self-explanatory. They should normally be installed no less than 50 feet in advance of the beginning of hazards.

Where construction or maintenance activity is present on bicycle trails, appropriate signs from Part VI of the Manual should be used.

\section{B-19 Guide Signs}

On highways where a bicyclist is sharing a lane with motor vehicles or is using an adjacent bikeway, the regular guide signing as described in Part II of this Manual will serve both modes of travel. Where a designated bikeway exists, special bicycle route signing should be

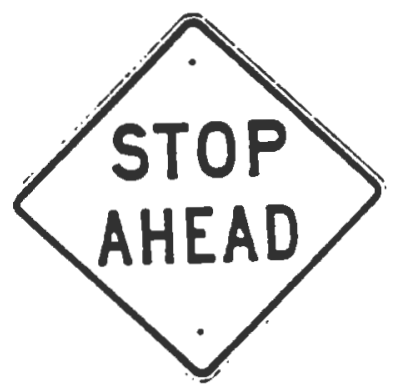

W3-1

$18^{\circ} \times 18^{\circ}$

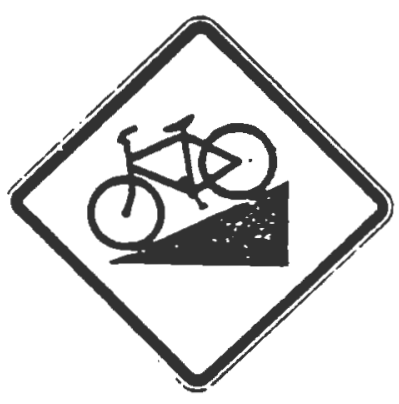

W7-5

$18^{\circ} \times 18^{\circ}$

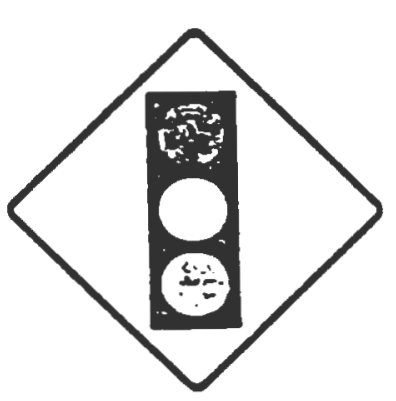

W3-3 $18^{\circ} \times 18^{\circ}$

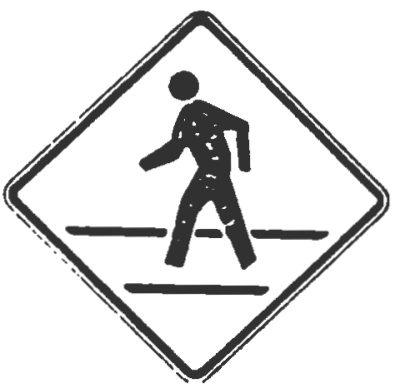

W11A-2 $18^{\circ} \times 18^{\circ}$

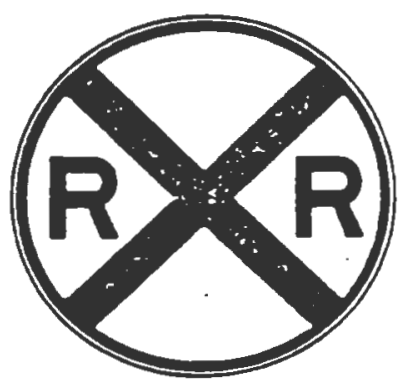

W10-1

18* Diamotor

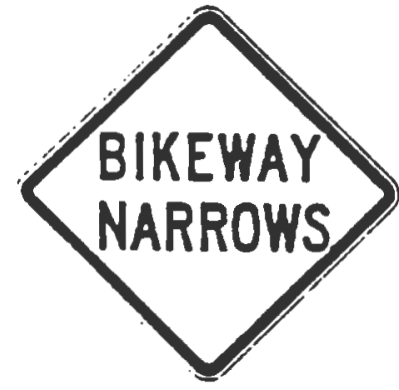

W5-4 $18^{\circ} \times 18^{\circ}$

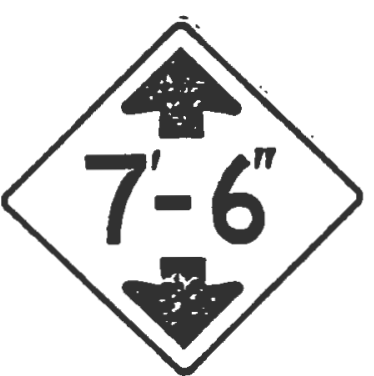

W12-2 $18^{\prime \prime} \times 18^{\circ}$ 
provided at decision points along the bikeway, including signs to inform cyclists of bicycle route direction changes and confirmatory signs to ensure that route direction has been accurately comprehended.

Figure 9-2 shows an example of the signing for the junction of a bicycle trail with a highway. Figure 9-3 shows the signing and marking for the beginning and ending of designated bikeways. Guide signing should be repeated at regular intervals to ensure that bicyclists approaching from side streets know they are traveling on an officially designated bikeway. Similar guide signing should be used for shared lane bikeways with intermediate signs placed frequently enough to ensure that cyclists already on the bikeway do not stray from it and lose their way.

\section{B-20 Bicycle Route Sign (D11-1)}

This sign is intended for use where no unique designation of routes is desired. It should be placed at intervals frequent enough to keep bicyclists informed of changes in route direction and to remind motorists of the presence of bicyclists.

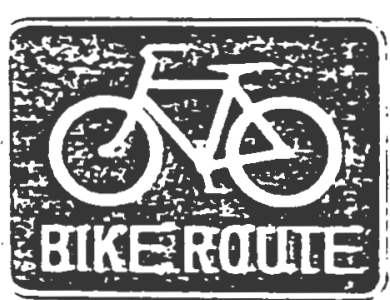

D11-1

$24^{\circ} \times 18^{*}$

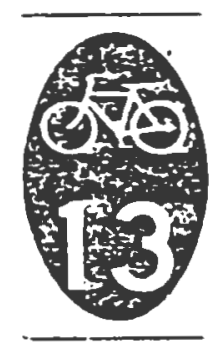

M1-8 $12^{\circ} \times 18^{\circ}$

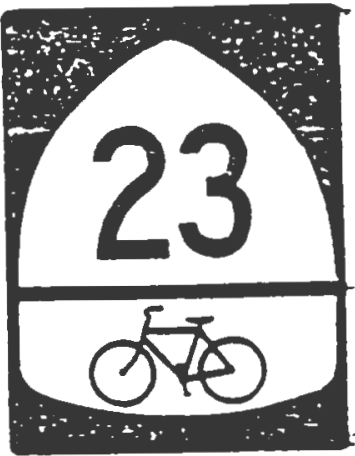

M1-9 $18^{*} \times 24^{*}$

\section{B-21 Bicycle Route Markers (M1-8, M1-9)}

Where it is desired to establish a unique identification (route designation) for a State or local bicycle route, the standard Bike Route Marker (M1-8) should be used. The route marker (Ml-8) shall contain a numerical designation and shall have a green background with a reflectorized white legend and border.

Where a bicycle route extends for long distances in two or more States, it is desirable to establish a unique numerical designation for that route. A coordinated submittal by the affected States for assignment of route number designations should be sent to the American Association of State Highway and Transportation Officials, 444 North Capitol Street NW., Suite 225, Washington, D.C. 20001. The route marker (.M1-9) shall contain the assigned numerical designation and have a black legend and border with a reflectorized white background.

Bike Route Markers are intended for use on both shared facilities and on designated bikeways, as required, to provide guidance for bicyclists. 


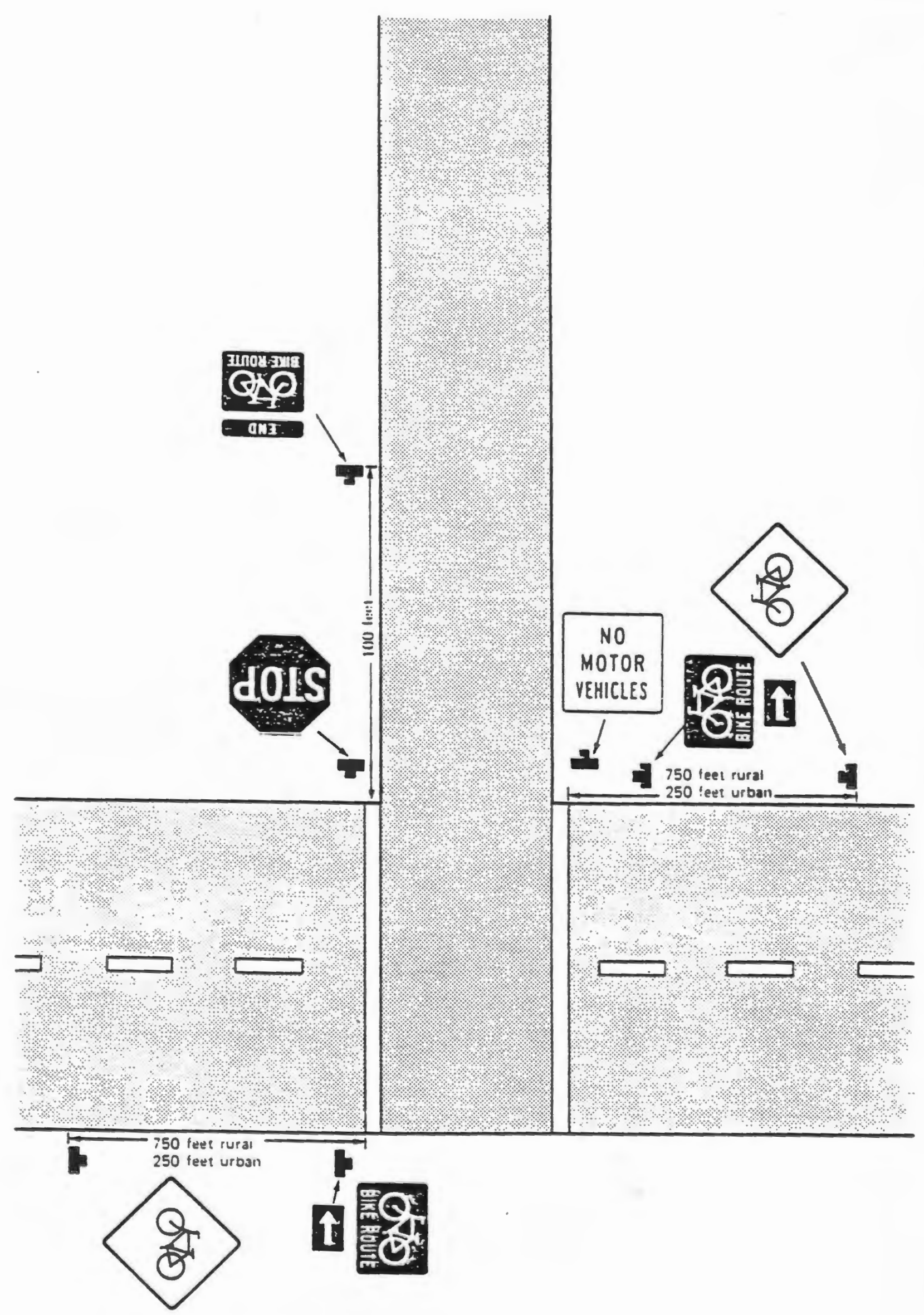

Figure 9-2. Trpical signing for beginning and ending of bickele trail.

$$
\text { A-15 }
$$




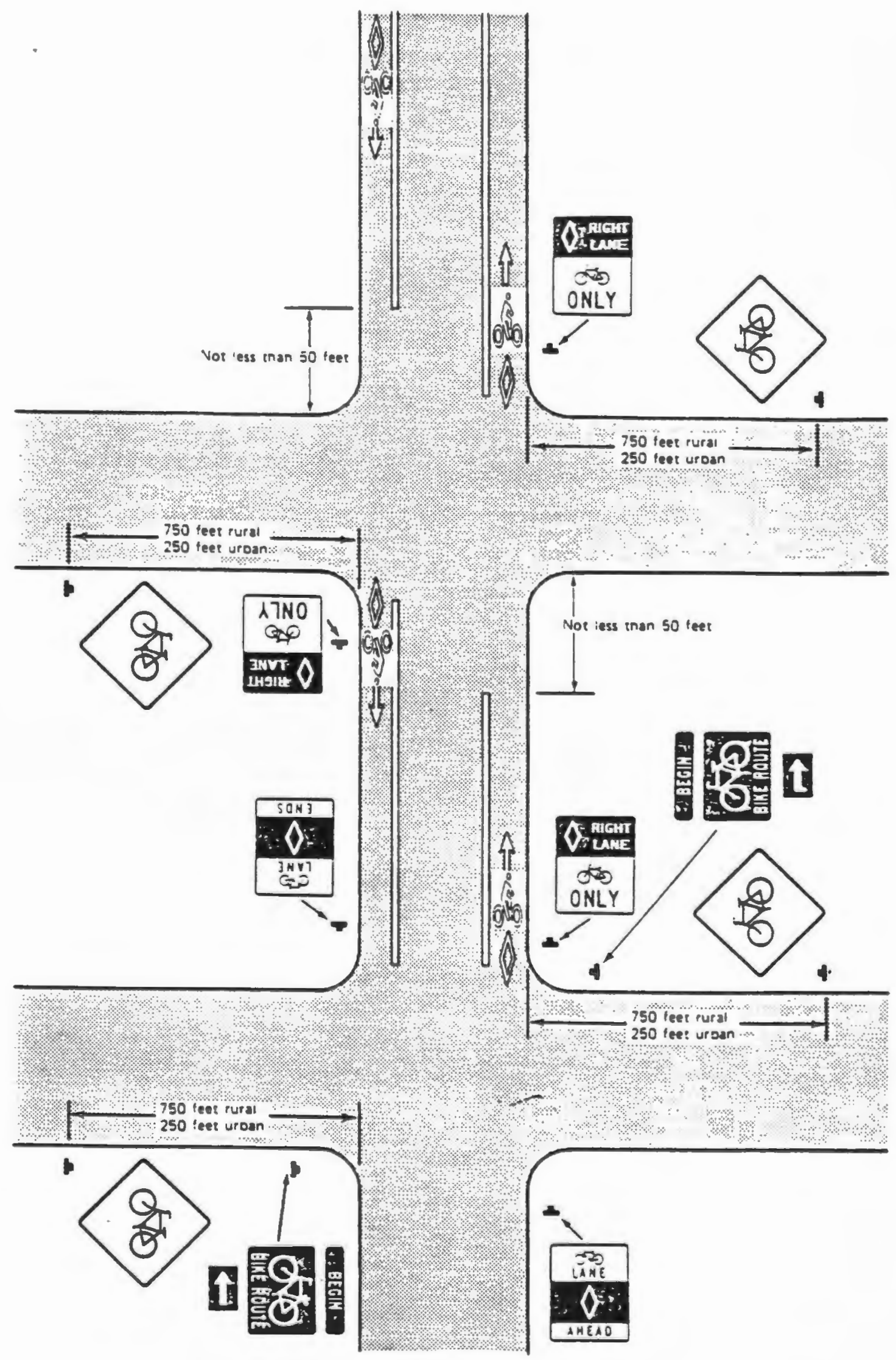

Figure 9-3. Typical signing for beginning and ending of designoted bievele lo.. 


\section{B-22 Supplemental Plaques for Route Signs and Route Markers}

Where desired, supplemental plaques can be used with the D11-1 and M1-8 signs to furnish additional information, such as directional changes in the route, and intermediate range distance and destination information. The M4-11 through M4-13 signs may be mounted above the appropriate Route Signs or Route Marker. Supplemental plaques DI- $1 b$ and $c$ are intended for use with the D11-1 Bicycle Route Sign. The appropriate arrow sign (M7-1 through M7-7), if used, should be placed below the Route Sign or Route Marker. These signs shall have a white arrow on a green background.
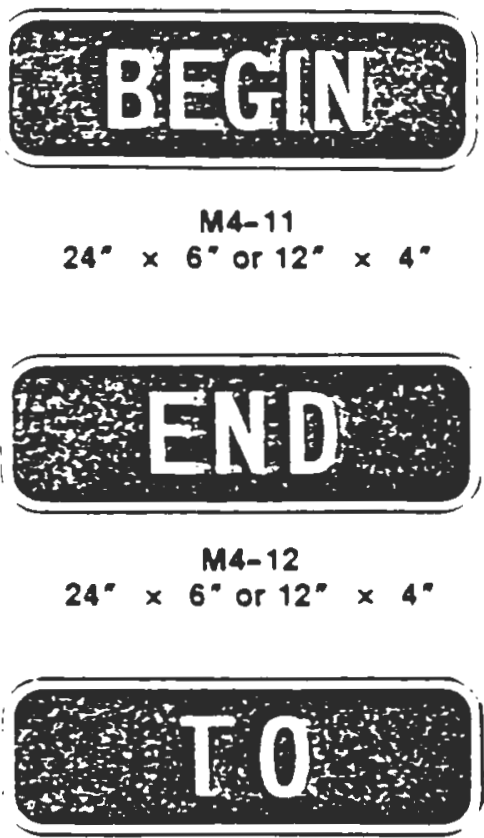

$24^{\circ} \times 6^{\prime \prime}$ or $12^{\circ} \times 4^{*}$

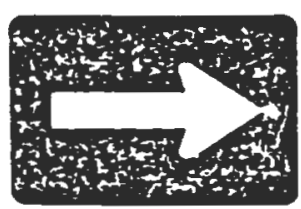

M7-1

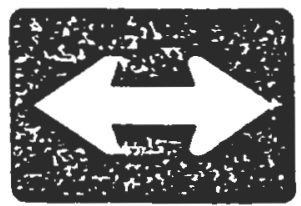

M7-5

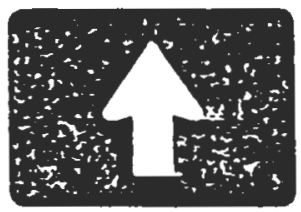

M7-2

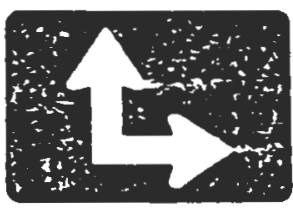

M7-6

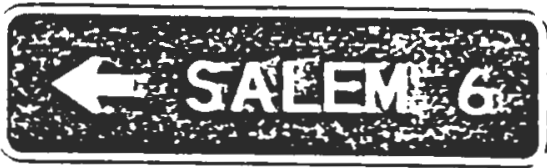

D1-16(L)

$24^{\circ} \times 6^{\circ}$

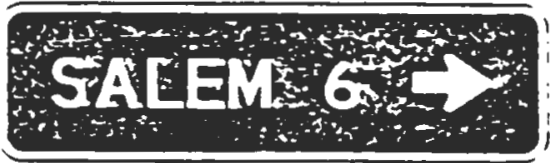

D1-1b(R)

$24^{*} \times 6^{*}$

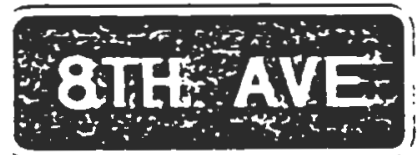

D1-1(c)

$24^{\circ} \times 6^{\circ}$

M7-1 through M7-7

$12^{\circ} \times 9^{\circ}$

A-17 ,

Rev. $12 / 83$ 


\section{B-23 Bicycle Parking Area Sign (D4-3)}

The Bicycle Parking Area sign may be used where it is desired to show the direction to a designated bicycle parking area within a parking facility or at other locations. The sign shall be a vertical rectangle of a standard size of 12 by 18 inches. It shall carry a standard bicycle symbol, the word PARKING, and an arrow. The legend and border shall be green on a reflectorized white background.

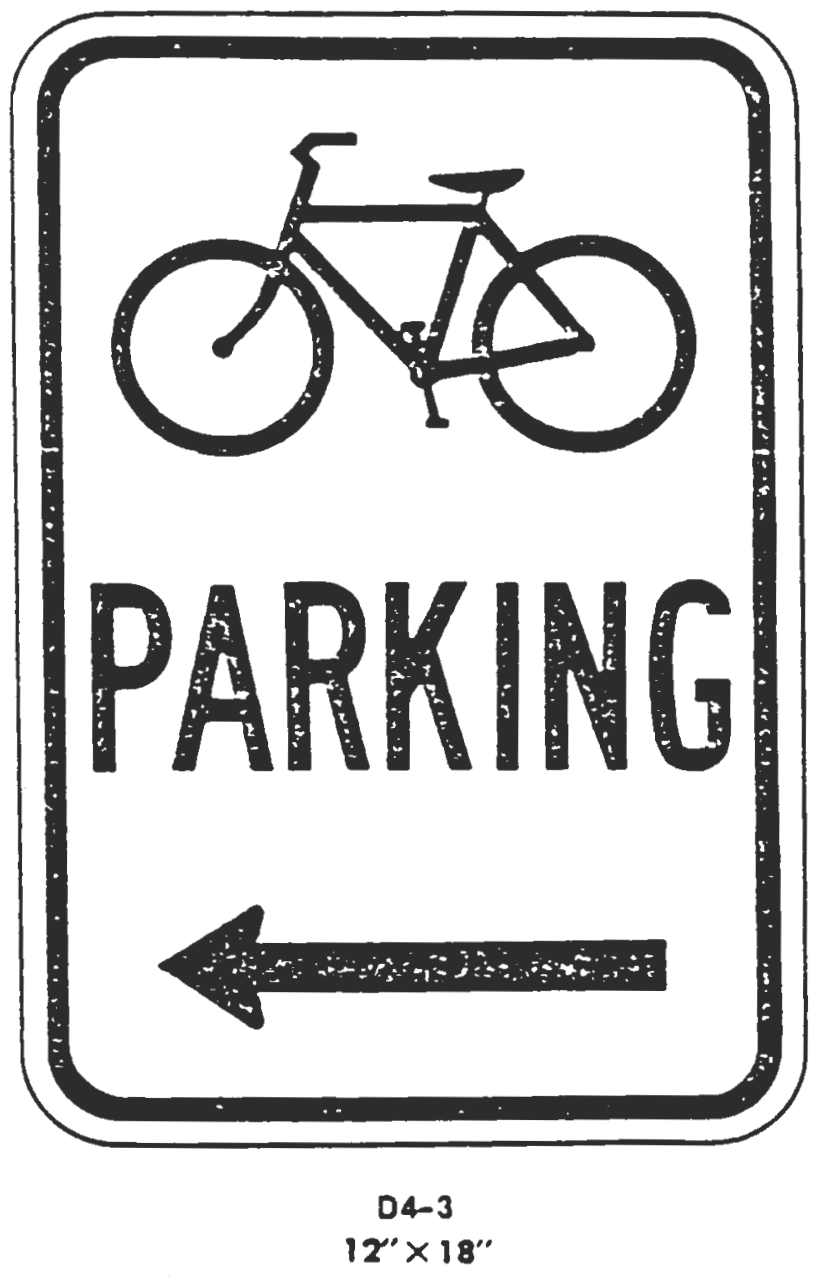




\section{MARKINGS}

\section{C-1 Functions and Limitations of Markings}

Markings are important on roadways that have a designated bicycle lane. Markings indicate the separation of the lanes for motor vehicle and bicycles, assist the bicyclist by indicating assigned travel paths, and can provide advance information for turning and crossing maneuvers.

\section{C-2 General Principles}

Although bicycles are generally not equipped with strong lighting equipment, the added visibility of reflectorized pavement markings is desirable even where there is exclusive use by bicyclists.

Markings shall be reflectorized on bicycle trails and on facilities used by both motor vehicles and bicycles.

Recognized bikeway design guides should be used when laying out markings for a bicycle lane on a highway facility (sec. 9A-S).

The frequent use of symbols and word messages stenciled in the bike lanes, is a desirable method of supplementing sign messages. Figures 9-4 through 9-6, show acceptable examples of the application of lines. word messages and symbols on designated bikeways with and without parking for motor vehicles.

If a specific path for a bicylist crossing an intersection is to be designated, a dotted line may be used to define such a path.

\section{C-3 Marking Patterns and Colors}

The color and type of lines used for marking bicycle facilities shall be as defined in section $3 A-T$. Normally, center lines would not be required on bicycle paths. Where conditions make it desirable to separate two directions of travel at particular locations, a double solid yellow line should be used to indicate no passing or no traveling to the left of the line.

Where bicycle paths are of sufficient width to designate two minimum width lanes, a broken yellow line may be used to separate the two directions of travel.

Broken lines used on bicycle paths should have the normal 1 to 3 segment-to-gap ratio. To avoid having gaps excessively long, a nominal 3-foot segment with a 9-foot gap is recommended.

Where bicycles and pedestrians use a common facility, it may be desired to separate the two traffic flows. A solid white line should be used to mark this separation of path use. The R9-7 sign may be used to supplement the pavement marking (sec. 9B-9). 


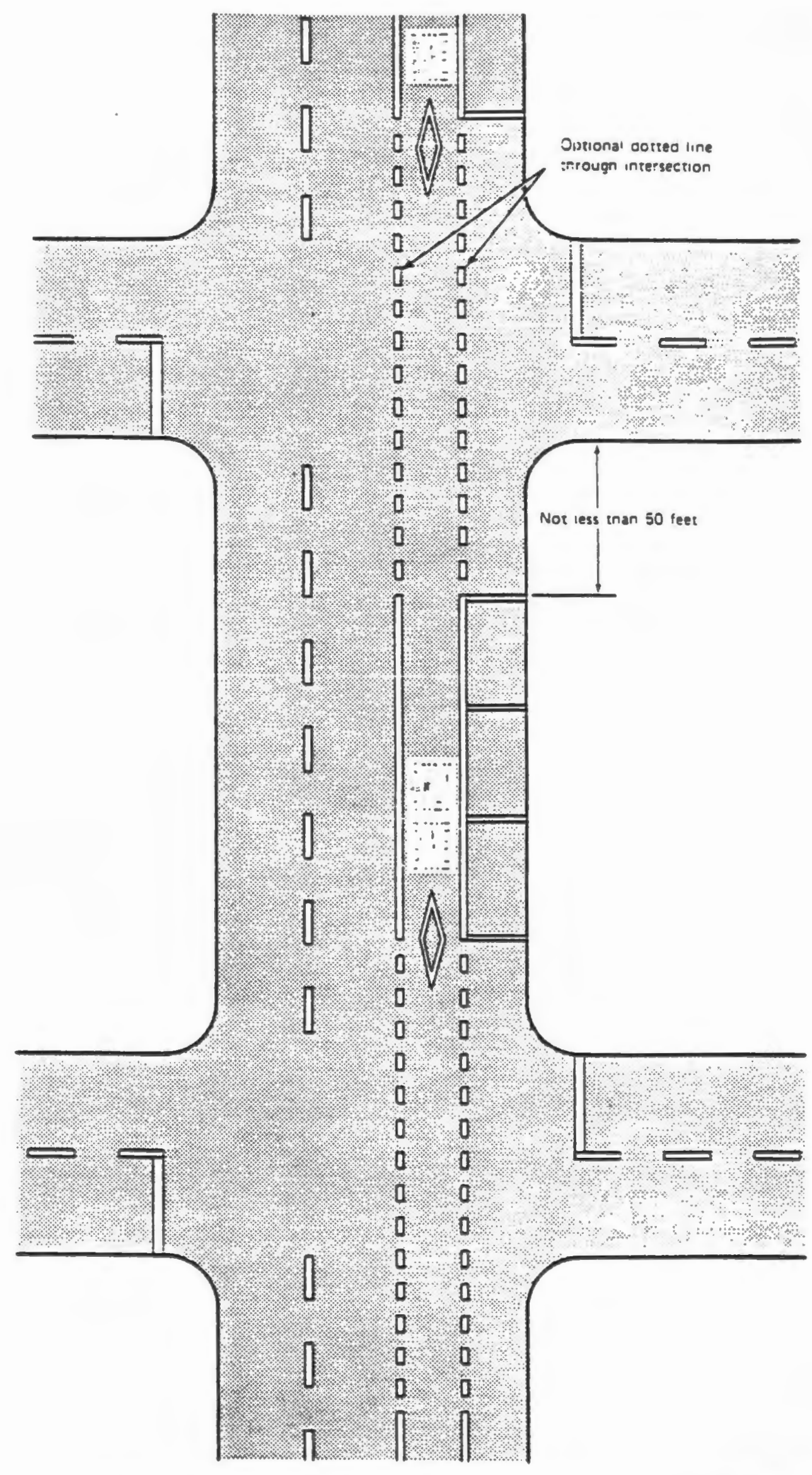

Figure 9-4. Typied povement merkings-dexignored bieyele lane, no-way motfie with parking and low righe rum valume. 


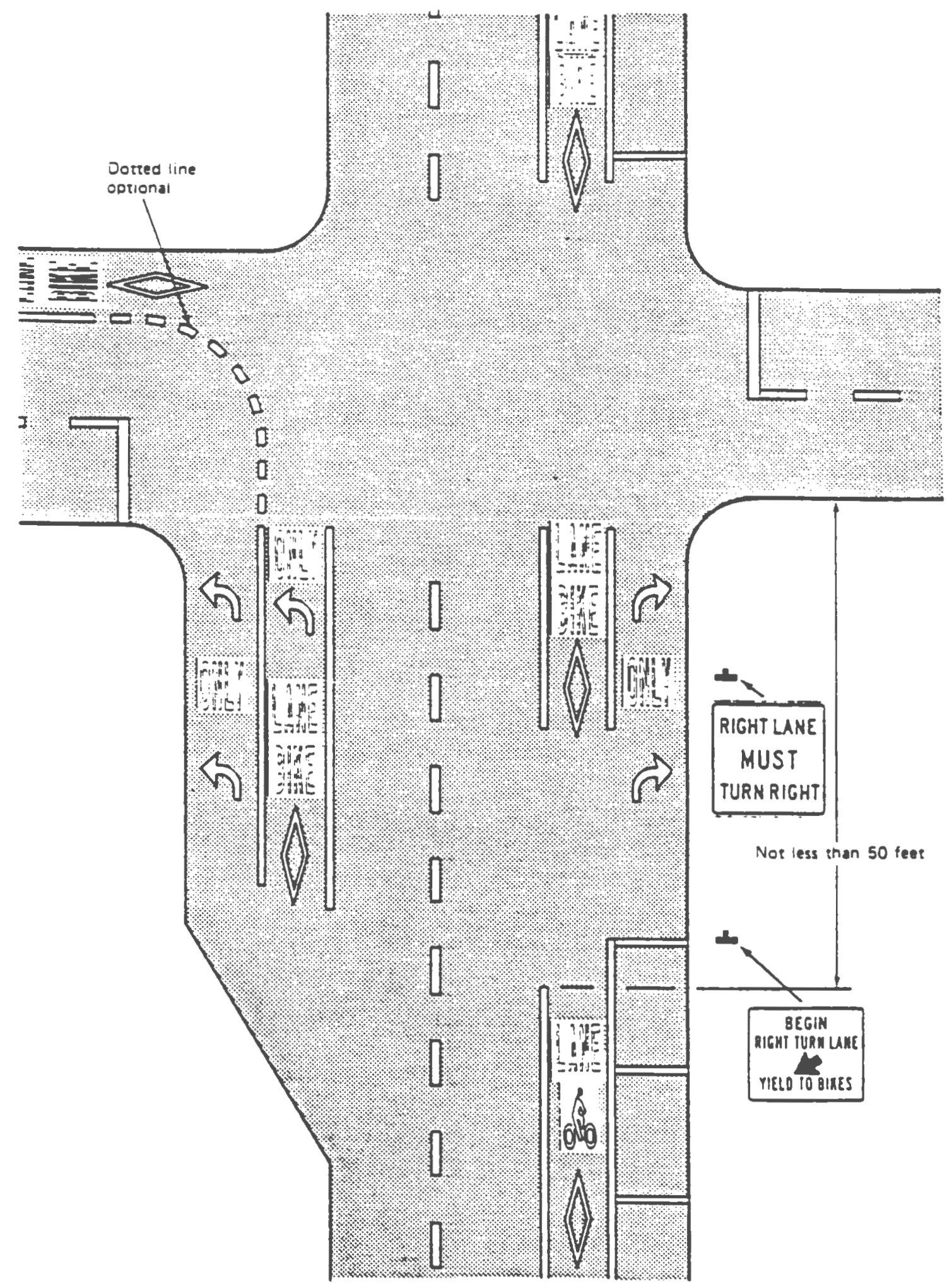

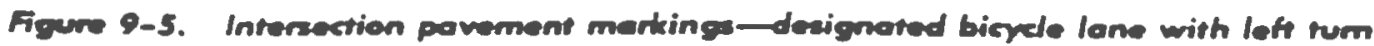
aree, hoovy ium volumes, parting, one-way proffic or divided roodwoy. 

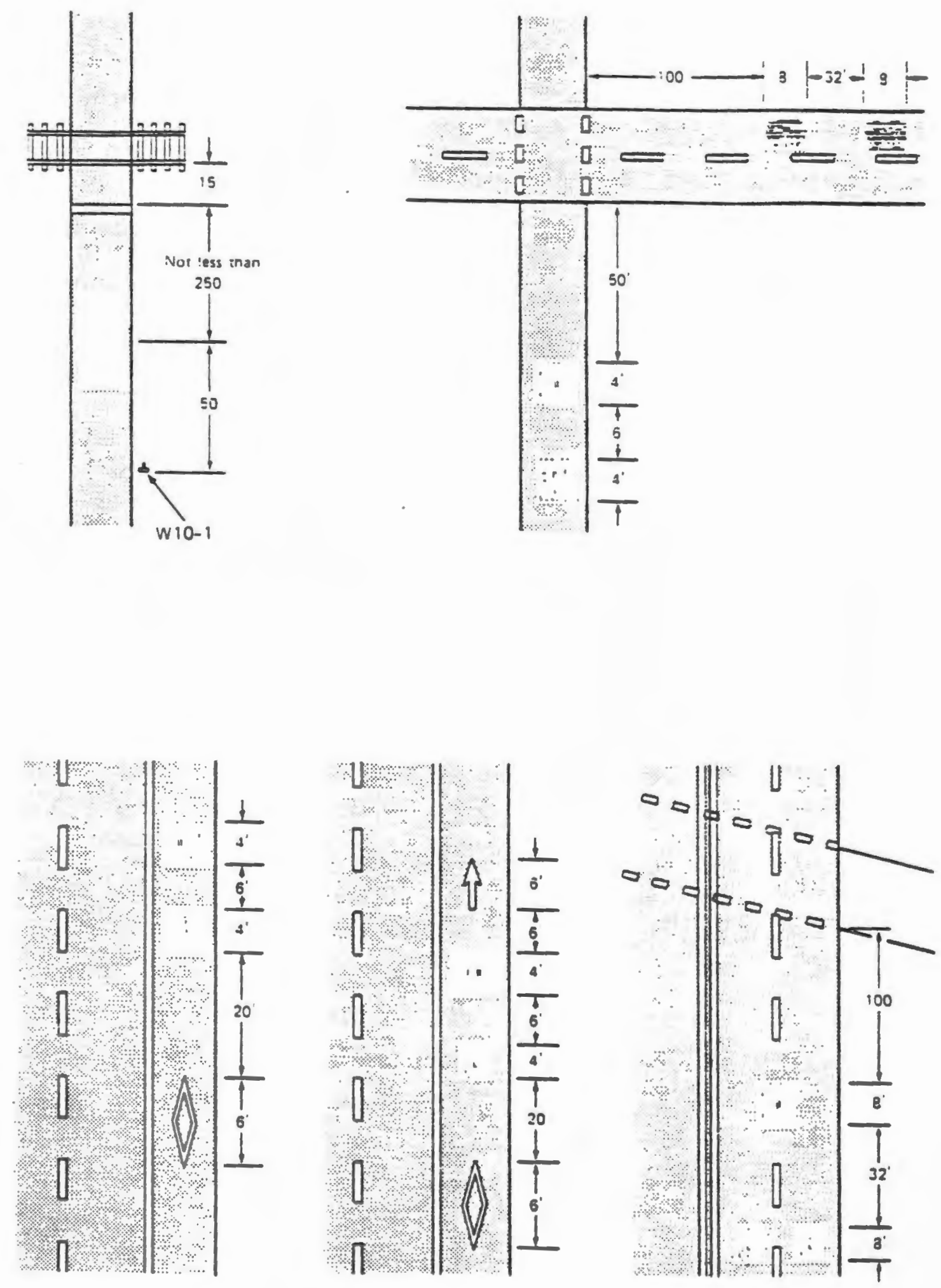

Figure 9-6. Word and symbel pavement morkings for biente focitivies. 


\section{$9 \mathrm{C}-4$ Marking of Designated Bikeways}

The diamond-shaped Preferential Lane Symbol is intended for use on highway facilities where lanes are reserved for exclusive use by a particular class of vehicle. Designated bikellays are considered as this type of lane and shall inclucie use of the Preferential Lane Symbol as a pavement marking and on appropriate signing (sec. 9B-8). The symbols as a pavement marking shall be whice and shall be used immediately after an intersection to inform motorists turning of the restricted nature of the lane. If the Preferential Lane Symbol is used in conjunction with other word or symbol messages, it shall precede them. A supplemental lane symbol or word may be used following as shown in figures 9-4 through 9-6.

\section{C-5 Word Messages and Symbols Applied to the Pavement}

Where messages are to be applied on the pavement, smaller size letters can be used on exclusive bike lanes than are used on regular highways. Where arrows are needed, half-size layouts of the arrows can be used (sec. 3B-17). Optional word and symbol markings considered appropriate for use with the Preferential Lane Symbol marking are shown in figure 9-6. Standard pavement marking alphabets and symbols have been prepared.*

\section{C-6 Object Markings on Bicycle Trails}

There may be hazarious objects located adjacent to bicycle trails which, if visible to the ricler, can be avoided with little difficulty. Such objects can be marked with highly visible markings to make their icientification by approaching riders more certain. Care should be taken to avoid having object markers become hazarcious objects. Corners of object markers as well as signs should be rouncled to prevent their becom-
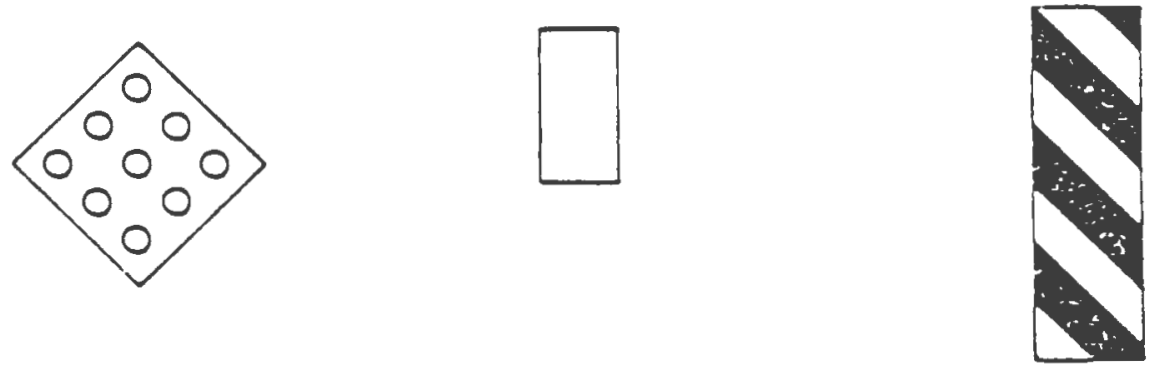

Type

$18^{\prime \prime} \times 18^{\prime \prime}$
Type 11

$6 " \times 12 "$
Type III

$12^{\prime \prime} \times 36^{\prime \prime}$

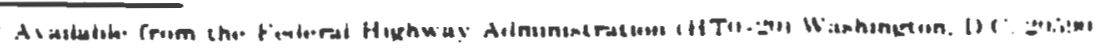


ing a hazarcl. All object markers should be clesigned using reflective materials or coatings. Where practical, markers such as those described in section $3 \mathrm{C}-1$ of this Manual should be used.

Where a storm clrain hazard cannot be eliminated, it may be made more visible to bicyclists by defining with a white marking applied as shown in figure $9-7$.

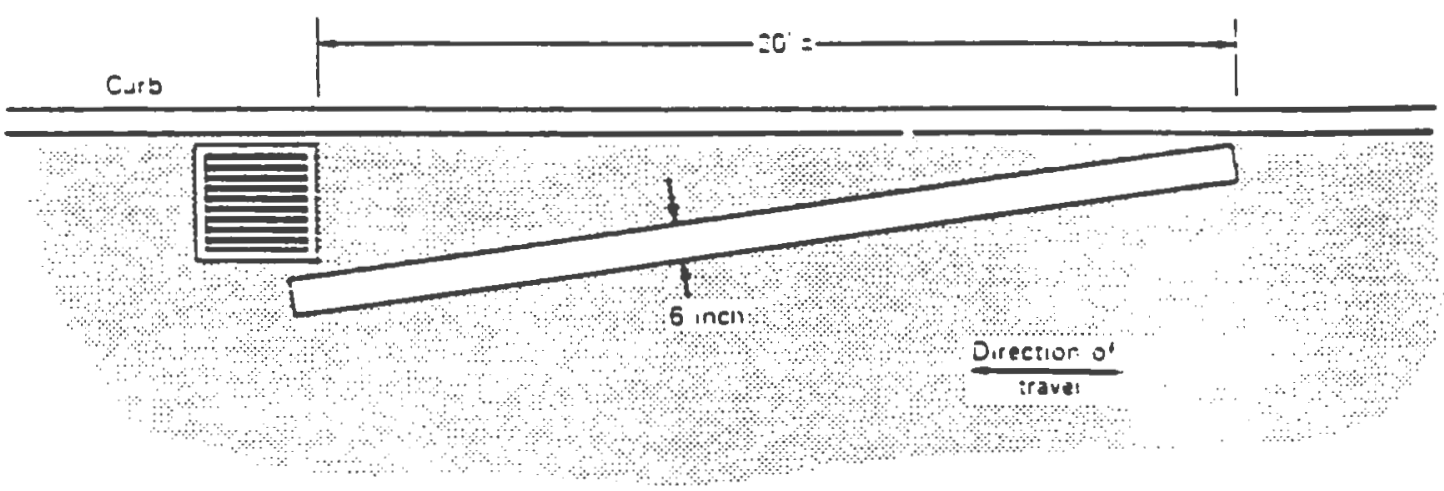

Figure 9-7. Typical marking in advance of drainoge hazard. 


\section{SIGNALS}

\section{D-1 Application}

It is rare when a traffic signal is installed solely for bicyclists; however, at some locations there may be a need to install signal devices to facilitate bicycle travel through the intersection. For warrants and other requirements relating to signal installations, see Part IV of this Manual. Warrants used for motor vehicles are considered appropriate for use in determining the need for signals to serve bicyclists. Warrant Four for school crossings is considered to be appropriate for bicyclists also.

\section{D-2 Visibility Requirements}

At installations where programmed signals are used, special attention should be given to adjusting the signals so bicyclists on the regular bicycle lanes or travel paths can see the signals. If programmed signals cannot be aimed to serve the bicyclist, then separate signals shall be provided.

\section{D-3 Signal Operation for Bicycles}

Bicycles generally can cross intersections under the same signal timing arrangement as motor vehicles. Where bicycle use is expected, extremely short change intervals should not be used and an all red clearance interval may be necessary. 


\section{APPENDIX B \\ AABHTO Design Guidelines for Bicycle Facilities Chapter 2}




\section{CHAPTER 2 - DESIGN}

There is a wide range of facility improvements which can enhance bicy- cle transportation. Improvements can be simple and involve minimal design consideration (e.g., changing drainage grate inlets) or they can involve a detailed design (e.g., providing a bicycle path). The controlling feature of the design of every bicycle facility is its location (i.e., whether it is on the roadway or on an independent alignment). Roadway improvements such as bicycle lanes depend on the roadway's design. On the other hand, bicycle paths are located on independent alignments; consequently, their design depends on many factors, including the performance capabilities of the bicyclist and the bicycle.

Improvements for motor vehicles through appropriate planning and design can enhance bicycle travel and in any event should avoid adverse impacts on bicycling. A community's overall goals for transportation improvements should, whenever possible, include the enhancement of bicycling. Public involvement in the form of public meetings or hearings or bicycle advisory groups is desirable during the design process.

Guidelines are presented in this chapter to help design and construct both roadway improvements and separate paths that accommodate the operating characteristics of "bicycles" as defined in this guide. Modifications to facilities (e.g., widths, curve radii, superelevations, etc.) that are necessary to accommodate adult tricycles, bicycle trailers, and other special purpose human powered vehicles and accessories should be made in accordance with expected use, using sound engineering judgment.

\section{ROADWAY IMPROVEMENTS}

To varying extents, bicycles will be ridden on all highways where they are permitted. All new highways, except those where bicyclists will be legally prohibited, should be designed and constructed under the assumption that they will be used by bicyclists. Bicycle-safe design practices, as described in this guide, should be followed to avoid the necessity for costly subsequent improvements. Because most highways have not been designed with bicycle travel in mind, there are often many ways in which roadways should be improved to more safely accommodate bicycle traffic. Roadway conditions should be examined and, where necessary, safe drainage grates and railroad crossings, smooth pavements, and signals responsive to bicycles should be provided. In addition, the desirability of adding facilities such as bicycle lanes, bicycle routes, shoulder improvements, and wide curb lanes should be considered. Information on each of the different roadway improvements is contained in this section.

\section{Drainage Grates}

Drainage grate inlets and utility covers are potential problems to bicyclists. When a new roadway is designed, all such grates and covers should be kept out of bicyclists' expected path. On new construction where bicyc- 
lists will be permitted, curb inlets should be used wherever possible to completely eliminate exposure of bicyclists 10 grate inlets. It is important that grates and utility covers be adjusted fush with the surface, including after a roadway is resurfaced.

Parallel bar drainage grate inlets can trap the front wheel of a bicycle causing loss of steering control and. often, the bar spacing is such that they allow narrow bicycle wheels to drop into the grates, resulting in serious damage to the bicycle wheel and frame and/or injury to the bicyclist. These grates should be replaced with bicycle-safe and hydraulically efficient ones. When this is not immediately possible, consideration should be given to welding steel cross straps or bars perpendicular to the parallel bars to provide a maximum safe opening between straps. This should be considered a temporary correction.

While identifying a grate with a pavement marking, as indicated in the MUTCD, would be acceptable in most situations, parallel bar grate inlets deserve special attention. Because of the serious consequences of a bicyclist missing the pavement marking in the dark or being forced over such a grate inlet by other traffic, these grates should be physically corrected, as described above, as soon as practicable after they are identified.

\section{Railroad Crossings}

Railroad-highway grade crossings should ideally be at a right angle to the rails. The greater the crossing deviates from this ideal crossing angle, the greater is the potential for a bicyclist's front wheel to be trapped in the llangeway causing loss of steering control. It is also important that the roadway approach be at the same elevation as the rails.

Consideration should be given to the materials of the crossing surface and to the flangeway depth and width. If the crossing angle is less than approximately 45 degrees, consideration should be given to widening the outside lane, shoulder, or bicycle lane to allow bicyclists adequate room to cross the tracks at a right angle. Where this is not possible, commercially available compressible nangeway fillers can enhance bicyclist safety. In some cases, abandoned tracks carr be removed. Warning signs and pavement markings should be installed in accordance with the MUTCD.

\section{Pavements}

Pavement surface irregularities can do more than cause an unpleasant ride. Gaps between pavement slabs or drop-offs at overlays parallel to the direction of travel can trap a bicycle wheel and cause loss of control; holes and bumps can cause bicyclists to swerve into the path of motor vehicle traffic. Thus, to the extent practicable, pavement surfaces should be free of irregularities and the edge of the pavement should be uniform in width. On older pavements it may be necessary to fill joints, adjust utility covers or, in extreme cases, overlay the pavement to make it suitable for bicycling. 


\section{Traffic Control Devices}

At intersections where bicycle traffic exists or is anticipated, bicycles should be considered in the timing of the traffic signal cycle, as well as the traffic detection device. Normally, a bicyclist can cross an intersection under the same signal phasing arrangement as motor vehicles; however, on multi-lane streets special consideration should be given to ensure that short clearance intervals are not used. If necessary, an all-red clearance interval may be used.

To check the clearance interval, a bicyclist's speed of $10 \mathrm{mph}(16 \mathrm{~km} / \mathrm{h})$ and a perception/reaction/braking time of 2.5 seconds should be used. Detectors for traffic-actuated signals should be sensitive to bicycles and should be located in the bicyclist's expected path, including left turn lanes. Where programmed visibility signal heads are used, they should be checked to ensure that they are visible to bicyclists who are properly positioned on the road.

The MUTCD should be consulted for guidance on signs and pavement markings. Where bicyclists are expected to use different routings than motorists, directional signing should be used to confirm to bicyclists that the special routing leads to their destination.

\section{Shoulders}

Wide curb lanes and bicycle lanes are usually preferred over shoulders for use by bicyclists. However, if it is intended that bicyclists ride on shoulders, smooth paved shoulder surfaces must be provided. Pavement edge lines supplement surface texture in delineating the shouider from the motor vehicle lanes. Rumble strips can be a deterrent to bicycling on shoulders and their benefits should be weighed against the probability that bicyclists will ride in the motor vehicle lanes to avoid them.

Shoulder width should be a minimum of 4 feet $(1.2 \mathrm{~m})$ when intended to accommodate bicycle travel. Roads with shoulders less than 4 feet $(1.2 \mathrm{~m})$ wide normally should not be signed as bikeways. If motor vehicle speeds exceed $35 \mathrm{mph}(55 \mathrm{~km} / \mathrm{h})$, if the percentage of trucks, buses, and recreational vehicles is high, or if static obstructions exist at the right side, then additional width is desirable.

Adding or improving shoulders can often be the best way to accommodate bicyclists in rural areas, and they are also a benefit to motor vehicle traffic. Where funding is limited, adding or improving shoulders on uphill sections first will give slow moving bicyclists needed maneuvering space and decrease conflicts with faster moving motor vehicle traffic.

\section{Wide Curb Lanes}

On highway sections without bicycle lanes, a right lane wider than 12 feet $(3.7 \mathrm{~m})$ can better accommodate both bicycles and motor vehicles in the same lane and thus is beneficial to both bicyclists and motorists. In 
many cases where there is a wide curb lane, motorists will not need to change lanes to pass a bicylist.

Also, more maneuvering room is provided when drivers are exiring from driveways or in areas with limited sight distance. In general, a lane width of 14 feet $(4.3 \mathrm{~m})$ of usable pavement width is desired. Usable pavement width would normally be from curb face to lane stripe, or from edge line to lane stripe, but adjustments need to be made for drainage grates, parking, and longitudinal ridges between pavement and gutter sections. Widths greater than 14 feet $(4.3 \mathrm{~m})$ can encourage the undesirable operation of two motor vehicles in one lane, especially in urban areas, and consideration should be given to striping as a bicycle lane when wider widths exist.

\section{Bicycle Routes}

It may be advantageous to sign some urban and rural roadways as bicycie routes. When providing continuity to other bicycle facilities, a bicycle route can be relatively short. However, a bicycle touring route can be quite long. For long bicycle routes, a standard bicycle route marker with a numerical designation in accordance with Part IX of the MUTCD can be used in place of a bicycle route sign. The number may correspond to a parallel highway, indicating the route is a preferred alternate route for bicyclists. It is often desirable to use supplemental plaques with bicycle route signs or markers to fumish additional information, such as direction changes in the route and intermediate range distance and destination information. Bicycle route signing should not end at a barrier. Information directing the bicyclist around the barrier should be provided.

Overall, the decision whether to provide a bicycle route should be based on the advisability of encouraging bicycle use on a particular road, instead of on parallel and adjacent highways. The roadway width, along with factors such as the volume, speed, and type of traffic; parking conditions: grade; and sight distance should be considered when determining the feasibility of a bicycle route. Generally, bicycle traffic cannot be diverted to a less direct alternate route unless the favorable factors outweigh the inconvenience to the bicyclist. Roadway improvements, such as safe drainage grates, railroad crossings, smooth pavements, maintenance schedules, and signals responsive to bicycles, should always be considered before a roadway is identified as a bicycle route.

Further guidance on signing bicycle routes is provided in the MUTCD.

\section{Bicycle Lanes}

Bicycle lanes can be considered when it is desirable to delineate available road space for preferential use by bicyclists and motorists, and to provide for more predictable movements by each. Bicycle lane markings can increase a bicyclist's confidence in motorists not straying into his/her path of travel. Likewise, passing motorists are less likely to swerve to the left out of their lane to avoid bicyclists on their right. 
Bicycle lanes should always be one-way facilities and carry traffic in the same direcrion as adjacent motor vehicle traffic. Two-way bicycle lanes on one side of the roadway are unacceptable because they promote riding against the flow of motor vehicle traffic. Wrong-way riding is a major cause of bicycle accidents and violates the Rules of the Road stated in the Uniform Vehicle Code. Bicycle lanes on one-way streets should be on the right side of the street, except in areas where a bicycle lane on the left will de. crease the number of conflicts (e.g., those caused by heavy bus traffic).

Under ideal conditions, minimum bicycle lane width is 4 feet $(1.2 \mathrm{~m})$. However, certain edge conditions dictate additional desirable bicycle lane width. To examine the width requirements for bicycle lanes. Figure 1 shows three usual locations for such facilities in relation to the roadway. Figure I (a) depicts bicycle lanes on an urban curbed street where a parking lane is provided. The minimum bicycle lane width for this location is 5 feet $(1.5 \mathrm{~m})$. Bicycle lanes should always be placed between the parking lane and the motor vehicle lanes. Bicycle lanes between the curb and the parking lane create hazards for bicyclists from opening car doors and poor visibility at intersections and driveways, and they prohibit bicyclists from making left turns; therefore this placement should never be considered.

Where parking is permitted but a parking lane is not provided, the coinbination lane, intended for both motor vehicle parking and bicycle use, should be a minimum of 12 feet $(3.7 \mathrm{~m})$ wide. However, if it is likely the combination lane will be used as an additional motor vehicle lane, it is preferable to designate separate parking and bicycle lanes as shown in Figure 1 (a). In both instances, if parking volume is substantial or turnover is high, an additional 1 or 2 feet $(0.3$ or $0.6 \mathrm{~m})$ of width is desiraole for safe bicycle operation.

Figure l (b) depicts bicycle lanes along the outer portions of an urban curbed street where parking is prohibited. Bicyclists do not generally ride near a curb because of the possibility of debris, of hitting a pedal on the curb, of an uneven longitudinal joint, or of a steeper cross-slope. Bicycle lanes in this location should have a minimum width of 5 feet $(1.5 \mathrm{~m})$ from the curb face. If the longitudinal joint between the gutter pan and the roadway surface is uneven and falls within 5 feet $(1.5 \mathrm{~m})$ of the curb face, a minimum of 4 feet $(1.2 \mathrm{~m})$ should be provided between the joint and the moror vehicle lanes.

Figure l(c) depicts bicycle lanes on a highway without curb or gutter. Bicycle lanes should be located between the motor vehicle lanes and the roadway shoulders. Bicycle lanes may have a minimum width of 4 feet $(1.2 \mathrm{~m})$, where the shoulder can provide additional maneuvering width. A width of 5 feet $(1.5 \mathrm{~m})$ or greater is preferable; additional widths are desirable where substantial truck traffic is present, where prevailing winds are a factor, on grades, or where motor vehicle speeds exceed $35 \mathrm{mph}(55 \mathrm{~km} /$ h).

Bicycle lanes tend to complicate both bicycle and motor vehicle turning movements at intersections. Because they encourage bicyclists to keep to 
(a) CURBED STREET WITH PARKING

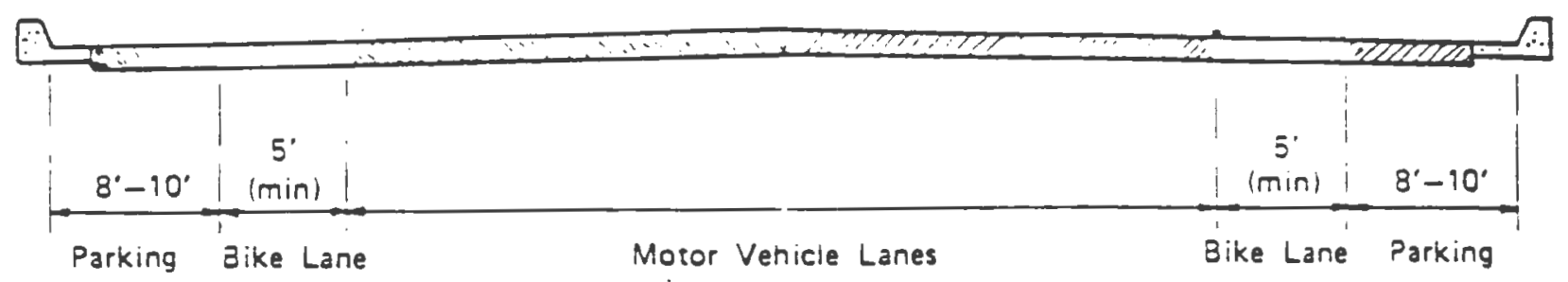

(b) CURBED STREET WITHOUT PARKING

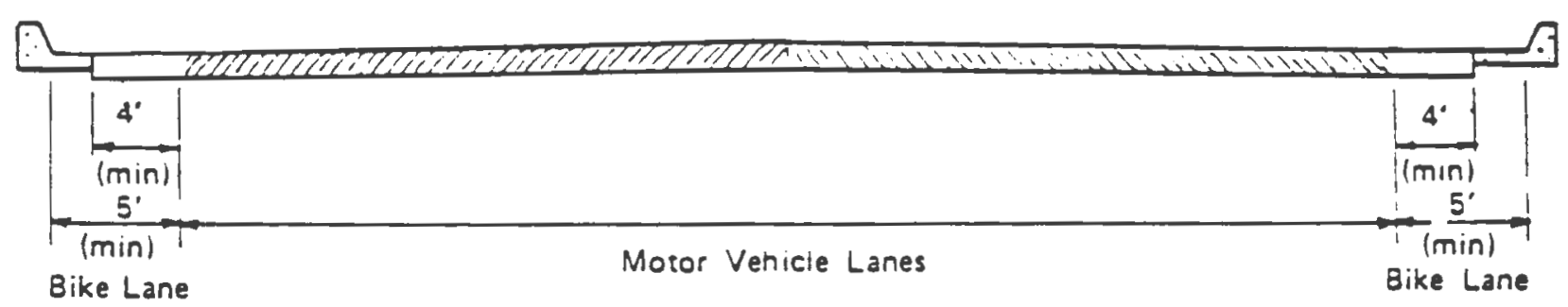

(c) STREET OR HIGHWAY WITHOUT CURB OR GUTTER

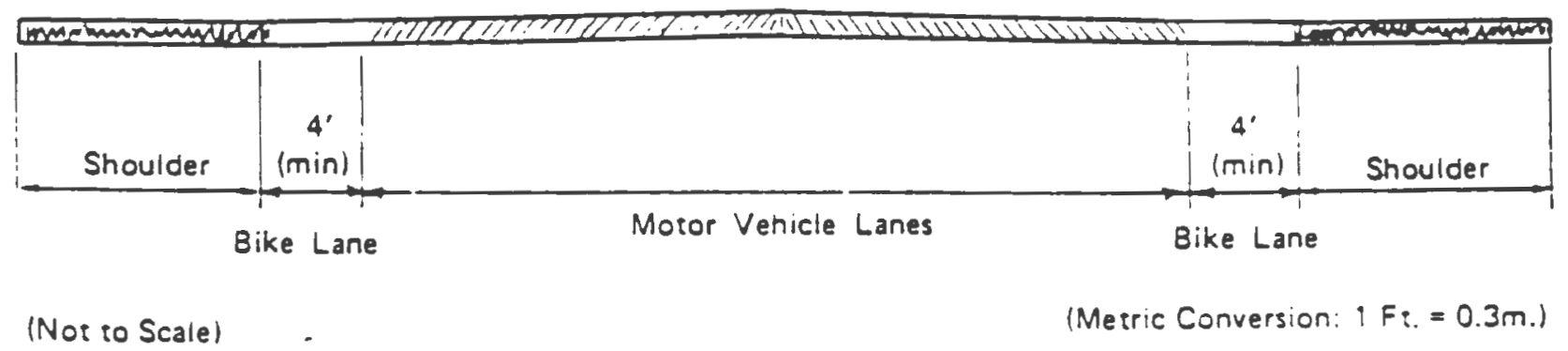

Figure 1. Typical Bicycle Lane Cross Sections 
the right and motorists to keep to the left, both operators are somewhat discouraged from merging in advance of turns. Thus, some bicyclists will begin left turns from the right-side bicycle lane and some motorists will begin right turns from the lane to the left of the bicycle lane. Both maneuvers are contrary to established Rules of the Road and result in conflicts.

At intersections, bicyclists proceeding straight through and motorists turning right must cross paths. Striping and signing configurations which encourage these crossings in advance of the intersection, in a merging fashion, are generally preferable to those that force the crossing in the immediate vicinity of the intersection. To a lesser extent, the same is true for left-turning bicyclists; however, in this maneuver, most vehicle codes allow the bicyclist the option of making either a "vehicular style" left turn (where the bicyclist merges leftward to the same lane used for motor vehicle left turns) or a "pedestrian style" left turn (where the bicyclist proceeds straight through the intersection, turns left at the far side, then proceeds across the intersection again on the cross street).

Figure 2 presents examples of details on pavement markings for bicycle lanes approaching motorist right-turn-only lanes. Where there are numerous left-turning bicyclists, a separate turning lane, as indicated in Part IX of the MUTCD, should be considered. The design of bicycle lanes should also include appropriate signing at intersections to reduce the number of conflicts. General guidance for pavement marking of bicycle lanes is contained in the MUTCD.

Adequate pavement surface, bicycle-safe grate inlets, safe railroad crossings, and traffic signals responsive to bicycles should always be provided on roadways where bicycle lanes are being designated. Raised pavement markings and raised barriers can cause steering difficulties for bicyclists and should not be used to delineate bicycle lanes.

\section{BICYCLE PATHS}

Bicycle paths are facilities on exclusive rights-of-way and with minimal cross flow by motor vehicles. Bicycle paths can serve a variety of purposes. They can provide a commuting bicyclist with a shortcut through a residential neighborhood (e.g., a connection between two cul-de-sac streets). Located in a park, they can provide an enjoyable recreational opportunity. Bicycle paths can be located along abandoned railroad rights-of-way, the banks of rivers, and other similar areas. Bicycle paths can also provide bicycle access to areas that are otherwise served only by limited access highways closed to bicycles. Appropriate locations can be identified during the planning process.

Bicycle paths should be thought of as extensions of the highway system that are intended for the exclusive or preferential use of bicycles in much the same way as freeways are intended for the exclusive or preferential use of motor vehicles. There are many similarities between design criteria for 


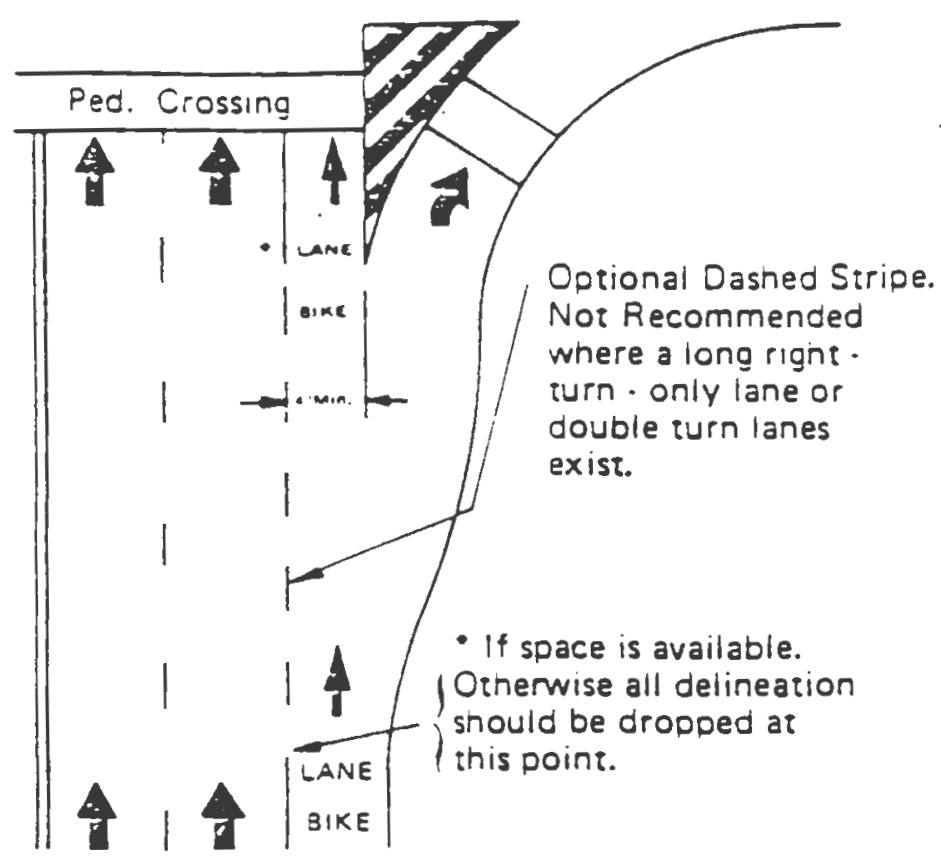

RIGHT-TURN-ONLY LANE

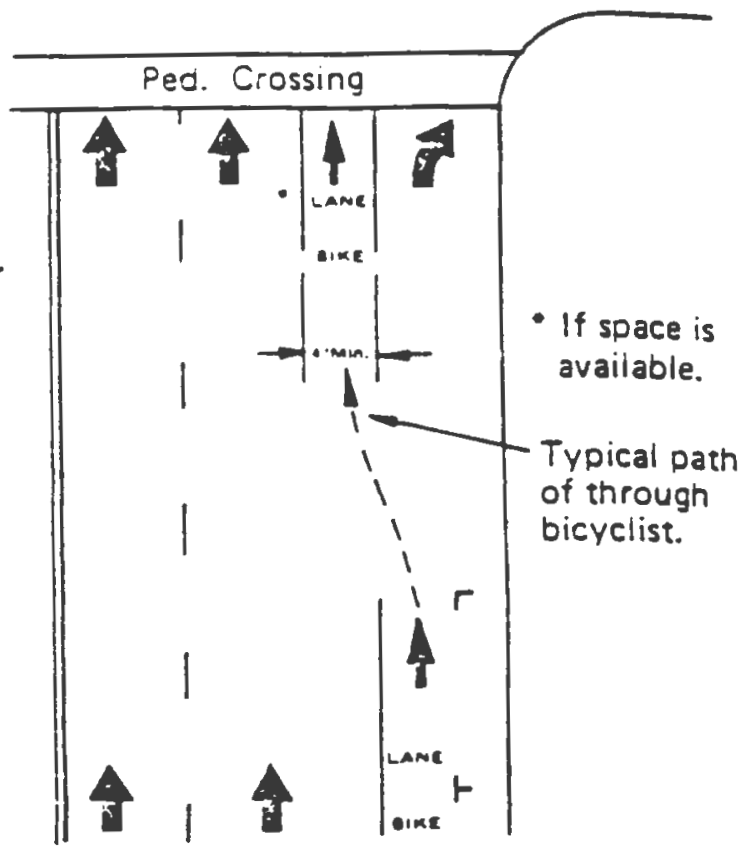

PARKING LANE BECOMES RIGHT-TURN-ONLY LANE
(Nor ro Scale)

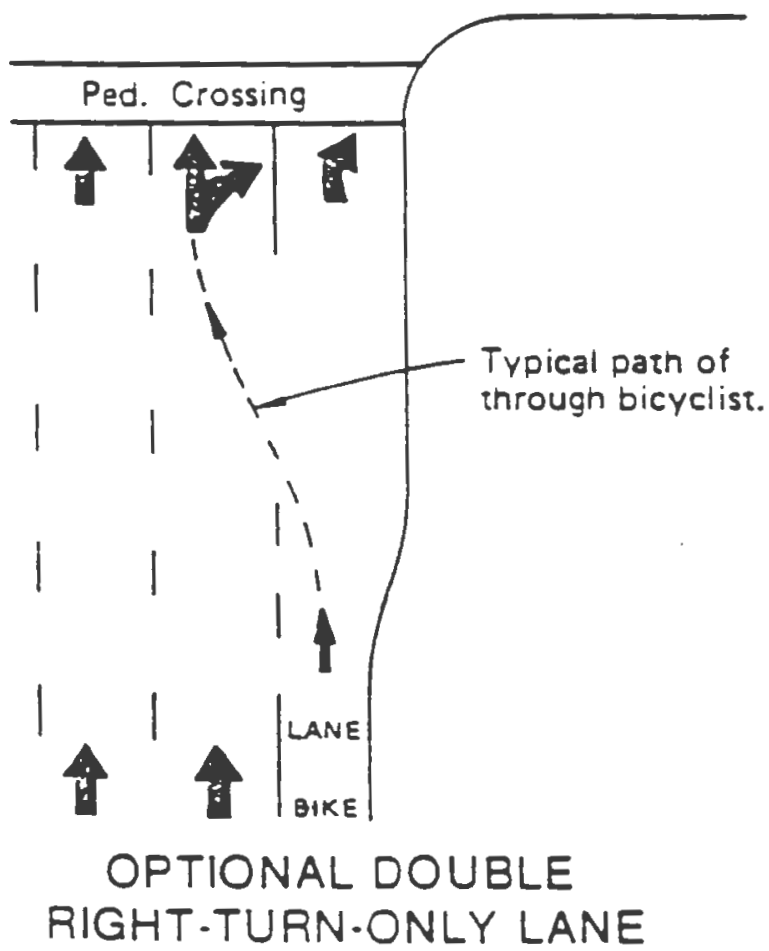

(Metric conversion: $1 \mathrm{t} .=0.3 \mathrm{~m}$. )

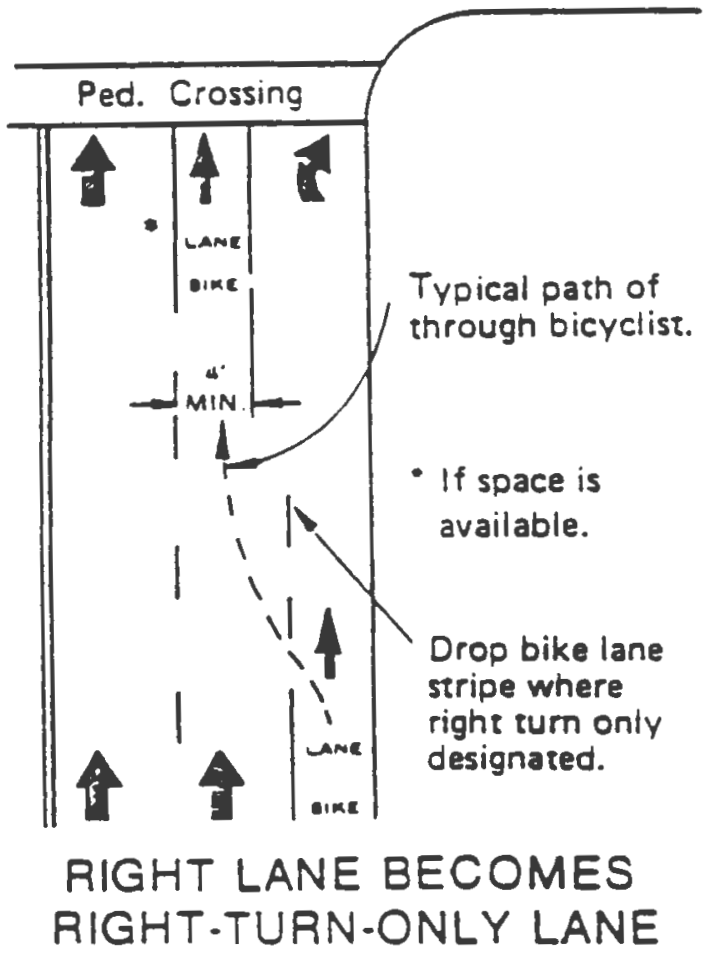

Figure 2. Bicycle Lanes Approaching Motor Vehicle Right-Turn-Only Lanes 
bicycle paths and those for highways (e.g., in determining horizontal alignment, sight distance requirements. signing, and markings). On the other hand, some criteria (e.g., horizontal and vertical clearance requirements, grades, and pavement structure) are dictated by operating characteristics of bicycles that are substantially different from those of motor vehicles. The designer should always be conscious of the similarities and the differences between bicycles and motor vehicles and of how these similarities and differences influence the design of bicycle paths. The following sections provide guidance for designing a safe and functional bicycle path.

\section{Width and Clearance}

The paved width and the operating width required for a bicycle path are primary design considerations. Figure 3 depicts a bicycle path on a separated right-of-way. Under most conditions, a desirable minimum all paved width for a two directional bicycle path is 10 feet $(3 \mathrm{~m})$. In some instances, however, a minimum of 8 feet $(2.4 \mathrm{~m})$ can be adequate. This minimum should be used only where the following conditions prevail: (1) bicycle traffic is expected to be low, even on peak days or during peak hours (2) pedestrian use of the facility is not expected to be more than occasional, (3) there will be good horizontal and vertical alignment providing safe and frequent passing opportunities, (4) the path will not be subjected to maintenance vehicle loading conditions that would cause pavement edge damage. Under certain conditions it may be necessary or desirable to increase the width of a bicycle path to 12 feet $(3.7 \mathrm{~m})$; for example, because of substantial bicycle volume, probable shared use with joggers and other pedestrians, use by large maintenance vehicles, steep grades and where bicyclists will be likely to ride two abreast.

The minimum width of a one directional bicycle path is 5 feet $(1.5 \mathrm{~m})$. It should be recognized, however, that one-way bicycle paths often will be used as two-way facilities unless effective measures are taken to assure one-way operation. Without such enforcement, it should be assumed that bicycle paths will be used as two-way facilities and designed accordingly.

A minimum 2-foot $(0.6 \mathrm{~m})$ width graded area should be maintained adjacent to both sides of the pavement; however, 3 feet $(0.9 \mathrm{~m})$ or more is desirable to provide clearance from trees, poles, walls, fences, guardrails, or their lateral obstructions. A wider graded area on either side of the bicycle path can serve as a separate jogging path.

A wide separation between a bicycle path and an adjacent highway is desirable to confirm to both the bicyclist and the motorist that the bicycle path functions as an independent highway for bicycles. When this is not possible and the distance between the edge of the roadway and the bicycle path is less than 5 feet $(1.5 \mathrm{~m})$, a suitable physical divider, such as a fence, dense shrubs or other barrier may be considered. Such dividers serve both to prevent bicyclists from making unwanted movements between the path

$$
\text { E-@ }
$$




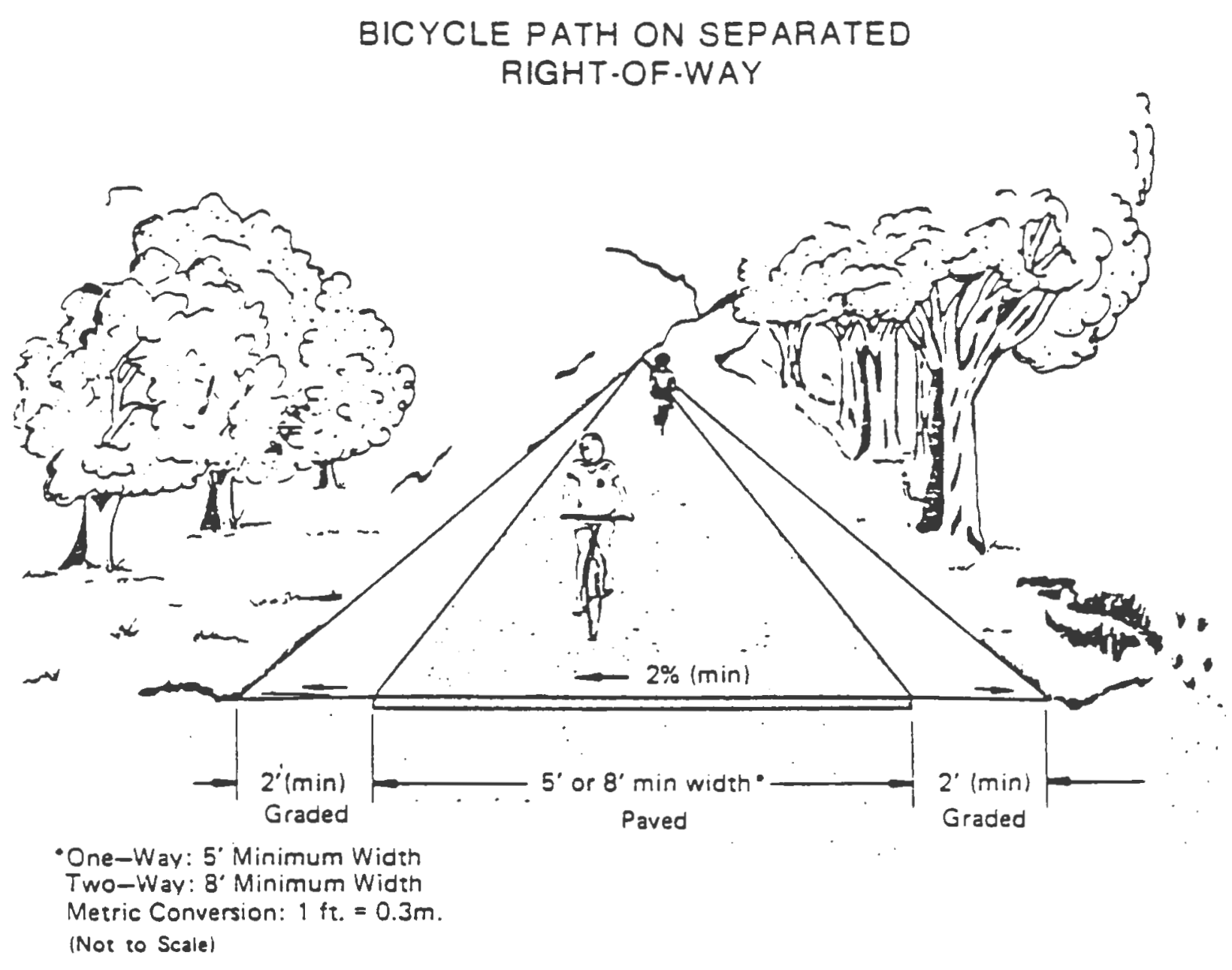

Figure 3. 
and the highway shoulder and to reinforce the concept that the bicycle path is an independent facility. Where used, the divider should be a minimum of 4.5 feet $(1.4 \mathrm{~m})$ high, to prevent bicyclists from toppling over it, and it should be designed so that it does not become a hazard in itself.

The vertical clearance to obstructions should be a minimum of 8 feet $(2.4 \mathrm{~m})$. However, vertical clearance may need to be greater to permit passage of maintenance vehicles and, in undercrossings and tunnels, a clearance of 10 feet $(3 \mathrm{~m})$ is desirable for adequate vertical shy distance.

\section{Design Speed}

The speed that a bicyclist travels is dependent on several factors, including the type and condition of the bicycle, the purpose of the trip, the condition and location of the bicycle path, the speed and direction of the wind, and the physical condition of the bicyclist. Bicycle paths should be designed for a selected speed that is at least as high as the preferred speed of the faster bicyclists. In general, a minimum design speed of $20 \mathrm{mph}$ $(32 \mathrm{~km} / \mathrm{h})$ should be used; however, when the grade exceeds 4 percent, or where strong prevailing tailwinds exist, a design speed of $30 \mathrm{mph}(48 \mathrm{~km} /$ h) is advisable.

On unpaved paths, where bicyclists tend to ride slower, a lower design speed of $15 \mathrm{mph}(24 \mathrm{~km} / \mathrm{h})$ can be used. Similarly, where the grades or the prevailing winds dictate, a higher design speed of $25 \mathrm{mph}(40 \mathrm{~km} / \mathrm{h})$ can be used. Since bicycles have a higher tendency to skid on unpaved surfaces, horizontal curvature design should take into account lower coefficients of friction.

\section{Horizontal Alignment and Superelevation}

The minimum radius of curvature negotiable by a bicycle is a function of the superelevation rate of the bicycle path surface, the coefficient of friction between the bicycle tires and the bicycle path surface, and the speed of the bicycle. The minimum design radius of curvature can be derived from the following formula:

$$
R=\frac{V^{2}}{15(e+f)}
$$

Where $\mathrm{R}=$ Minimum radius of curvature $(\mathrm{ft})$,

$V=$ Design speed (mph),

$\mathrm{e}=$ Rate of superelevation,

$f=$ coefficient of friction.

For most bicycle path applications, the superelevation rate will vary from a minimum of 2 percent (the minimum necessary to encourage adequate drainage) to a maximum of approximately 5 percent (beyond which maneuvering difficulties by slow bicyclists and adult tricyclists might be expected). The minimum superelevation rate of 2 percent will be adequate for most conditions and will simplify construction. 
The coefficient of friction depends upon speed: surface type, roughness, and condition; tire type and condition; and whether the surface is wet or dry. Friction factors used for design should be selected based upon the point at which centrifugal force causes the bicyclist to recognize a feeling of discomfort and instinctively act to avoid higher speed. Extrapolating from values used in highway design, design friction factors for paved bicycle paths can be assumed to vary from 0.30 at $15 \mathrm{mph}(24 \mathrm{~km} / \mathrm{h})$ to 0.22 at $30 \mathrm{mph}(48 \mathrm{~km} / \mathrm{h})$. Although there are no data available for unpaved surfaces, it is suggested that friction factors be reduced by 50 percent to allow a sufficient margin of safety.

Based upon a superelevation rate (e) of 2 percent, minimum radii of curvature can be selected from Table 1.

\section{TABLE 1 - DESIGN RADII FOR PAVED BICYCLE PATHS}

$\begin{array}{lll}\begin{array}{l}\text { Design Speed }-V \\ (\mathrm{mph})\end{array} & \begin{array}{l}\text { Friction } \\ \text { Factor }-\mathrm{f}\end{array} & \begin{array}{l}\text { Design Radius }-\mathrm{R} \\ (\text { Feet })\end{array} \\ (1 \mathrm{mph}=1 / 6 \mathrm{~km} / \mathrm{hr}) & & (1 \mathrm{ft}=0.3 \mathrm{~m}) \\ 20 & 0.27 & 95 \\ 25 & 0.25 & 155 \\ 30 & 0.22 & 250 \\ 35 & 0.19 & 390 \\ 40 & 0.17 & 565\end{array}$

$$
\text { (e }=2 \text { percent) }
$$

$$
\text { Friction }
$$

0.27

0.19

0.17
Design Radius - $\mathrm{R}$

$(1 \mathrm{ft}=0.3 \mathrm{~m})$

95

565

When substandard radius curves must be used on bicycle paths because of right-of-way, topographical or other considerations. standard curve warning signs and supplemental pavement markings should be installed in accordance with the MUTCD. The negative effects of substandard curves can also be partially offset by widening the pavement through the curves.

\section{Grade}

Grades on bicycle paths should be kept to a minimum, especially on long inclines. Grades greater than 5 percent are undesirable because the ascents are difficult for many bicyclists to climb and the descents cause some bicyclists to exceed the speeds at which they are competent. Where terrain dictates. grades over 5 percent and less than 500 feet $(150 \mathrm{~m})$ long are acceptable when a higher design speed is used and additional width is provided.

\section{Sight Distance}

To provide bicyclists with an opportunity to see and react to the unexpected, a bicycle path should be designed with adequate stopping sight distances. The distance required to bring a bicycle to a full controlled stop is a function of the bicyclist's perception and brake reaction time, the initial speed of the bicycle, the coefficient of friction between the tires and the pavement. and the braking ability of the bicycle.

$$
B-12
$$


Figure 4 indicates the minimum stopping sight distance for various design speeds and grades based on a total perception and brake reaction time of 2.5 seconds and a coefficient of friction of 0.25 to account for the poor wet-weather braking characteristics of many bicycles. For two-way bicycle paths. the sight distance in the descending direction. that is, where " $G$ " is negative, will control the design.

Figure 5 is used to select the minimum length of vertical curve neces. sary to provide minimum stopping sight distance at various speeds on crests. The eve height of the bicyclist is assumed to be 4.5 feet $(1.4 \mathrm{~m})$ and the object height is assumed to be zero to recognize that hazards to bicycle travel exist at pavement level.

Figure 6 indicates the minimum clearance that should be used to lineof-sight obstructions for horizontal curves. The desired lateral clearance is obtained by entering Figure 6 with the siopping sight distance from Figure 4 and the proposed horizontal radius of curvature.

Bicyclists frequently ride abreast of each other on bicycle paths and, on narrow bicycle paths, bicyclists have a tendency to ride near the middle of the path. For these reasons, and because of the serious consequences of a head-on bicycle accident, lateral clearances on horizontal curves should be calculated based on the sum of the stopping sight distances for bicyclists traveling in opposite directions around the curve. Where this is not possible or feasible, consideration should be given to widening the path through the curve, installing a yellow center stripe, installing a curve ahead warning sign, in accordance with the MUTCD, or some combination of these alternatives.

\section{Intersections}

Intersections are an important consideration in bicycle path design. If alternate locations for a bicycle path are available, the one with the fewest intersections and/or the most favorable intersection conditions should be selected. For crossings of freeways and orher high speed, high volume arterials, a grade separation structure may be the only possible or practical treatment. Unless bicycles are prohibited from the crossing highway, providing for turning movements must be considered. In most cases. however, the cost of a grade separation will be prohibitive.

When intersections occur at grade, a major consideration is the establishment of right of way. The type of traffic control to be used (signal, stop sign, yield sign, etc.) should be selected by application of the warrants in the MUTCD. Bicycles should be counted as vehicles in these determinations and thus, bicycles may be given priority at some intersections.

Sign type, size and location should also be in accordance with the MUTCD. Care should be taken to ensure that bicycle path signs are located so that motorists are not confused by them and that highway signs are placed so that bicyclists are not confused by them.

It is preferable that the crossing of a bicycle path and a highway be at a location away from the influence of intersections with other highways. 


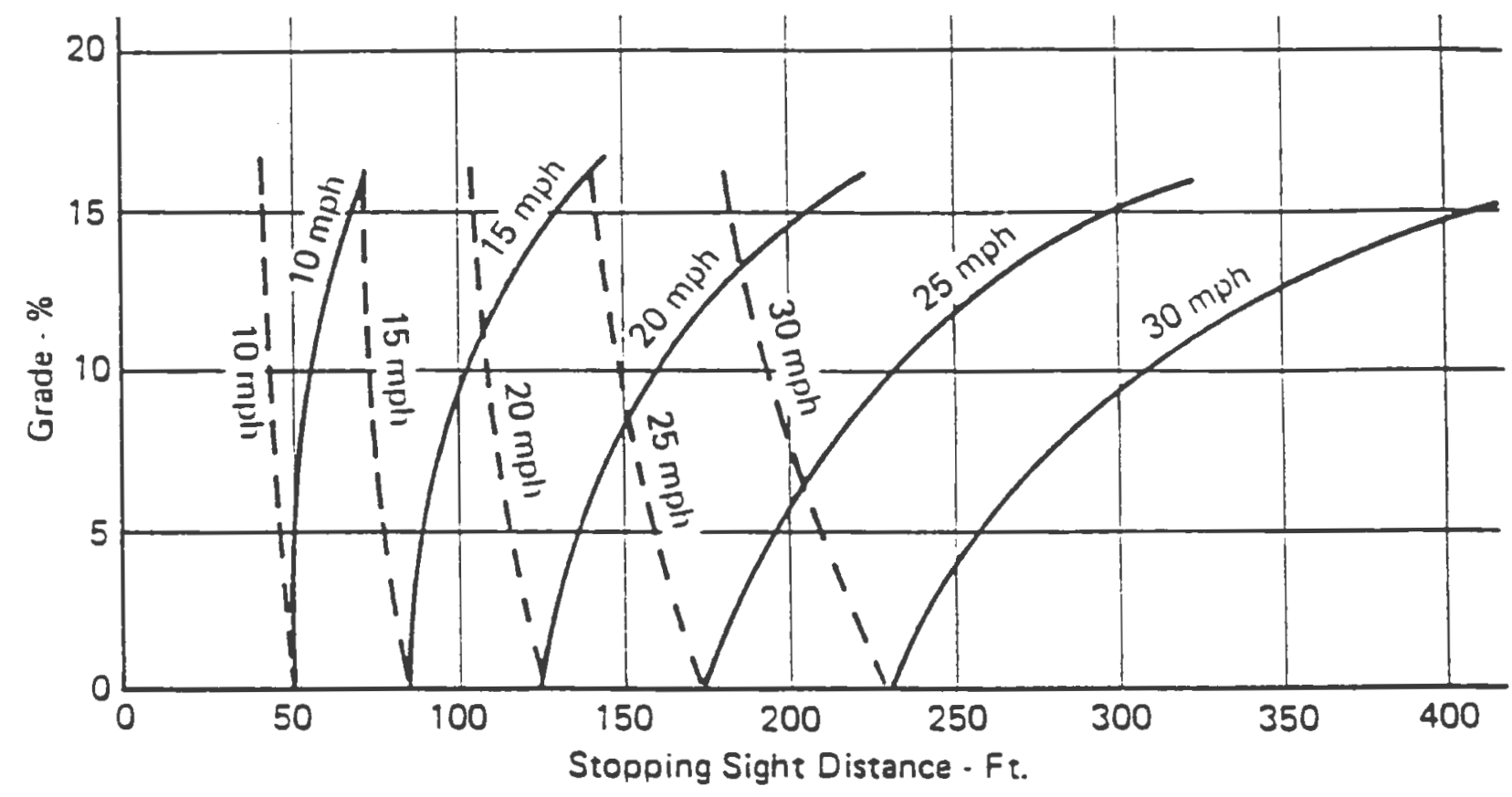

$$
S=\frac{V^{2}}{30(f \pm G)}+3.67 V
$$

Where: $S=$ Stopping Sight Distance, $F t$.

Decend $(-G) \longrightarrow$

$V=$ Velocity, $\mathrm{mph}$

$f=$ Coefficient of Friction (use 0.25 )

$\mathrm{G}=$ Grade $\mathrm{Ft} . / \mathrm{Ft}$. (rise/run)

(Metric conversion: $1 \mathrm{fr} .=0.3 \mathrm{~m}, 1 \mathrm{mph}=1.6 \mathrm{~km} / \mathrm{h}$ )

Figure 4. Stopping Sight Distances 


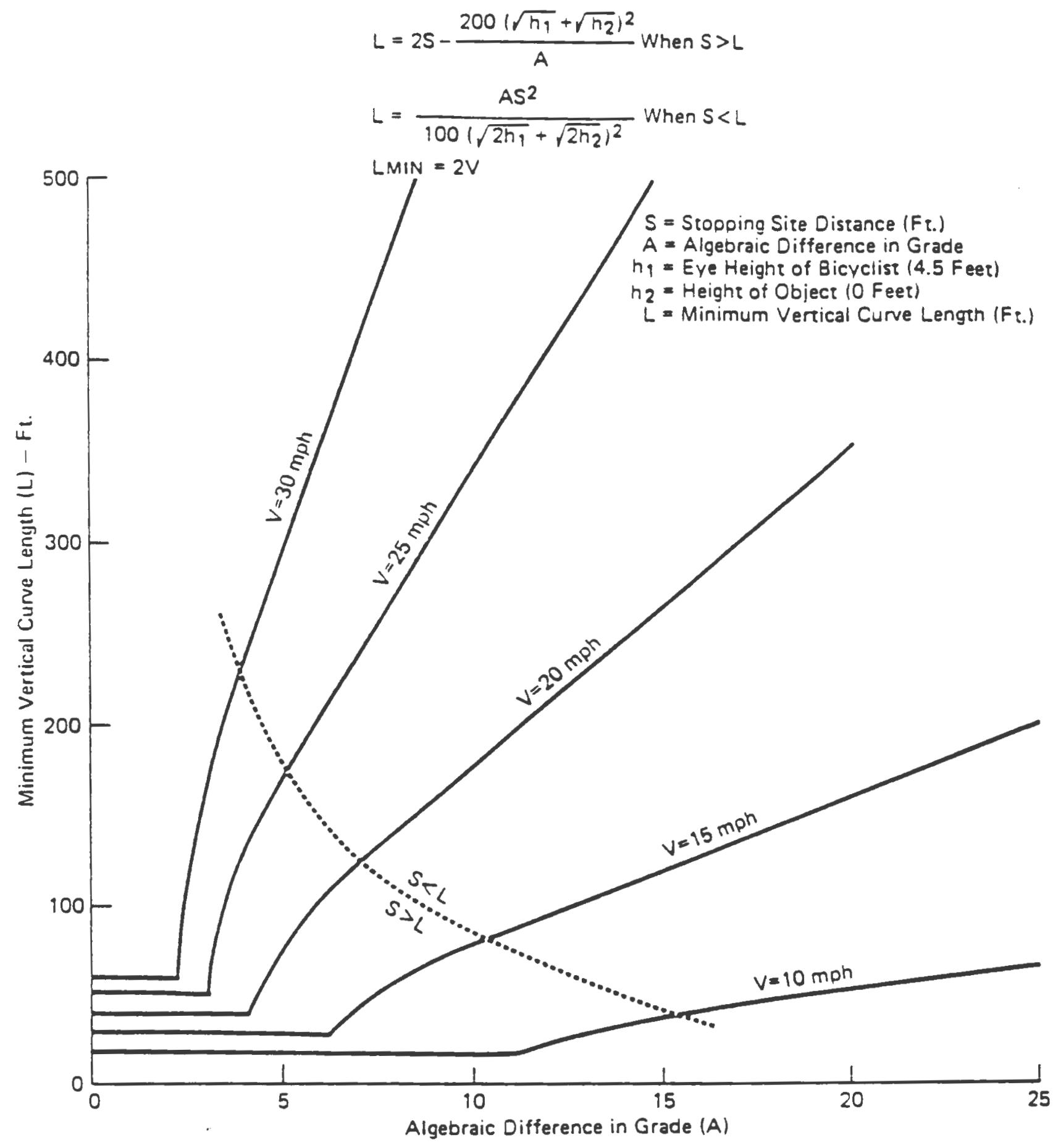

Figure 5. Sight Distances for Crest Vertical Curves 


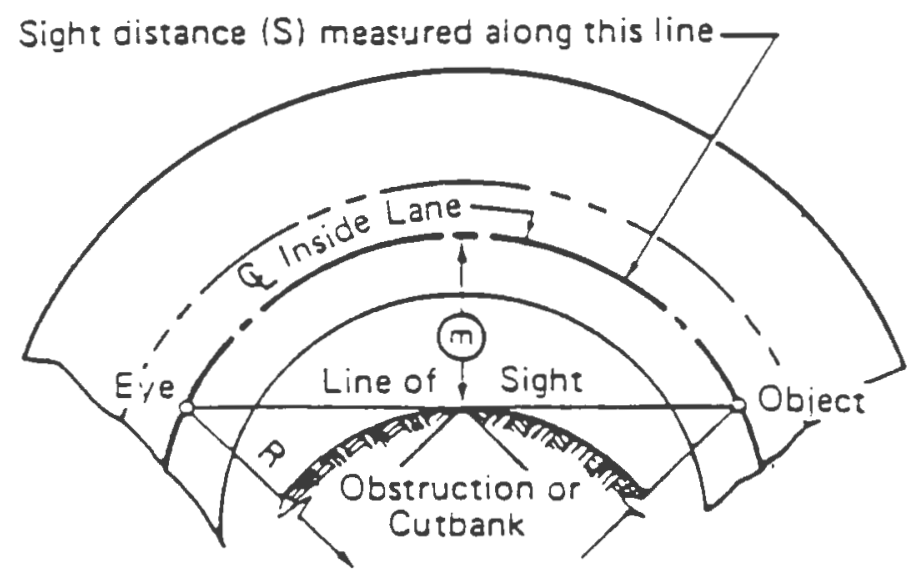

Line of sight is $2.0^{\circ}$ above $E$ inside lane at point of obstruction.
$S=$ Sight distance in feet.

$R=$ Radius of $G$ inside lane in feet.

$m=$ Distance from $G$ inside lane in feet.

$V=$ Design soeed for $S$ in mph.

Angle is expressed in degrees

$$
\begin{aligned}
& m=R\left[\operatorname{vers}\left(\frac{28.655}{R}\right)\right] \\
& S=\frac{R}{28.65}\left[\cos ^{-1}\left(\frac{R-m}{R}\right)\right]
\end{aligned}
$$

Formula aoplies only when $S$ is equal to or less than length of curve.

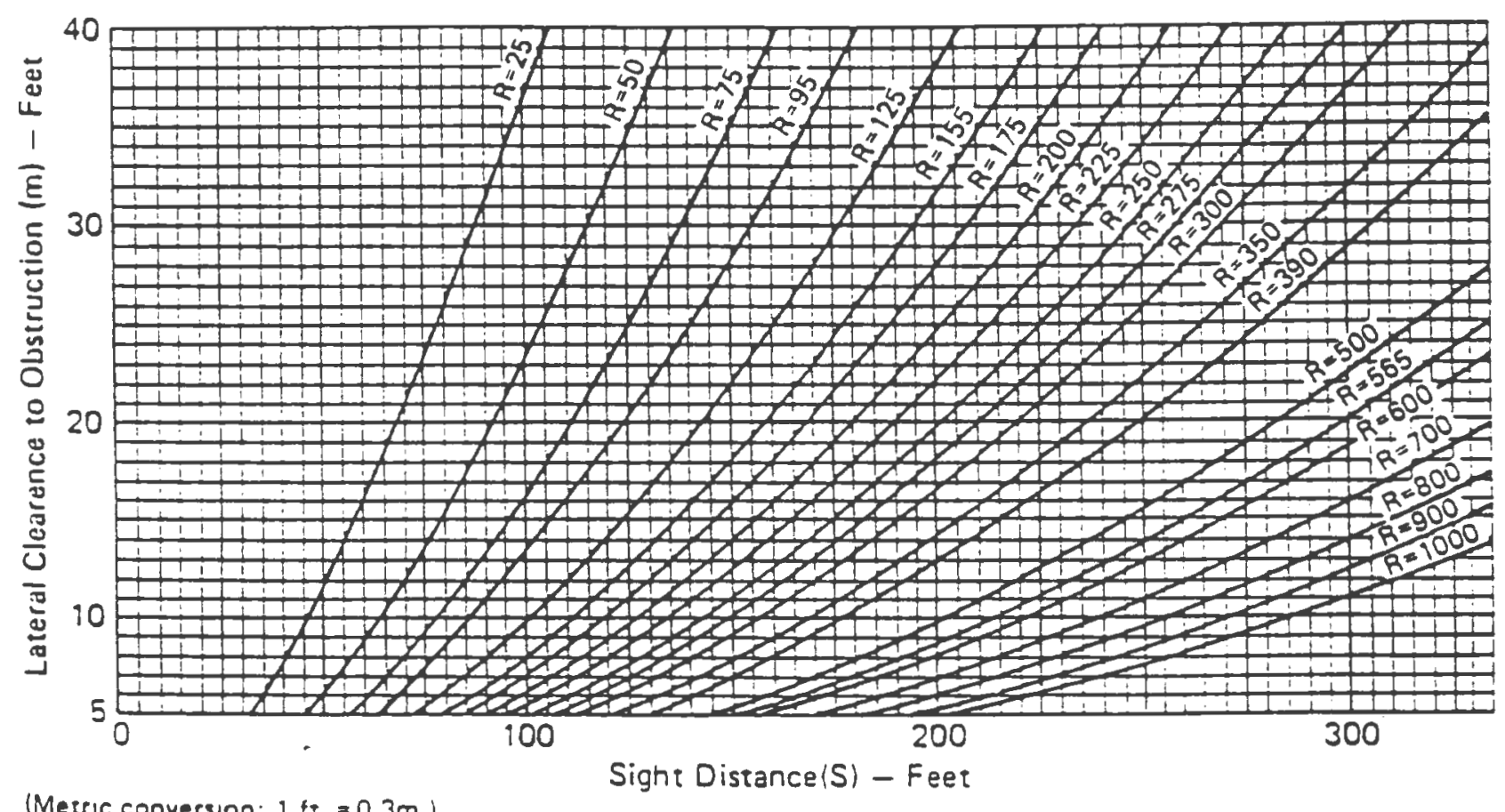

Figure 6. Lateral Clearances on Horizontal Curves 
Controlling vehicle movements at such intersections is more easily and safely accomplished through the application of standard traffic control devices and normal Rules of the Road. Where physical constraints prohibit such independent intersections, the crossings may be at or adjacent to the pedestrian crossing. Rights of way should be assigned and sight distance should be provided so as to minimize the potential for conflict resulting from unconventional turning movements. At crossings of high-volume multilane arterial highways where signals are not warranted. consideration should be given to providing a median refuge area for crossing bicyclists.

Bicycle path intersections and approaches should be on relatively flat grades. Stopping sight distances at intersections should be checked and adequate warning should be given to permit bicyclists to stop before reaching the intersection, especially on downgrades.

\section{Signing and Marking}

Adequate signing and marking are essential on bicycle paths, especially to alert bicyclists to potential hazards and to convey regulatory messages to both bicyclists and motorists at highway intersections. In addition, guide signing, such as to indicate directions, destinations, distances, route numbers, and names of crossing streets, should be used in the same manner as they are used on highways. In general, uniform application of traffic control devices, as described in the MUTCD, will tend to encourage proper bicyclist behavior.

A designer should consider a 4 -inch $(10 \mathrm{~cm})$ wide yellow centerline stripe to separate opposite directions of travel. This is particularly beneficial in the following circumstances: (1) for heavy volumes of bicycles, (2) on curves with restricted sight distance, and (3) on unlighted paths where night-time riding is expected. Edge lines can also be very beneficial where night-time bicycle traffic is expected.

Care should be exercised in the choice of pavement marking materials. Some marking materials, for example, are slippery when wet and should be avoided in favor of more skid resistant materials.

General guidance on signing and marking is provided in the MUTCD. Part IX of the MUTCD refers specifically to traffic controls for bicycle facilities.

\section{Pavement Structure}

Designing and selecting pavement sections for bicycle paths is in many ways similar to designing and selecting highway pavement sections. A soils investigation should be conducted to determine the load carrying capabilities of the native soil and the need for any special provisions. The investigation need not be elaborate, but should be done by, or under the supervision of, a qualified engineer.

In addition, there are several basic principles that should be followed to recognize some basic differences between the operating characteristics of 
bicycles and those of motor vehicles. While loads on bicycle paths will be substantially less than highway loads, paths should be designed to sustain without damage wheel loads of occasional emergency, patrol, maintenance. and other motor vehicles that are expected to use or cross the path.

Special consideration should be given to the location of motor vehicle wheel loads on the path. When motor vehicles are driven on bicycle paths, their wheels will usually be at or very near the edges of the path. Since this can cause edge damage that, in turn, will result in the lowering of the effective operating width of the path, adequate edge support should be provided. Edge support can be either in the form of stabilized shoulders or in constructing additional pavement width. Constructing a typical pavement width of twelve feet, where right-of-way and other conditions permit, eliminates the edge raveling problem and offers two other additional advantages over shoulder construction. First, it allows additional maneuvering space for bicyclists and second. the additional construction cost can be less than for constructing shoulders because the separate construction operation is eliminated.

It is important to construct and maintain a smooth riding surface on bicycle paths. Bicycle path pavements should be machine laid: soil sterilants should be lised where necessary to prevent vegetation from erupting through the pavement; and, on portland cement concrete pavements, transverse joints, necessary to control cracking, should be saw cut to provide a smooth ride. On the other hand, however, skid resistance qualities should not be sacrificed for the sake of smoothness. Broom finish or burlap drag concrete surfaces are preferred over trowel finishes. for example.

In areas where climates are extreme, the effects of freeze-thaw cycles should be anticipated and designed for. At unpaved highway or driveway crossings of bicycle paths, the highway or driveway should be paved a minimum of ten feet on either side of the crossing to reduce the amount of gravel being scattered along the path by motor vehicles. The pavement structure at the crossing should be adequate to sustain the expected loading at that location.

Hard, all weather pavement surfaces are usually preferred over those of crushed aggregate. sand. clay, or stabilized earth since these materials provide a much lower level of service.

Good quality pavement structures can be constructed of asphaltic or portland cement concrete. Because of wide variations in soils, loads, materials and construction practices. it is not practical 10 present specific or recommended typical structural sections that will be applicable nationwide. Altention to the local governing conditions and to the principles outlined above is needed. Experience in highway pavement, together with sound engineering judgment, can assist in the selection and design of a proper bicycle path pavement structure and may identify energy-conserving practices. such as the use of sulfur-extended asphalt, asphalt emulsions. and fused waste. 


\section{Structures}

An overpass. underpass, small bridge or facility on a highway bridge may be necessary to provide continuity to a bicycle path. On new structures, the minimum clear width should be the same as the approach paved bicycle path; and the desirable clear width should include the minimum 2foot $(0.6 \mathrm{~m})$ wide clear areas. Carrying the clear areas across the structures has two advantages: first, it provides a minimum horizontal shy distance from the railing or barrier, and, second, it provides needed maneuvering space to avoid conflicts with pedestrians and other bicyclists who are stopped on the bridge. Access by emergency, patrol, and maintenance vehicles should be considered in establishing the design clearances of structures on bicycle paths. Similarly, vertical clearance also may be dictated by occasional motor vehicles using the path. However, where practical, a vertical clearance of 10 feet $(3 \mathrm{~m})$ is desirable for adequate vertical shy distance.

Railings, fences, or barriers on both sides of a bicycle path bridge should be a minimum of 4.5 feet $(1.4 \mathrm{~m})$ high. Smooth rub rails should be attached to the barriers at a handlebar height of 3.5 feet $(1.1 \mathrm{~m})$.

Bridges designed exclusively for bicycle traffic may be designed for pedestrian live loadings. On all bridge decks, special care should be taken to ensure that bicycle safe expansion joints are used.

Where it is necessary to retrofit a bicycle path onto an existing highway bridge, several alternatives should be considered in light of what the geometrics of the bridge will allow.

One option is to carry the bicycle path across the bridge on one side. This should be done where: (1) the bridge facility will connect to a bicycle path at both ends, (2) sufficient width exists on that side of the bridge or can be obtained by widening or restriping lanes and (3) provisions are made to physically separate bicycle traffic from motor vehicle traffic as discussed above.

A second option is to provide either wide curb lanes or bicycle lanes over the bridge. This may be advisable where (1) the bicycle path transitions into bicycle lanes at one end of the bridge, and (2) sufficient width exists or can be obtained by widening or restriping.

A third option is to use existing sidewalks as one-way or two-way facilities. This may be advisable where (1) conflicts between bicyclists and pedestrians will not exceed tolerable limits and (2) the existing sidewalks are adequately wide.

Because of the large number of variables involved in retrofitting bicycle facilities onto existing bridges, compromises in desirable design criteria are often inevitable. Therefore, the width to be provided is best determined by the designer, on a case by case basis, after thoroughly considering all the variables. 


\section{Drainage}

The recommended minimum pavement cross slope of 2 percent adequately provides for drainage. Sloping in one direction instead of crowning is preferred and usually simplifies the drainage and surface construction. A smooth surface is essential to prevent water ponding and ice formation. Where a bicycle path is constructed on the side of a hill. a ditch of suitable dimensions should be placed on the uphill side to intercept the hillside drainage. Such ditches should not create hazards for bicycilists. Where necessary, catch basins with drains should be provided to carry the intercepted water under the path. Drainage grates and manhole covers should be located outside of the travel path of bicyclists. To assist in draining the area adjacent to the bicycle path, the design should include considerations for preserving the natural ground cover. Seeding, mulching, and sodding of adjacent slopes, swales, and other erodible areas should be included in the design plans.

\section{Lighting}

Fixed-source lighting reduces conflicts along paths and at intersections. In addition, lighting allows the bicyclist to see the bicycle path direction, surface conditions, and obstacles. Lighting for bicycle paths is important and should be considered where riding at night is expected, such as bicycle paths serving college students or commuters, and at highway intersections. Lighting should also be considered through underpasses or tunnels, and when nighttime security could be a problem. Depending on the location, average maintained horizontal illumination levels of 0.5 foot-candle ( 5 lux ) to 2 foot-candles ( 22 lux) should be considered. Where special security problems exist, higher illumination levels may be considered. Light standards (poles) should meet the recommended horizontal and vertical clearances. Luminaires and standards should be at a scale appropriate for a pedestrian or bicycle path.

\section{Restriction of Motor Vehicle Traffic}

Bicycle paths often need some form of physical barrier at highway intersections to prevent unauthorized motor vehicles from using the facilities. Provisions can be made for a lockable. removable post to permit entrance by authorized vehicles. The post should be permanently reflectorized for nighttime visibility and painted a bright color for improved daytime visibility. When more than one post is used, a 5-foot $(1.5 \mathrm{~m})$ spacing is desirable. Wider spacing can allow entry to motor vehicles, while narrower spacing might prevent entry by adult tricycles and bicycles with trailers.

An alternative method of restricting entry of motor vehicles is to split the entry way into two 5 -foot $(1.5 \mathrm{~m})$ sections separated by low landscaping. Emergency vehicles can still enter if necessary by straddling the landscaping. The higher maintenance costs associated with landscaping should be acknowledged, however, before this alternative method is selected. 


\section{Multi-L'se}

In general. multi-use paths are undesirable: bicycles and pedestrians do not mix well. Whenever possible, separate bicycle and pedestrian paths should be provided. If this is not feasible. additional width, signing and striping should be used to minimize conflicts.

Providing a sidewalk bicycle path is unsatisfactory for a variety of reasons. Sidewalks are typically designed for pedestrian speeds and maneuverabilities and are not safe for higher-speed bicycle use. Conflicts are common between pedestrians traveling at low speeds (or exiting stores. parked cars, etc.) and bicyclists, as are conflicts with fixed objects (e.g., parking meters, utility poles, sign posts, bus benches; trees, fire hydrants, mail boxes, etc.). Walkers, joggers, and roller skaters can, and often do, change their speed and direction almost instantaneously leaving bicyclists insufficient time to react to avoid collisions. Similarly, pedestrians often have difficulty predicting the direction an oncoming bicyclist will take. At intersections, motorists are often not looking for bicyclists (who are traveling at higher speeds than pedestrians) entering the crosswalk area. particularly when motorists are making a turn. Sight distance is often impaired by buildings, walls, property fences, and shrubs along sidewalks. especially at driveways.

Bicycles riding on sidewalks can be expected in residential areas with young children. With lower bicycle speeds and lower motor vehicle speeds, potential conflicts are somewhat lessened, but still exist. This type of sidewalk bicycle use is generally accepted, but it is inappropriate to sign a sidewalk as a bicycle path or bicycle route if to do so would prohibit bicyclists from using an alternate facility that might better serve their needs.

It is also undesirable to mix mopeds and bicycles on the same facility. Where it is necessary to do so, the facility should be designed to account for the higher operating speeds of mopeds, the additional maneuvering requirements of mopods, and the increased frequency of passing maneuvers. Many of the design guidelines prescribed in Chapter 2 under "Bicycle Paths" (e.g., widths, design speeds, horizontal alignments, grades, etc.) would be inadequate for facilities intended for moped use. Mopeds also contribute to a lessening of the quiet, relaxing experience most bicyclists desire on bicycle paths.

Using a path for bicycles and horses creates an unsatisfactory and possibly dangerous mix. Horses startle easily and may kick out suddenly if they perceive bicyclists as a danger. A bicycle path and a bridle path are also incompatible in their surface design requirements. Bicycles function best on hard surfaces: horses function best on soft surfaces. A compromise to accommodate both would result in a less than adequate surface for both.

During the winter months, where there is insufficient bicycle traffic to justify plowing snow, operators of bicycle paths may allow them to be used by cross-country skiers or snowmobile operators. 


\section{SUPPLEMENTAL FACILITIES}

Providing bicycle parking facilities is an essential element in an overall eifort to promote bicycling. People are discouraged from bicycling unless adequate parking is available. Bicycle parking faciilites should be provided at both the trip origin and the trip destination and should offer protection from theft and damage.

The wide variety of bicycle parking devices fall into two categories of user needs: commuter or long-term parking, and convenience or shortterm parking. The minimum needs for each differ in their placement and protection. Long-term parking is needed at locations such as employment centers, transit or subway stations, and multifamily dwellings. Facilities should be provided which secure the frame, both wheels, and accessories and which offer protection from the weather. Bicycle lockers and attended storage areas are gnod examples of long-term parking facilities. Short-term parking is needed at locations such as shopping centers, libraries, recreation areas, and post offices. Facilities should be very convenient and be near building entrances or other highly visible areas which are self-policing. The facility should be designed so that it will not damage bicycles (bent rims are common with racks that only support one wheel). If bicycle parking is not properly designed and located, bicyclists will use trees, railings, and other appurtenances. This practice can damage the appurtenances and create a hazard for pedestrians.

Several factors should be considered when planning and providing bicycle parking facilities. Care should be given in selecting the location to ensure that bicycles will not be damaged by motor vehicles. Parking facilities should not interfere with the normal pedestrian flow. Also, facilities should be designed so that persons parking their bicycles will not disturb other parked bicycles. The amount of security needed 10 prevent theft needs to be evaluated for each area.

Facilities should be able to accommodate a wide range of bicycle shapes and sizes including tricycles and trailers if used locally. Finally, facilities should be simple to operate. If possible, signs depicting how to operate the facility should be posted.

In addition to bicycle parking facilities, there are several other improvements that complement bicycle paths and roadway improvements. Provisions should be considered for interfacing bicycle travel with public transit, such as racks on buses, buses converted to carry bicycles aboard, or allowing bicycles on rapid rail facilities. Printing and distributing bicycle route maps is a high-benefit, low-cost project that is easily accomplished. Maps can help bicyclists locate bikeways, parking facilities, and identify the relative suitability of different segments of the road system. Also, maps can help bicyclists avoid narrow, high-speed, or high-volume roads, one-way streets, barriers, and other problems to bicycists. In addition. maps can provide information on Rules of the Road, bicycle safety tips, and interfacing with mass transit. 
APPENDIX C

Rhode Island Bicycle Facilities Pollcy Document 1985 Part Two: Policy summary 


\section{PART TWO: POLICY SUMMARY}

The Rhode Island Department of Transportation recognizes that, in its continuing program for bicycle facilities, a systematic delineation of basic policies is needed. For this purpose, the RIDOT has completed a separate document on bicycle facilities policies.l The broad purpose of the document is to identify the policies and procedures for bicycle facilities planning that provide proper roles and directions for the many state, local and private interests concerned with bicycling.

The RIDOT is concerned that the bicycle mode is a very viable but underutilized transportation mode. Ror this reason the policy document and this manual focus on the bicycle as a mode of transportation. As a result, a set of policies have been articulated and adopted by the RIDOT for Bicycle Facilities Planning in Rhode Island. The following is a summary of these policies, listed by area of concern.

\section{Facilities construction and operation}

- All roads and highways (excluding Interstates), where feasible, shall accommodate bicycle transportation.

- Bicycle compatible elements will be incorporated, where feasible, in the reconstruction and new construction of highway facilities to meet the goal of a bicycle tolerant system.

- The connectivity of bicycle facilities has a high priority within the context of a system-wide plan.

1 Bhode Island Bicycle Racilities Policy Document 1985. 
Design criteria developed by the American Association of State and Bighway Transportation officials (AASBTO) will serve as a minimum design standard for all bicycle facilities, unless compelling safety reasons indicate the need for stricter standards.

- The Manual on Oniform Traffic Control Derices will serve as a guide in developing a consistent system of signing for all bicycle facilities.

- Existing rights-of-way that coincide with transportation destination objectives will be utilized wherever possible.

- Where needed, bicycle storage facilities will be installed on state properties to serve inter-modal transportation (park \& ride) or for state offices or otber state land and buildings.

- Private establishments and employers (1.e., shopping centers, employment centers, etc.) will be encouraged to install bicycle parking facilities.

- Funding for and encouragement of local governments to include bicycle storage facilities for schools, local shopping centers, recreational facilities, parks. and playfields will continue.

- Technical assistance to private and local agencies relative to different types of facilities and relative safety of these facilities will be provided.

- Provision of facilities to a accommodate bicycles on public transportation vehicles will be encouraged.

- Signs used on all bikeways will conform with part IX of the Manual on Oniform Traffic Control Devices.

- Regulation and warning signs will be used where warranted for bicycling safety. 
- Bicycle routes that are designated and signed will meet one of the following criteria:

- The route is a separate bike path;

- The route provides access to an important attraction:

- It is desirable to direct bicycle traffic to the route to avoid other less safe bighways.

- Bicycle facilities construction eligible for federal funds will be administered by the RIDOT.

- The development of a system plan which will integrate bicycle tolerant roads with independent bicycle paths and supportive facilities will help achieve the goal of connectivity within the State of Rhode Island.

Maintenance and Security

- The maintenance activity for state roadways will incorporate the proper and necessary maintenance of bikeways incidental to these roads.

- A maintenance agreement will be a prerequisite for the participation of the RIDOT in construction of independent bicycle patbs of local significance.

- Responsibility for the maintenance of bicycle storage facilities on state property lies with the state.

- The maintenance of bicycle storage facilities at locally-owned sites will be the responsibility of the municipality.

\section{Safety and Education}

- The RIDOT will continue to take the lead role in the promotion of safety through education.

- Increasing the safety of the bicycleusing population can be accomplished through the educational efforts of education, civic and bicycle organizations. 
- Revisions to the Motor Vehicle Code to provide consistency or elaborate on safety issues for the bicycle riding community may, at some time, be necessary. The RIDOT will support appropriate legislation when change is deemed necessary.

- The preparation of bicycle facility maps at the state and local level support bicycle transportation and can be a valuable resource for bicyclists and motorists.

The Institutionalization of Bicycle Racilities Development

- The established transportation planning process will continue to be used for incorporating bicycle facilities into the transportation system.

- The inclusion of bicycle facilities in the Ground Transportation element of the State Guide Plan prepared by the Rhode Island Office of State Planning is supported and encouraged.

- The inclusion of bicycle facility projects in the Transportation Improvement Plan is required for federal funding.

- Bicycle Facility projects will be included in the RIDOT's Six Year Plan and Annual Program of Projects.

- A continuous planning process for Blcycle Pacilities and Programs will be maintained by the RIDOT.

- The lead responsibility for coordination of state-level bicycle programs will be assumed by the RIDOT Division of planning.

- Cooperative efforts in the implementation of the RIDOT bicycle facilities policies will continue to be handled by the Divisions of Planning and Public Works - Design Section. 
- All state highway-related projects will be reviewed for compliance with the RIDOT adopted guidelines for bicycle compatibility.

- Advisory committees may be formed when appropriate to offer advice and support for tbe RIDOT efforts. Public participation and input will be emphasized through the committees as well as in public workshops and hearings, when appropriate.

The State-Iocal connection

- Technical assistance to local government will continue to be provided through the Division of Planning at the RIDOT.

- Rhode Island's cities and towns will be provided with a manual delineating the state and local roles in bicycle facilities planning. 
APPENDIX D

Land F Nater Conservation Fund and Grant Assistance Program National Park service ract sheet 
L.S. Deparment of the Interiur

National Park Sericic

\section{Purpose}

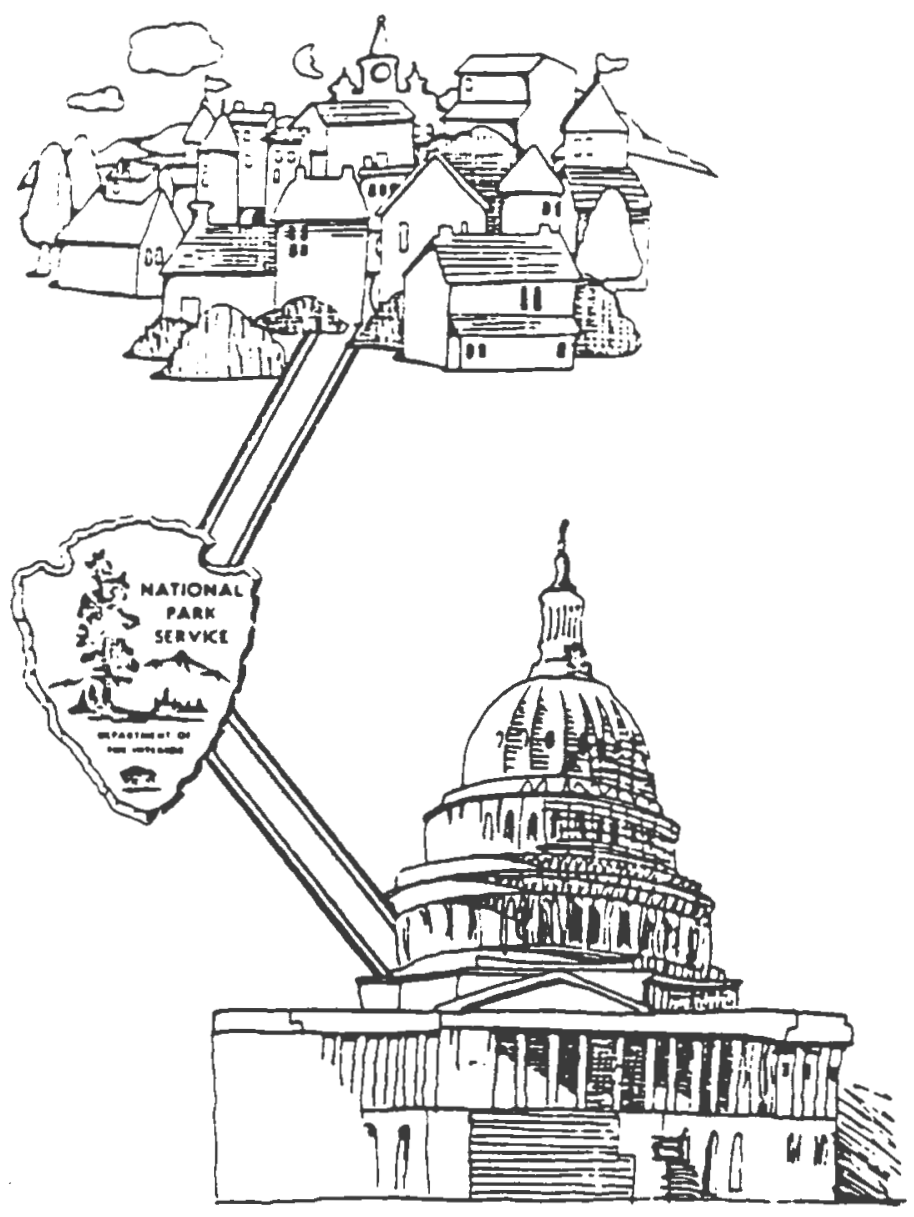

\section{Land and Water Conservation Fund Grant Assistance Program}

\section{Fact Sheet}

The Land and Water Conservation Fund (L\&WCF) program (Public Law 88-578) was enacted in 1964 to encourage nationwide creation and expansion of high quality. outdoor recreation opporiunities. The L\&WCF Act established an account that serves as a funding source both for Federal acquisition of public park and recreation lands and for grantin-aid to State and local governments for acquisition and development of outdoor recreation areas. An additional objective of this State assistance program is to simmulate. through its planning and matching requirements, greater non-Federal and private investments in the provision and maintenance of outdoor recreation facilities. The L\&WCF grants program is administered by the National Park Service (NPS).

For the purposes of the Act, 56 "States" (the 50 States, plus Guam, American Samoa, Pueno Rico, Virgin Islands. Northern Mariana Islands. and the District of Columbia) share Fund monies. The Governor of each State has designated an individual in the State government to represent him for purposes of the Act. These individuals, called State Liaison Officers, are the primary liaison channels between the Service, the States and local governments.

At the Federal level. the fund program is administered by NPS through seven regiona! offices. Project proposals are submitted to NPS regional offices through the state agency or individual authorized to represent the State tor vurposes of administering the L\&WCF ACt. The States are responsible for analyzing needs, determining priorities for funding projects, supervising projects, and ensuring program compliance with Federal regulations and administrative guidelines affecting the D-1 program. 


\section{Sources of Land and Water Conservation Fund Monies}

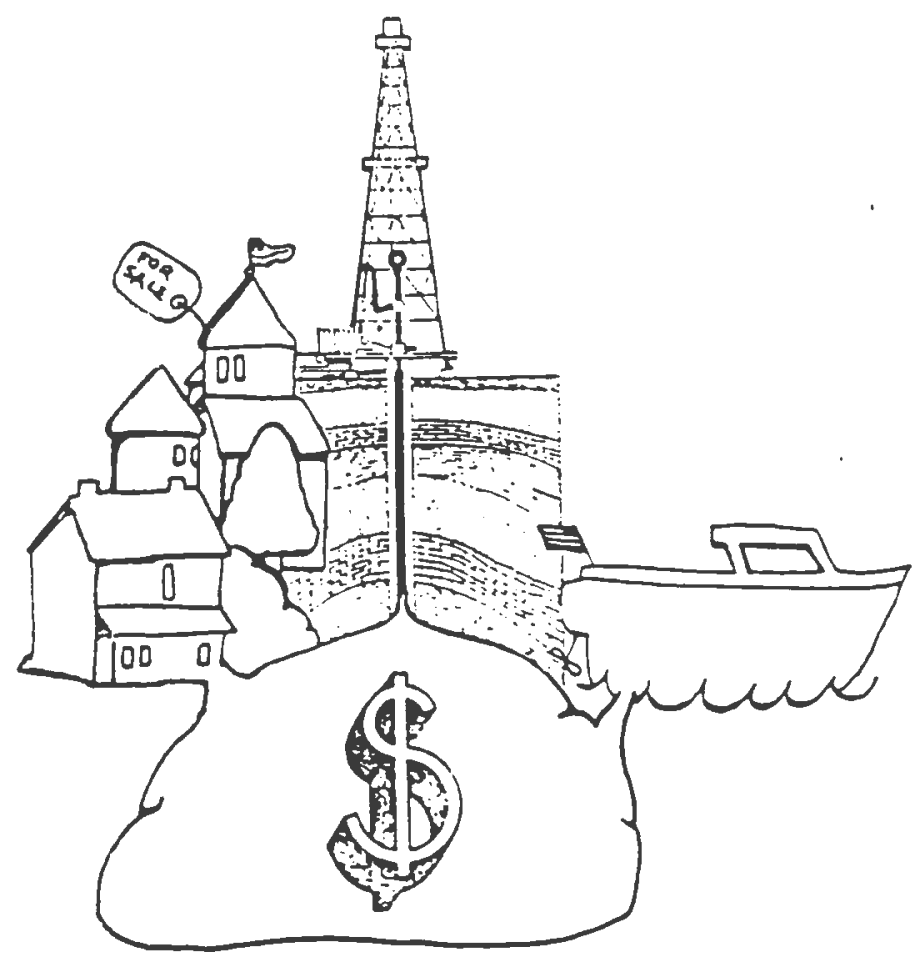

Grants-in-Aid Program

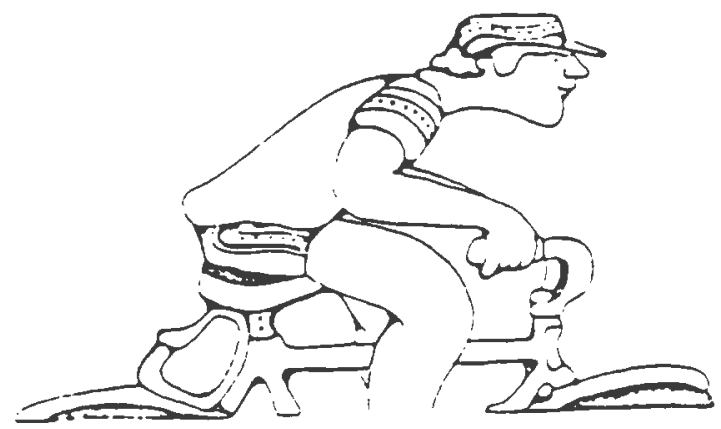

The Land and Water Conservation Fund account is currently authorized to receive $\$ 900$ million annually from four sources: Oute Continental Shelf mineral receipts, the Federa motorboat fuels tax, the sale of Federal surplus real property, and recreation fees. The larges single source, Outer Continental Shelf minera receipts, has been considered by some as a means by which a portion of our nation's non renewable natural resources can be reinvested to acquire, protect and make accessible parks and open space for the present and future. B) law, the L\&WCF is divided into two portions the "Federal" side and the "State" side. No less than 40 percent of any appropriation made goes toward acquisition of land at Federal sites with the remainder, as designated Congress, for L\&WCF grants.

Fitty-percent matching grants from the Fund are available to the States, and through the States to local units of government, for acquisitior and/or development of outdoor recreatior areas in locations ranging from densel: populated metropolitan areas to wildernes? sites. Project types also vary widely: from bicycle paths to sports fields, from roadsidt picnic grounds to swimming complexes, anc from improvement of park landscapes th construction of boating facilities. Progran policies and guidelines favor projects whict are for the public-at-large rather than elaborate facilities, and which cannot be easily supporter by alternative public or private investmen sources.

Projects funded with L\&WCF assistance art covered by Section 6(f)(3) of the L\&WCF ACt which protects areas acquired or developer from conversion to other than public outdoo recreation use. 


\section{Statewide Comprehensive Outdoor Recreation Plan (the State Plan)}

\section{Open Project Selection}

\section{Process}

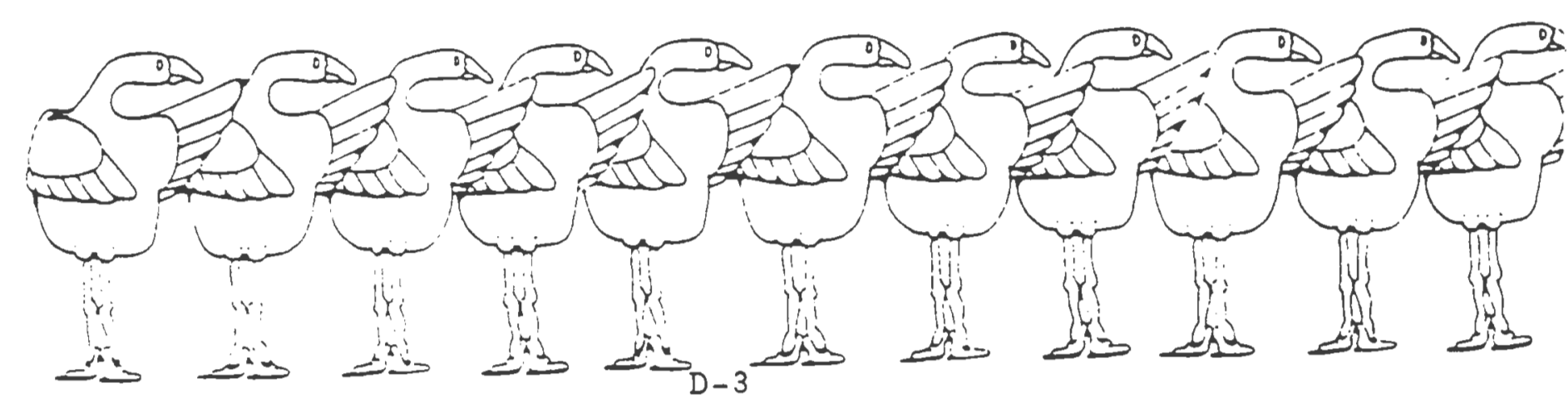

To become eligible for acquisition and development grant assistance, a State must prepare and regularly update a comprehensive Statewide outdoor recreation plan. The State plan must be comprehensive in scope and must take into account all State, local, and Federal resources and programs within the State, in nearby States, and the private sector. It must also cover all significant forms of outdoor recreation and include consideration of segments of the population with specialized needs, such as the handicapped and the aged. Once a State plan is approved by the National Park Service, acquisition and development applications must be in accord with plan goals and priorities, and funding availability continues only during periods of eligibility based on the State's contınuing planning eftorts.

To ensure public paricipation and tairness in the awarding of L\&WCF grants and to better address the highest priority outdoor recreation, needs, each State participating in the program has developed its own Open Project Selection Process. This process includes a priority ranking system which allows consideration 0 . the quality of a grant proposal in relation tc goals and priorities established in a State's planning program. Open project selectior systems are designed to provide regula opporunities for all eligible State and loca agencies and interested citizens to become aware of the L\&WCF program and to submi applications to the authorized State administrator. States are generally prepared to assist potential project sponsors in formulatin? proposals and preparing applications to eligible projects. 


\section{Funding History}

\section{Current Status of Funding}

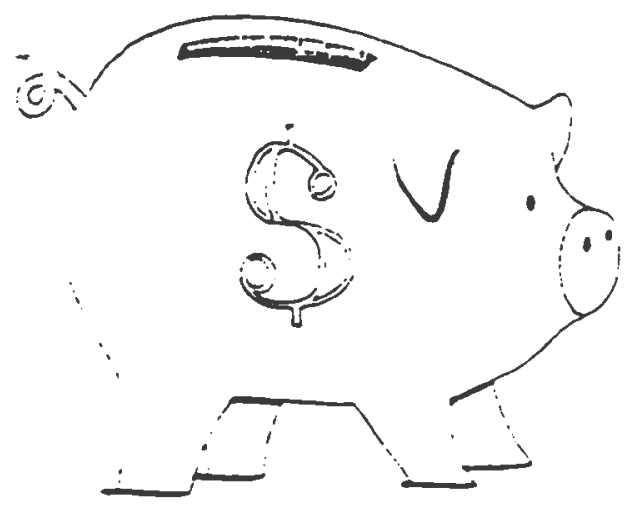

Since the origin of the L\&WCF in 1965. \$2.943 billion have been appropriated and apportioned to the 50 States, the District of Columbia, Puerto Rico. Guam. the Virgin Islands, Northern Mariana islands, and American Samoa for acquisition, development, and planning projects designed to improve the quantity and quality of outdoor recreation opportunities in the United States. Over 33,000 projects and $\$ 2.87$ billion in Federal assistance have been approved for parkland acquisition and outdoop recreation development. This amount has been matched by equal State and local contributions, for a total investment exceeding $\$ 5.6$ billion. Of the total number of projects approved through December 1985, 6,667 have been for acquisition of land and 23,175 have been for development of outdoor recreational facilities. An additional 2.787 projects have been for a combination of acquisition and development. Over 2.7 million acres of land have been acquired for outdoor recreation. Sixty-six percent of the toial funds obligaied have gone to locally-sponsored projects which supply close-10-home recreational opportunities more readily accessible 10 community residents. Recent annual appropriallons: FY 1984. $\$ 72.919 .000$ : FY 1985-\$71.853,000.

The amounts available for L\&WCF grants vary substantially from year to year and from State to State. Any amount appropriated by Congress in a given fiscal year is apportioned to each of the 56 "States" and may be carried over to subsequent years. For further information of funding avallability. project eligibility, selection criteria or application procedures, contact your State Liaison Officer. 


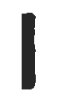

I

I

I

BIBLIOGRAPHY

I

I

I

I

I

I

I

I

I

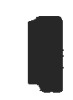

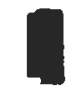

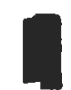

I 
American Association of state Highewway and Transportation officials. Guide for Development of New Bicycle Facilities 1981. Washington, D.C.. 1981.

Axhausen K.W. and Smith R.L. Jr.. Bicyclist Link Evaluation: A Stated-Preference Approach. Transportation Research Record 1085.1986.

Beard, Karl and Didato, Barry. Building Greenways in the Hudson River Valley. Albany, NY. Scenic Hudson, Inc. and the National Park Service. 1989.

Bicycle Strategies to Reduce Air Pollution. Washington, D.C.. Environmental Protection Agency, office of Transportation and Land Use Policy. 1978.

Bicycling Magazine Press Release, Harris Poll on Bicycling Commuting. Rodale Press Publication. March 1991.

Bikeways oregon Inc. Bicycles in Cities: The Eugene Experience. Eugene, OR. 1981.

Boyle, Terrance J. and Boehm, David W. Burlington Bicycle Path. A preliminary report for the Community and Economic Development office. 1984.

The Community Plan - Eugene Oregon. Good Work! Eugene, OR. 1981.

Didato, Barry. "The Paths Less Traveled", Planning Magazine. January 6-10, 1990.

Dillion, Thomas. Developing A Bikeway system for Chittenden County. Written Report. 1982 .

Goals and Guidelines, Seminar Series Book, Rails-to-Trails Congress. Washington, D.C. 1990.

Jones, Daniel R. and Battaglia, A. Mark. Main street Rivers. Penn State University, 1989.

Jordan, Roberta, and Simmer, Bill. The open Space Imperative. Greenspaces and Greenways. 1987.

Kozlowski, Dr. James $C$. The Supply of Recreational Lands and Landowner Liability: Recreational Use Statutes Revisited. University Press. 1988.

Little, Charles E. Greenways for America. Baltimore, MD. John Hopkins University Press. 1990.

Montange, Charles H. Legal Manual: Preserving Abondoned 
Railroad Rights-of-Way for Public Use. Washington, D.C.. Rails-to-Trails Conservancy. 1989.

Nevel, Bonnie and Hintz, David. A Guide to America's Rails-toTrails Conservancy. Washington, D.C.. 1989.

New Jersey Department of Transportation, Bicycle Compatible Roadways Planning and Design Guidelines. Trenton, NJ. December, 1982 .

Office for Planning. Evaluation of the Burke - Gilman Trails Effect on Property Values and Crime. Seattle Engineering Department. 1987.

Oppenlander, Joseph C., Bicycle - Pedestrian Planning and Design Study: International Business Machines Corporation. Trans/op Inc. Systmes Engineers and Consultants. Burlington, VT. 1981.

Pena, Nelson. Power in Numbers. Bicycling Magazine. April, 1991.

Pena, Nelson. The Chain Gang. Bicycling Magazine. March, 1991.

Pena, Nelson. Fighting Back. Bicycling Magazine. May, 1991.

Replogle, Michael A. Bicycle Access: New Boost for Transit Performance. Washington, D.C.. Bicycle Federation. 1984 .

Rhode Island Bicycle Coalition. Metropolitan Providence Bicycle Map. RIBC. 1983.

Rhode Island Bicycle Coalition News. October 18, 1982.

Rhode Island Department of Administration. RI State Rail Plan, Division of Planning Report \#68. 1990.

Rhode Island Department of Environmental Management. A proposal to conduct a feasibility and preliminary design study for a class I bicycle facility between Providence and Woonsocket. 1985-87.

Rhode Island Department of Environmental Management. State Comprehensive Outdoor Recreation Plan. 1986.

Rhode Island Department of Environmental Management. State Comprehensive Outdoor Recreation Plan. 1991.

Rhode Island Department of Transportation, Division of Public Works. Design Policy Memo, No. 100-3. August 22, 1989.

Rhode Island Department of Transportation. Manual for local 
government participation in developing bicycle facilities in Rhode Island, Planning Division. 1985.

Rhode Island Department of Transportation. Rhode Island Bicycle Facilities Policy Document, Planning Division. 1985.

Rhode Island Department of Transportation. State of Rhode Island Bicycle Related Laws, Planning Division. 1985.

Rhode Island Department of Transportation. Rhode Island Bike Rules. 1989.

Rhode Island Department of Transportation. DOT Acquisition Program. 1991.

Safety Design and operational Practices for streets and Highways. Technology Sharing Report, U.S. Department of Transportation. 1980.

Schweck, Tim and Dave Sprehn. A Look at Visitors on Wisconsin's Elroy-Sparta Trail. Madison, WI. January 1989.

Smith, Dan Jr.. Bikeways - state of the Art - 1974. Washingotn, D.C.. Federal HIghway Administration. 1974 .

Trailblazer Newsletter. Volume 4. Number 4. Rails-to-Trails Conservancy. October-December 1989.

Trailblazer Newsletter. Volume 5. Number 1. Rails-to-Trails Conservancy. January-March 1990.

Trailblazer Newsletter. Volume 5. Number 21. Rails-to-Trails Conservancy. April-June 1990.

Transportation Research Board. Highway Capacity Manual, Special Report 209. Washington, D.C.. 1985.

Unique Roadway Design Reduces Bus-Bike Conflicts. ITE Journal XII. February 1986.

U.S. Department of the Interior, Division of National Parks Service. Land and Water Conservation Fund Grant Assistance Program Fact Sheet. Washington, D.C..

U.S. Department of Transportation. Bicycle and Pedestrian Facilities in the Federal-Aid Highway Program. Washington, D.C.. Publication \# FHWA-ED-90-020. 1990.

U.S. Department of Transportation. Environmental Policy statement. Washington, D.C.. Publication \# FHWA-RE-90-005. 1990. 
U.S. Department of Transportation. Manual on Uniform Traffic Control Devices. Washington, D.C.. 1978.

U.S. Department of Transportation. Safety and Locational Criteria for Bicycle Facilities. Washingotn, D.C.. Publication \# FHWA-RD-75-112. 1977.

U.S. Department of Transportation. Transportation strategies for the 21st Century. Washington, D.C.. Publication \# FHWA-ED90-048. 1990 .

wilkinson, W.C., and Moran, C.G. Highway Route Designation Criteria for Bicycle Routes: A Handbook. Springfield, virginia. National Technical Information Services. 1986. 
